\title{
The COVID-19 pandemic and eating disorders in children, adolescents, and emerging adults: virtual care recommendations from the Canadian consensus panel during COVID-19 and beyond
}

Jennifer Couturier ${ }^{1,2^{*}}$ (D) Danielle Pellegrini ${ }^{1}$, Catherine Miller ${ }^{3}$, Neera Bhatnagar ${ }^{1}$, Ahmed Boachie ${ }^{4}$, Kerry Bourret ${ }^{5}$, Melissa Brouwers ${ }^{6}$, Jennifer S. Coelho ${ }^{7}$, Gina Dimitropoulos ${ }^{8}$, Sheri Findlay ${ }^{1,2}$, Catherine Ford ${ }^{9}$, Josie Geller ${ }^{7}$, Seena Grewal ${ }^{4}$, Joanne Gusella ${ }^{10}$, Leanna Isserlin ${ }^{6}$, Monique Jericho ${ }^{8}$, Natasha Johnson ${ }^{1,2}$, Debra K. Katzman ${ }^{4}$, Melissa Kimber ${ }^{1}$, Adele Lafrance ${ }^{11}$, Anick Leclerc ${ }^{2}$, Rachel Loewen ${ }^{12}$, Techiya Loewen ${ }^{13}$, Gail McVey ${ }^{4}$, Mark Norris ${ }^{6}$, David Pilon ${ }^{10}$, Wendy Preskow ${ }^{14}$, Wendy Spettigue ${ }^{6}$, Cathleen Steinegger ${ }^{4}$, Elizabeth Waite ${ }^{15}$ and Cheryl Webb ${ }^{1,2}$

\begin{abstract}
Objective: The COVID-19 pandemic has had detrimental effects on mental health. Literature on the impact on individuals with eating disorders is slowly emerging. While outpatient eating disorder services in Canada have attempted to transition to virtual care, guidelines related to optimal virtual care in this field are lacking. As such, the objective of our Canadian Consensus Panel was to develop clinical practice guidelines related to the provision of virtual care for children, adolescents, and emerging adults living with an eating disorder, as well as their caregivers, during the COVID-19 pandemic and beyond.

Methods: Using scoping review methodology (with literature in databases from 2000 to 2020 and grey literature from 2010 to 2020), the Grading of Recommendations, Assessment, Development, and Evaluation system, the Appraisal of Guidelines, Research and Evaluation tool, and a panel of diverse stakeholders from across Canada, we developed high quality treatment guidelines that are focused on virtual interventions for children, adolescents, and emerging adults with eating disorders, and their caregivers.
\end{abstract}

\footnotetext{
* Correspondence: coutur@mcmaster.ca

'McMaster University, Hamilton, ON, Canada

${ }^{2}$ McMaster Children's Hospital, 1200 Main St W, Hamilton, Ontario L8N 3Z5,

Canada

Full list of author information is available at the end of the article
}

(c) The Author(s). 2021 Open Access This article is licensed under a Creative Commons Attribution 4.0 International License, which permits use, sharing, adaptation, distribution and reproduction in any medium or format, as long as you give appropriate credit to the original author(s) and the source, provide a link to the Creative Commons licence, and indicate if changes were made. The images or other third party material in this article are included in the article's Creative Commons licence, unless indicated otherwise in a credit line to the material. If material is not included in the article's Creative Commons licence and your intended use is not permitted by statutory regulation or exceeds the permitted use, you will need to obtain permission directly from the copyright holder. To view a copy of this licence, visit http://creativecommons.org/licenses/by/4.0/ The Creative Commons Public Domain Dedication waiver (http://creativecommons.org/publicdomain/zero/1.0/) applies to the data made available in this article, unless otherwise stated in a credit line to the data. 
(Continued from previous page)

Results: Strong recommendations were supported specifically in favour of in-person medical evaluation when necessary for children, adolescents, and emerging adults, and that equity-seeking groups and marginalized youth should be provided equal access to treatment. For children and adolescents, weak recommendations were supported for telehealth family-based treatment (FBT) and online guided parental self-help FBT. For emerging adults, internet cognitive-behavioural therapy (CBT)-based guided self-help was strongly recommended. Weak recommendations for emerging adults included CBT-based group internet interventions as treatment adjuncts, internet-based relapse prevention Maudsley Model of Anorexia Nervosa Treatment for Adults (MANTRA) guided selfhelp, telehealth relapse prevention using MANTRA, and guided CBT-based smartphone apps as treatment adjuncts. For caregivers of children and adolescents, weak recommendations were supported for virtual parent meal support training, and moderated online caregiver forums and support groups. For caregivers of emerging adults, guided parental self-help CBT was strongly recommended, and unguided caregiver psychoeducation self-help was weakly recommended.

Conclusions: Several gaps for future work were identified including the impact of sex, gender, race, and socioeconomic status on virtual care among children, adolescents, and emerging adults with eating disorders, as well as research on more intensive services, such as virtual day hospitals.

Keywords: Guidelines, Eating disorders, COVID-19, Virtual care, Self-help, Anorexia nervosa, Bulimia nervosa, Binge eating disorder, Children, Adolescents, Emerging adults

\section{Plain English summary}

The objective of this project was to develop Canadian Practice Guidelines for the virtual treatment of children, adolescents, and emerging adults with eating disorders. We reviewed the literature for relevant studies, rated the quality of the scientific information within these studies, and then created recommendations for virtual care for children and adolescents (< 18 years), emerging adults (18-25 years), and their caregivers. We presented our key findings and proposed recommendations to a panel of clinicians, researchers, parents, and those with lived experience from across the country. Based on the discussions by the panel during our presentation, we revised the recommendations accordingly. This was followed by anonymous voting in an online survey, where panel members could vote and provide comments on the revised recommendations. Our final recommendations include strong recommendations for in-person medical evaluation, when necessary, for children, adolescents, and emerging adults, and that equity-seeking groups and marginalized youth should be provided equal access to treatment. For emerging adults, internet cognitive behavioural therapy (CBT)-based guided self-help was strongly recommended. Guided parental self-help CBT for caregivers of emerging adults was strongly recommended. For children and adolescents, weak recommendations were determined for telehealth family-based treatment (FBT), and online guided parental self-help FBT. For caregivers of children and adolescents, virtual parent meal support training, and moderated online caregiver forums and support groups were supported with weak recommendations. For emerging adults, weak recommendations were determined for CBT-based group internet interventions, internet-based relapse prevention Maudsley Model of Anorexia Nervosa Treatment for Adults (MANTRA) guided self-help, telehealth relapse prevention using MANTRA, guided CBT-based smartphone apps, and unguided caregiver psychoeducation self-help. The panel also identified several areas for future research, including the impact of sex, gender, race, and socioeconomic status on virtual care for eating disorders, as well as the need for further research on more intensive services such as virtual day hospitals.

\section{Introduction}

The negative impact of COVID-19 and the associated social isolation on mental health has been well-described in terms of heightened anxiety and depression [1-3]. To cope with the stress of the pandemic, populations around the world are reporting changes in dietary patterns, such as increasing food intake or consuming more comfort food, and feeling anxious due to changed eating habits or activity levels $[4,5]$. Survey results from a subset of the general population in Italy $(n=602)$, found that almost half of the respondents reported feeling anxious due to changed eating habits (e.g. consuming more comfort food in quarantine, and being inclined to increase food intake to feel better during COVID-19). During this time, females were also more prone to emotional eating than male counterparts [4]. In a survey in New Delhi, India, $79.5 \%$ of total respondents $(n=992)$ reported that their dietary pattern changed during the country's lockdown [5]. This was especially true among people aged 35 to 50 years, who reported either increasing or decreasing their caloric intake (relative to before 
the pandemic) in response to stress related to social distancing laws and fears of acquiring COVID-19 [5].

Individuals with eating disorders (EDs) are also experiencing negative impacts related to COVID-19. A study in Spain found that after only 2 weeks of quarantine, nearly $40 \%$ of adults with EDs reported a worsening of ED symptomatology and almost $60 \%$ reported increased anxiety [6]. In the USA, Netherlands, and Australia, adults with Anorexia Nervosa (AN) reported increased restriction and fears about not being able to find foods consistent with their meal plan; those with Bulimia Nervosa $(\mathrm{BN})$ and Binge Eating Disorder (BED) reported increases in binge eating and urges to binge; all respondents with EDs noted greater concerns about COVID-19 on their mental health than physical health, as well as concerns of ED relapse related to confinement $[7,8]$. With closures of ED day hospitals occurring across Canada, Spain, Austria, USA, and the UK, the most severely ill ED patients were left without the intensive treatment they required [6].

There has been a lack of direction in terms of the best options for virtual ED care during the COVID-19 pandemic, and as a result, individuals, families, and clinicians are suffering the repercussions of health care systems that were ill-equipped for such a disruptive event [9]. As the ED population is particularly vulnerable and at significant risk of death should they not receive appropriate care [10], there is an urgent need to identify and prioritize the implementation of viable virtual care options.

Importantly, evidence indicates that telehealth is a promising alternative for the delivery of outpatient care [11]. The implementation of evidence-based treatments in mental health practice via video or teleconferencing, such as cognitive behavioural therapy (CBT) and family therapy, consistently demonstrates a comparable efficacy between online and face-to-face delivery, as well as similar therapeutic alliance and satisfaction between these delivery modes [see reviews for CBT [12-15] and family therapy [16, 17]]. The telehealth format, however, can present significant challenges for ED care with respect to developing rapport with individuals with EDs, as well as engaging in an appropriate assessment of medical stability. Reports have been made by adults with $\mathrm{AN}, \mathrm{BN}$, and BED in the USA and Netherlands about the quality of ED treatment during the pandemic being "somewhat" or "much" worse than usual care [7]. While some people with EDs may be willing to engage in virtual therapy, a preference for in-person care remains high [18]. Individuals with EDs often experience ambivalence regarding video calls, reporting a heightened self-criticism and awareness of bodily appearance, which respondents indicate creates a negative experience during virtual visits [6]. Furthermore, individuals with EDs and caregivers have voiced concern over the lack of face-to-face accountability with virtual weigh-ins, as well as concerns that social isolation may result in long periods of time to engage in excessive exercise $[6,19]$.

Technologies such as mobile applications ('apps'), selfhelp resources, and web-based information can be important sources of support during COVID-19 [18, 19]. However, social media posts and advertisements continue to bombard users with messages about "inevitable" weight gain related to staying at home, and have been argued to promote shape and weight concerns as well as restrictive and compensatory behaviours among those with, or at-risk for, EDs [20-23]. News media reports of food scarcity can cause individuals with EDs to restrict further due to a sense of altruism, or households maintaining a week-long supply of groceries can be a trigger for binge eating episodes [24].

Our team recently published Canadian Practice Guidelines for the treatment of children and adolescents with EDs [25]; however, many of the recommended interventions are focused on in-person individual and family treatment or group therapy, which currently cannot be delivered. Common challenges of delivering evidencebased treatment for EDs, as well as possible solutions and practical considerations have been recently published [26], taking into consideration the COVID-19 pandemic, yet formal guidelines are lacking. The present project represents an addendum to our guidelines and focuses on the generation of recommendations related to the provision of effective virtual care and online support for children, adolescents, and emerging adults who are living with an ED, and their caregivers. We expect these guidelines to have relevance for clinicians, administrators, and policymakers wishing to provide the best possible ED care during the COVID-19 pandemic and beyond.

\section{Objectives}

Our aim was to synthesize the best available evidence on: a) the impact of COVID-19 on children, adolescents, and emerging adults with EDs, and their caregivers, and, b) virtual treatments and other supports and technologies for this population. The research questions listed below were created and discussed by our research team and guideline development panel, consisting of clinicians (e.g. health care professionals), researchers, knowledge users, and patient/parent advocates from across Canada.

\section{Research questions}

In children, adolescents and emerging adults with EDs and their caregivers: 1) What is the impact of COVID19? 2) What evidence exists for treatments that can be delivered virtually? 3) What evidence exists for self-help for affected individuals and caregivers? 4) What evidence 
exists for other e-technology (email therapy, text messaging therapy, smartphone apps)? 5) What evidence exists for virtual day hospital, virtual group therapy, and virtual meal support? 6) When should individuals with EDs be seen in-person for evaluation? And how can medical monitoring be done at home? 7) How do sex and gender impact virtual care? and, 8) What are the gaps in the research evidence?

\section{Methods}

\section{Overview}

Since it was expected that the literature would be limited but diverse, we used scoping review methodology [2730] to ensure we collated all evidence on the impact of COVID-19 on the ED population, virtual ED treatment in the COVID-19 context, and research focusing on other novel technologies, online self-help support, and individual/caregiver experiences with online approaches. This was followed by a grading of the evidence using the Grading of Recommendations, Assessment, Development, and Evaluation (GRADE) system [31-33]. These evidence profiles were then presented to a panel of stakeholders from across Canada, followed by a voting system and arrival at consensus on the recommendations. The Appraisal of Guidelines, Research and Evaluation (AGREE II) tool was used to inform guidelines development and reporting [34]. In addition to recommendations based on existing research evidence, recommendations were also made representing the consensus of the panel with respect to good clinical practice. Preferences, implementability factors, and previous experiences of the expert panel were considered when making each recommendation, in combination with research evidence, or in place of research evidence where none existed.

Virtual care is a broad term which encompasses all the methods in which healthcare providers remotely interact with their patients [35]. Telemedicine is one of these methods, as are a variety of video and audio methods that we included in our literature search. The World Health Organization (WHO) defines telemedicine as: "the delivery of health care services at a distance, by health care professionals using information and communication technologies related to diagnosis, treatment, evaluation, research, or education, all in the interest of advancing health care" [36]. Generally, the terms 'telemedicine' and 'telehealth' are synonymous and can be used interchangeably [36]. Virtual care can be synchronous, involving the use of audiovisual technology in realtime for patient and health care professional communication, or asynchronous, consisting of health information being collected at one location and virtually transferred to another for review by a health professional [37]. The panel mutually agreed on including various synchronous and asynchronous virtual modalities including telehealth/telemedicine, telephone support services, text messaging, smartphone apps, email, e-mental health platforms (e.g. mental health services delivered via the internet or other digital technologies), self-help, and moderated online forums. The panel decided to exclude social media as there was consensus that social media were not an overt method of treatment/support (and likely have a mix of benefit and harm). Additionally, given the volume of literature that exists related to social media and EDs, and the short timeline of our project, it was decided it was not feasible to include this literature.

\section{Synthesis methods \\ Eligibility criteria}

Our inclusion criteria were: a) all literature, including quantitative, qualitative, and mixed methods papers on the impact of COVID-19, as well as virtual and online treatments/supports for children/adolescents ( $<18$ years) and emerging adults (18-25 years) with EDs and/or their caregivers; and b) articles written in any language. The inclusion of emerging adults differs from our previous Canadian Practice Guidelines [25], which only included children and adolescents ( $<18$ years). Prior to the present literature search, the panel unanimously agreed to include a target population of up to and including 25 years of age, where those aged 18 to 25 years were defined as emerging adults. This was decided so that studies on the transition of services from pediatric to adult services, which may involve virtual components, could be reviewed. The panel also anticipated that there would be little research on virtual treatments for those under 18 years of age, and that most research would focus on the 18 to 25 age range. During the screening process, the citation reviewers agreed to include studies whose participants had a mean age of up to and including 25 years. This was not ideal, as means are heavily influenced by sample size and range of values. Many of the studies also did not include an upper age limit, or if they did it was greater than 25 years. Despite these concerns, the citation reviewers agreed that including studies with a mean age of up to and including 25 years ensured that participants that did meet our target age group would be accounted for in our findings and ultimately, in the recommendations. Our exclusion criteria were: a) studies primarily involving adults ( $>25$ years); and b) studies that did not include EDs or disordered eating behaviours.

\section{Identifying potentially eligible studies Databases}

A literature search was completed using the following databases: Medline, PsycINFO, EMBASE, Cochrane Database of Systematic Reviews, Cochrane Central 
Register of Controlled Trials (CENTRAL), and CINAHL. The references of relevant articles obtained were also reviewed.

\section{Literature search strategy}

Our library scientist (NB) designed and executed comprehensive searches in the databases listed above to obtain evidence for each of the research questions dating back the last 20 years (2000 to 2020). This time frame was chosen based on the fact that there was likely little or no virtual care prior to 20 years ago and based on feasibility. The searches included a combination of keyword and subject heading for each concept. The sample search strategy included, but was not limited to, various combinations of the following terms as appropriate for the questions being addressed: Anorexia Nervosa OR Bulimia Nervosa OR Eating Disorder Not Otherwise Specified OR eating disorder OR Other Specified Feeding and Eating Disorder OR Avoidant/Restrictive Food Intake Disorder OR Binge Eating Disorder OR Atypical Anorexia Nervosa; AND virtual care OR self-help OR telemedicine OR telehealth OR videoconferencing OR COVID-19 OR coronavirus OR pandemic.

\section{Other strategies}

Grey literature was also reviewed, including conference proceedings from the International Conference on Eating Disorders between 2010 to 2020. Databases of ongoing research were searched including CENTRAL and clinicaltrials.gov. We also hand searched the International Journal of Eating Disorders from the last 10 years (2010 to 2020) for relevant articles.

\section{Applying eligibility criteria and extracting data}

Two members of the research team independently evaluated the results generated by our searches and came to consensus on which studies met eligibility criteria. We used Endnote and DistillerSR software to organize our studies. Duplicate records were removed. DistillerSR was used for article screening and data extraction. Titles and abstracts were used to exclude obviously irrelevant reports by the two reviewers. Potentially relevant articles were reviewed in full text by two reviewers who had to agree on inclusion. Articles in other languages were translated into English using Google Translate $(n=6)$. References of included reviews and book chapters were examined to find other potentially relevant studies. There were no disputes. Data extraction included the indexing of the type of paper, type of control group (if any), methodology, type of virtual intervention, ED diagnosis, age range, sample size, description of intervention, outcomes, results, and whether or not the paper described sex and/or gender as impacting virtual care. Sex was defined as sex assigned at birth, categorized into male or female. Gender was defined as the individual's self-identified gender role/identity categorized as girl, boy, cis, trans, or other gender identities.

\section{Appraising studies and guideline-related frameworks} The GRADE system [31-33] explicitly describes how to rate the quality of each study, as well as how to synthesize the evidence and grade the strength of a recommendation. Using this system, we used GRADEpro software to develop an evidence profile for intervention studies where treatment outcomes could be summarized in this fashion. With GRADEpro, we synthesized and classified the overall quality of evidence for each intervention based on the quality of all of the studies, taking into account risk of bias, inconsistency, indirectness, imprecision, publication bias, dose-response, and effect size [32]. Although we examined each outcome independently, when the rating of the evidence was the same, we collapsed the treatment outcomes in the GRADEpro tables for the sake of efficiency. We also used the AGREE II tool as well as the Guideline Implementability for Decision Excellence Model (GUIDE-M) to inform guideline development and this report [38, 39].

\section{The guideline team}

The Guideline Team is comprised of a core research team and a larger guideline development panel (GDP). This team is skilled in guideline development having just published the first Canadian Practice Guidelines for the treatment of children and adolescents with EDs [25]. The research team presented the research questions to the GDP, reviewed evidence summaries, formulated practice recommendations, drafted the guideline, and limited biases that could impeach upon the guideline development process [40-42]. The chair of the GDP (MB) is a methodological expert in guideline development, with content expertise outside the field of eating disorders. She led the consensus discussions of the GDP and oversaw conflict-of-interest disclosures and management. Our multi-disciplinary GDP of 27 diverse stakeholders from across Canada included experts in the field of EDs, multi-disciplinary front-line clinicians/knowledge users, those with lived experience (parents and individuals), hospital administrators, and policymakers (all authors on this guideline).

\section{Procedures}

An initial videoconference (via Zoom) was held on May 29, 2020 with the Guideline Team. The videoconference was recorded to provide an opportunity to review at a later date if necessary. The aims of the videoconference were to confirm the research questions, review the guideline development process and roles and responsibilities of the GDP, and identify potential conflicts of 
interest. During the meeting, the research questions were refined, the clinical population and outcomes were discussed, and the target audience was reviewed.

Once the literature searches were completed and the evidence profiles generated, a second videoconference (via Zoom) was held on September 25, 2020, which was also recorded so it could be reviewed if required. Two members of the core research team (JC and DP) presented evidence profiles for discussion with the GDP. This was followed by a facilitated discussion of the evidence profiles and draft recommendations generated by the core team. For each question, the panel reviewed the evidence, and discussed: (i) whether the interpretation of the evidence put forward by the core team aligned with that of the GDP; (ii) strengths and limitations of the evidence base; and (iii) considerations of the generalizability of the studies, precision of the estimates, and whether the evidence aligned with values and preferences of Canadian individuals with EDs and clinicians. Alternative interpretations and suggestions for further research were discussed. Minor or dissenting opinions were noted. Issues regarding implementability of the recommendations were considered, and suggestions for dissemination of the guidelines were elicited. In terms of formulating the recommendations, the panel generally defined a recommendation as 'weak' if it was supported by low certainty evidence (e.g. case report, case study, open trial data); a recommendation was defined as 'strong' if it was supported by high certainty evidence (e.g. randomized controlled trial data), while also taking into consideration all of the contextual factors mentioned above. Additionally, the recommendation could be formulated as 'for' or 'against' the intervention.

Following the virtual meeting, GDP members were provided with the draft guidelines for review. Group consensus on recommendations and strength of recommendations was obtained by using a modified Delphi method [43], with voting by all team members (except JC, DP, MB and NB) using an anonymous web-based survey platform, Lime Survey (www.limesurvey.com). For a recommendation to be approved, at least $70 \%$ of the GDP were required to identify their agreement with the recommendation [33]. Consensus was achieved in the first round of voting.
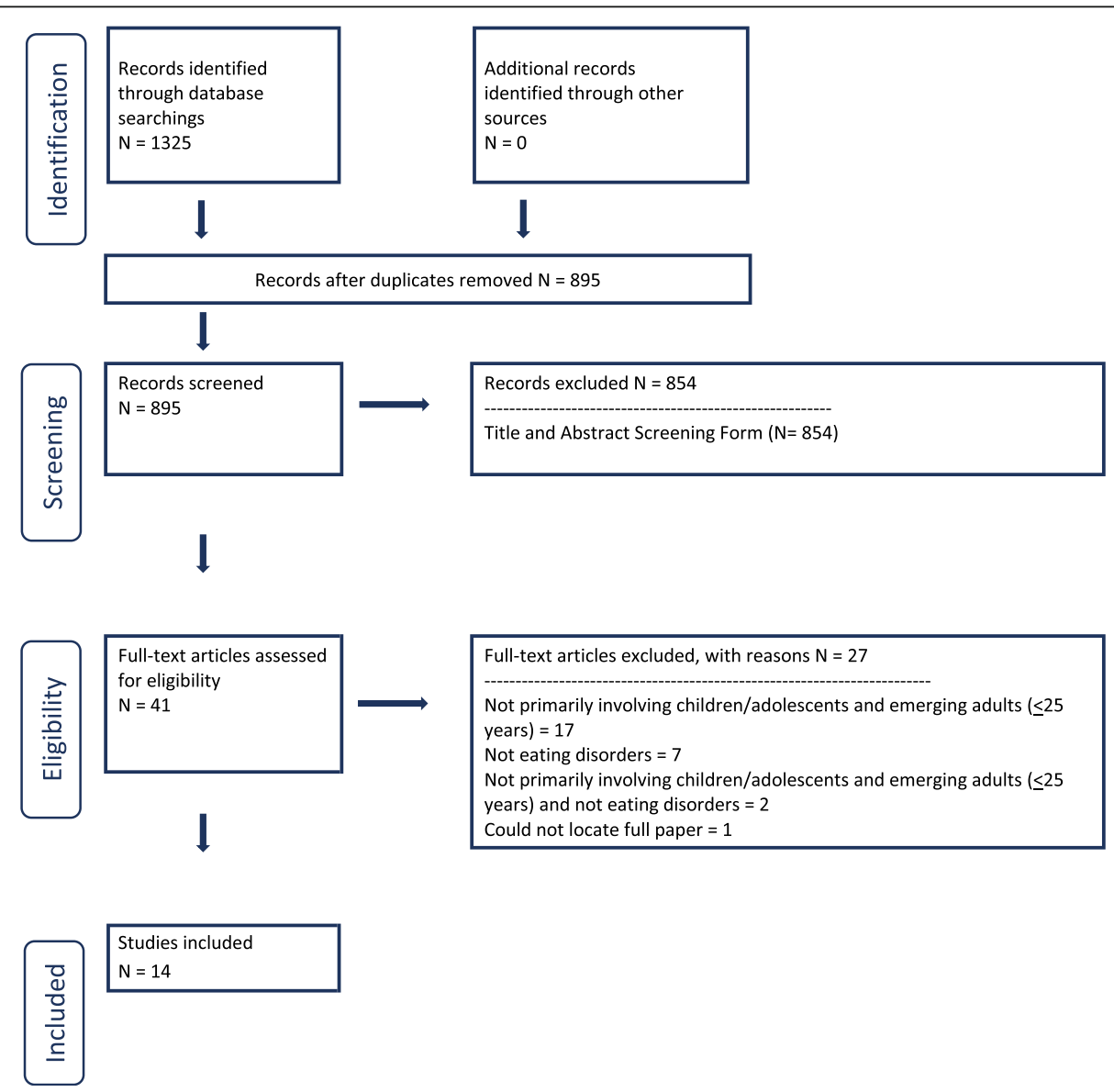

Fig. 1 PRISMA flow diagram for the impact of COVID-19 on children/adolescents and emerging adults with EDs, as well as their families and clinicians 


\section{Results}

The impact of COVID-19 on eating disorders

One thousand, three hundred and twenty-five abstracts were identified for review within the impact of COVID19 on EDs section of our guideline (see PRISMA flow diagram, Fig. 1). After duplicates were removed, abstracts screened, and full-text articles reviewed, 14 papers were included within this section. No additional abstracts were identified through review of reference lists. See Appendix A for a summary of the included studies regarding the impact of COVID-19 on EDs.

\section{Treatment modifications and/or ED symptoms experienced}

Children/adolescents Some evidence described the impact of COVID-19 on children and adolescents, and/or their caregivers and clinicians. Four descriptive studies revealed a rapid scale-up of telehealth for adolescents in ED programs as a result of the pandemic [26, 44-46]. According to clinicians, telehealth created some challenges, including difficulties in ensuring accurate communication when monitoring remotely, privacy concerns, difficulties building rapport with individuals with EDs, individuals with EDs not being physically present for weigh-ins, issues ensuring family involvement in Family-Based Treatment (FBT) sessions, inability to oversee mealtime, and individuals with EDs and/or parents disconnecting or leaving video sessions unexpectedly [26]. COVID-19-related modifications to treatment led to an increased workload experienced by clinicians and an increased caregiver burden (e.g. parents having to weigh their child at home) [45, 46]. Despite these challenges, in one descriptive study that featured a case report, the individual with an $\operatorname{ED}(n=1)$ achieved calorie goals, reduced purging episodes and emotional outbursts, engaged in telehealth care, and avoided rehospitalization [44].

Emerging adults Like children and adolescents, descriptive study evidence revealed an increase from 0 to $97 \%$ in 1 month for telemedicine visits for emerging adults with EDs in an Adolescent and Young Adult Medicine Clinic, and that this population in particular benefitted from telemedicine [47]. Challenges included privacy issues and inability to assess anthropometric data [47]. If weights and vital signs were unable to be collected at home by caregivers, partnerships with local primary care providers were formed to collect data [47, 48]. One qualitative study outlined themes of the impact of COVID-19 treatment modifications for individuals with EDs and caregivers [49]. For individuals the themes included: reduced access to ED services, varying levels of acceptability for remote therapy, reduced motivation for recovery, heightened psychological distress and ED symptoms, and increased attempts at self-management in recovery. For caregivers the themes included: fears of premature discharge from treatment, increased caregiver burden, managing new challenges around patient wellbeing (e.g. spotting signs of relapse), and new opportunities (e.g. gratitude for increased time at home).

\section{Impact on clinicians treating individuals with EDs during COVID-19}

Clinicians caring for individuals with EDs of any age Six articles [50-55], provided suggestions for clinicians for ED care and research during the COVID-19 pandemic, and one article [18] described the impact on clinicians working with individuals with EDs during this time.

Two descriptive studies provided recommendations to combat the challenges associated with remote delivery of ED care $[50,51]$. These included stressing telehealth sessions were 'business as usual' to individuals with EDs who might view telehealth as 'second best', using reliable video-call platforms instead of audio calls to deliver virtual treatment, acknowledging the challenges associated with COVID-19 to those with EDs, and having COVID19-specific ED psychoeducation for CBT or enhanced CBT (CBT-E) sessions. Other descriptive research suggested clinicians consider a different approach to ED treatment during the COVID-19 pandemic, such as implementing a person-centered and harm-reduction approach [52], or specifically for individuals with Avoidant/Restrictive Food Intake Disorder (ARFID), fostering communities of kindness towards ARFID that would involve carefully listening to individuals, family members, and partners of those affected by the disorder and COVID-19 [53]. For research, one editorial [54] and one cross-sectional study [55] indicated a need to fast-track ED research and publications related to COVID-19. Additionally, it was recommended that research disruptions be handled by employing technology, reprioritizing study goals (e.g. changing research directions), and encouraging collaboration between sites [54, 55].

In terms of clinician impact, one editorial revealed clinicians' concern over e-technology adding to their workload, where there may be a new expectation for them to handle patient-related issues during off-work hours given accessiblity to virtual patient data and inquiries [18].

\section{Virtual care and eating disorders}

Six thousand, five hundred and fifteen abstracts were identified for review within the virtual care and EDs section of our guideline (see PRISMA flow diagram, Fig. 2). Nine additional abstracts were identified through review of reference lists. After duplicates were removed, 


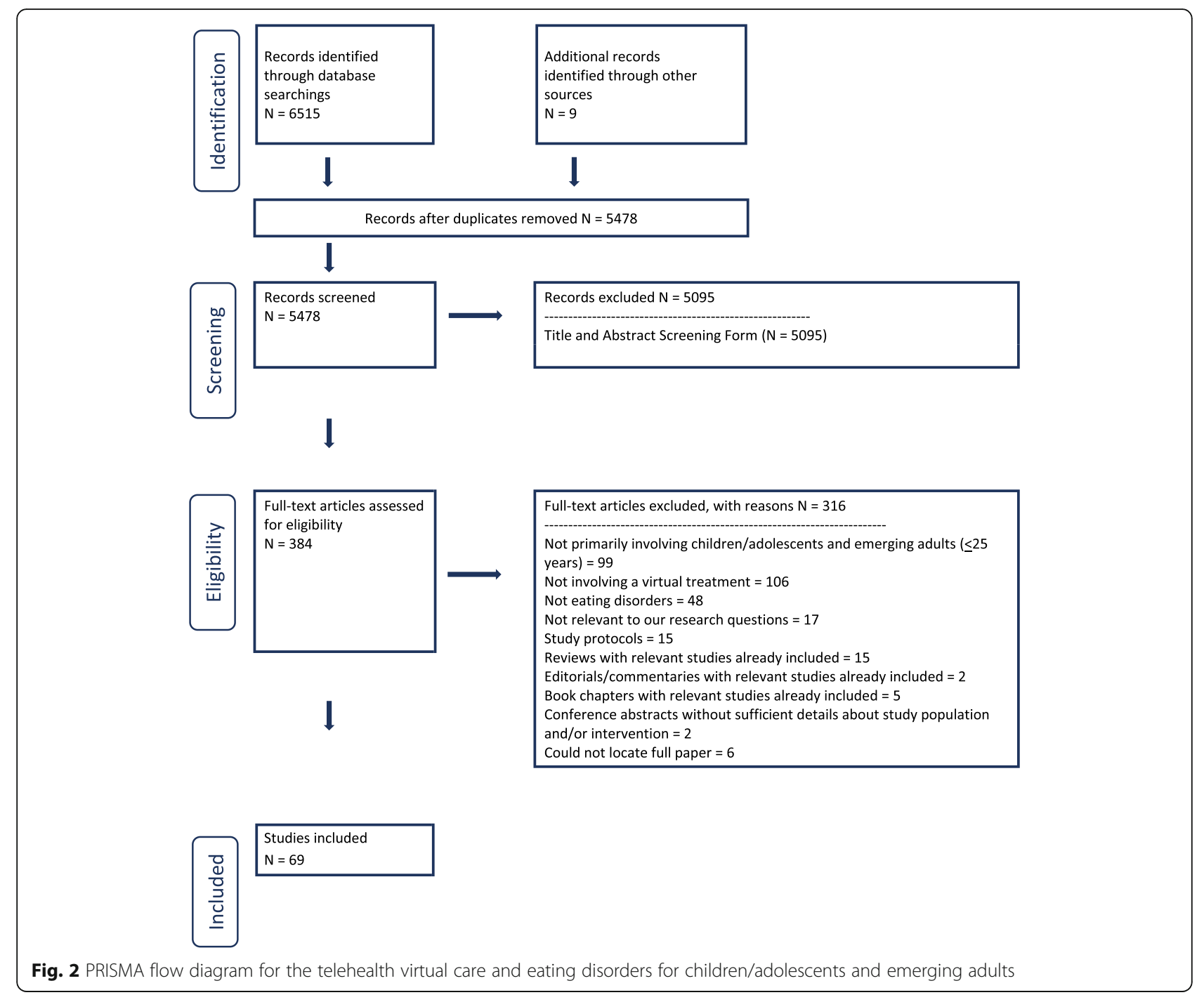

abstracts screened, and full-text articles reviewed, 69 studies were included within this section of our guideline. See Appendix B for a summary of the included studies regarding virtual care and EDs. Two distinct groups of treatments were found: established treatments used routinely face-to-face being delivered virtually (e.g. via video or teleconferencing), and interventions designed specifically for remote use delivered in a variety of ways. In terms of evidence related to treatments traditionally delivered face-to-face, we did not report on all of this research, but we did consider the existence of this evidence base when creating our recommendations.

Telehealth using synchronous videoconferencing and/or teleconferencing

Family-based treatment (FBT)

Children/adolescents Two studies were found using telehealth FBT, which followed an FBT manual but involved therapists virtually assisting parents to support nutritional recovery of their child via a telehealth platform or telephone, in children and adolescents with AN or atypical AN $[56,57]$. In a feasibility study $(n=10)$, examining the preliminary effect of telehealth FBT on weight gain [56], significant weight gain was achieved from baseline to end of treatment and at follow-up (with moderate to large effect sizes). Significant weight gain was also achieved from baseline to end of treatment in a case report $(n=1)$ for telehealth FBT [57] (Table 1).

\section{Relapse prevention (MANTRA)}

Emerging adults In one open trial using a post hospitalization sample of individuals with AN, trial completers $(n=12)$ in the Maudsley Model of AN Treatment for Adults (MANTRA) intervention (consisting of 10 sessions of a relapse prevention programme for AN over 4 months) delivered via telehealth demonstrated 
Table 1 Telehealth FBT for children and adolescents

\begin{tabular}{|c|c|c|c|c|c|c|c|c|c|}
\hline \multicolumn{7}{|c|}{ Certainty assessment } & \multirow[t]{2}{*}{ Impact } & \multirow[t]{2}{*}{ Certainty } & \multirow[t]{2}{*}{ Importance } \\
\hline $\begin{array}{l}\text { № of } \\
\text { studies }\end{array}$ & Study design & $\begin{array}{l}\text { Risk of } \\
\text { bias }\end{array}$ & Inconsistency & Indirectness & Imprecision & $\begin{array}{l}\text { Other } \\
\text { considerations }\end{array}$ & & & \\
\hline \multicolumn{10}{|c|}{ Outcomes: Weight gain } \\
\hline 2 & $\begin{array}{l}\text { observational } \\
\text { studies }\end{array}$ & $\begin{array}{l}\text { very } \\
\text { serious }^{a, b}\end{array}$ & not serious & not serious & not serious & $\begin{array}{l}\text { strong } \\
\text { association }^{c}\end{array}$ & $\begin{array}{l}1 \text { feasibility open trial [56] and } 1 \text { case } \\
\text { report [57] with children with AN } \\
\text { (total } n=11 \text { ). Significant weight gain } \\
\text { was achieved in both studies, from } \\
\text { baseline to end of treatment } \\
\text { and/or at follow-up. }\end{array}$ & $\begin{array}{l}\oplus \oplus \oplus \\
\text { MODERATE }\end{array}$ & CRITICAL \\
\hline
\end{tabular}

${ }^{\mathrm{a}}$ No control condition

${ }^{\mathrm{b}}$ No randomization

'The open trial [56] had moderate to large effect sizes for participant weight gain from baseline to end of treatment and from baseline to 6-month follow-up Bibliography:

Observational studies: Open trial - Anderson 2017 [56]; Case report - Goldfield 2003 [57]

increased Body Mass Index (BMI) and lower eating, shape and weight concerns (Eating Disorder Examination - Questionnaire [EDE-Q] scores), compared to baseline [58] (Table 2). This was a pilot study, examining the subjective need for a relapse prevention intervention, the feasibility and acceptance of the intervention and delivery via videoconference, as well as, exploratory measures of change in weight, relapse rates, ED pathology, and transition to outpatient care.

\section{Cognitive behavioural therapy (CBT)}

Children/adolescents Case report evidence was found for telehealth cognitive and behavioural treatment for ARFID and Other Specified Feeding and Eating Disorder (OSFED); however, both studies had small sample sizes $[59,60]$. For instance, in one case report, teleconsultations between clinicians and caregivers related to feeding interventions for ARFID resulted in an increase in the frequency of bites of nonpreferred foods consumed, though results were for one individual only (8-year-old male) [59]. Likewise, another case report involving CBT telepsychologist visits (using videoconferencing platforms) for Eating Disorder Not Otherwise Specified (EDNOS) resulted in an increase in food intake, improvements in growth, and reduced depression scores; however, again the case report only studied one individual (14-year-old female) [60].

\section{Self-help and guided self-help \\ Guided self-help \\ Internet CBT-based guided self-help}

Emerging adults Of all self-help treatments examined, internet CBT-based guided self-help had the most evidence to support its use in emerging adults with $\mathrm{AN}$, BN, BED, and EDNOS. Three RCTs [61-63] and their subsequent studies [64-67] demonstrated reduced ED psychopathology, improvements in ED symptoms (e.g. cessation from binge eating and purging), and/or significant weight gain among various internet CBT-based guided self-help interventions ('Featback' [61], 'Overcoming Bulimia Online' [62], and 'VIA-Virtual Intervention for AN' [63]) compared to controls. Of these, one RCT that compared intensities of virtual therapist support $($ low $=$ one time per week versus high $=$ three times per week) in addition to the internet-based program ('Featback') revealed no added value of therapist support in symptom reduction, but the added support contributed to greater program satisfaction [61] (Table 3).

Table 2 Telehealth relapse prevention using MANTRA for emerging adults

\begin{tabular}{|c|c|c|c|c|c|c|c|c|c|}
\hline \multicolumn{7}{|c|}{ Certainty assessment } & \multirow[t]{2}{*}{ Impact } & \multirow[t]{2}{*}{ Certainty } & \multirow[t]{2}{*}{ Importance } \\
\hline $\begin{array}{l}\text { № of } \\
\text { studies }\end{array}$ & $\begin{array}{l}\text { Study } \\
\text { design }\end{array}$ & $\begin{array}{l}\text { Risk of } \\
\text { bias }\end{array}$ & Inconsistency & Indirectness & Imprecision & $\begin{array}{l}\text { Other } \\
\text { considerations }\end{array}$ & & & \\
\hline \multicolumn{10}{|c|}{ Outcomes: BMI; EDE-Q } \\
\hline \multirow[t]{2}{*}{1} & $\begin{array}{l}\text { open } \\
\text { trial }\end{array}$ & $\begin{array}{l}\text { very } \\
\text { serious }{ }^{a, b}\end{array}$ & not serious & not serious & not serious & none & $\begin{array}{l}1 \text { pilot open trial with emerging adults with } \\
\text { AN }(n=16)[58] \text {. BMI increased after the } \\
\text { 4-month intervention. }\end{array}$ & $\begin{array}{l}\oplus \oplus \\
\mathrm{LOW}\end{array}$ & CRITICAL \\
\hline & & & & & & & $\begin{array}{l}\text { Programme completers ( } n=12 \text { ) had significantly } \\
\text { lower eating, shape, and weight concerns } \\
\text { (EDE-Q scores) at the end of the intervention } \\
\text { vs. baseline [58]. }\end{array}$ & & \\
\hline
\end{tabular}

\footnotetext{
${ }^{a}$ No control condition
}

${ }^{\mathrm{b}}$ No randomization

Bibliography:

Open trial - Giel 2015 [58] 
Table 3 Internet CBT-based guided self-help for emerging adults

\begin{tabular}{|c|c|c|c|c|c|c|c|}
\hline \multicolumn{7}{|c|}{ Certainty assessment } & \multirow[t]{2}{*}{ Impact } \\
\hline $\begin{array}{l}\text { № of } \\
\text { studies }\end{array}$ & $\begin{array}{l}\text { Study } \\
\text { design }\end{array}$ & $\begin{array}{l}\text { Risk of } \\
\text { bias }\end{array}$ & Inconsistency & Indirectness & Imprecision & $\begin{array}{l}\text { Other } \\
\text { considerations }\end{array}$ & \\
\hline \multicolumn{8}{|c|}{ Outcomes: ED psychopathology (SEED, EDE-Q) } \\
\hline 2 & $\begin{array}{l}\text { randomized } \\
\text { trials }\end{array}$ & $\begin{array}{l}\text { not } \\
\text { serious }\end{array}$ & not serious & not serious & not serious & none & $\begin{array}{l}1 \text { RCT [61] and a subsequent study [65] } \\
\text { with emerging adults with AN, BN, BED, } \\
\text { and EDNOS (total } n=87 \text { Featback; } n=88 \\
\text { Featback + low-intensity therapist support; } \\
n=89 \text { Featback + high-intensity therapist } \\
\text { support; } n=90 \text { waitlist control). Baseline } \\
\text { levels of ED psychopathology were found } \\
\text { to moderate intervention response. The } 3 \\
\text { Featback conditions were superior to } \\
\text { waiting list control in reducing bulimic } \\
\text { psychopathology (SEED and EDE-Q scores). } \\
\text { No added value of therapist support was } \\
\text { found in symptom reduction but did } \\
\text { improve intervention satisfaction; no } \\
\text { significant differences between Featback } \\
\text { conditions, and no effects were found } \\
\text { regarding anorectic psychopathology. }\end{array}$ \\
\hline
\end{tabular}

Outcomes: costs (related to intervention, health care utilization, medication; assessed using Health and Labor Questionnaire)

\begin{tabular}{|c|c|c|c|c|}
\hline $\begin{array}{l}\text { randomized } \\
\text { trials }\end{array}$ & $\begin{array}{l}\text { not } \quad \text { not serious } \\
\text { serious }\end{array}$ & not serious not serious & none & $\begin{array}{l}1 \text { subsequent study [64] to the Featback } \\
\text { RCT [61]: no significant differences } \\
\text { between the study conditions were found } \\
\text { regarding societal costs. Mean costs per } \\
\text { participant were lowest in the Featback } \\
\text { condition with low-intensity therapist } \\
\text { support, followed by Featback with } \\
\text { high-intensity therapist support, Featback } \\
\text { without therapist support, and waiting list. } \\
\text { Featback seems to be cost-effective vs. } \\
\text { waitlist. }\end{array}$ \\
\hline
\end{tabular}

\section{Outcomes: BMI (Weight gain)}

$2 \begin{array}{ll}\text { randomized } & \text { not } \\ \text { trials } & \text { serious }\end{array}$ not serious not serious not serious none

\section{Outcomes: dropout rate}

$\begin{array}{lll}\text { randomized } & \text { not } \\ \text { trials } & \text { serious }\end{array}$ not serious not serious not serious none

\section{Outcomes: ED symptoms (frequency of binge eating, vomiting, etc.)}

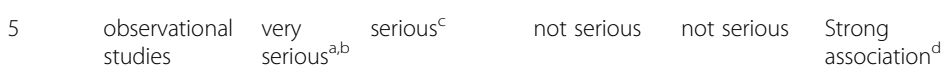
1 RCT with individuals with AN $(n=128$ VIA intervention; $n=130$ control) for relapse prevention [63]. Intervention completers gained significantly more weight than treatment as usual controls. At 9-month follow-up of this RCT [67] (at 9-month follow-up, $n=92$ VIA intervention; $n=120$ control), very good results for $\mathrm{BMI}$ were seen for ful completers of the intervention. Predictors for favourable course (concerning BMI) were adherence to intervention, more spontaneity, and better self-esteem.

A subsequent study [66] to the VIA RCT [63] reported VIA was well-received and highly feasible with a moderate dropout rate (15.5\%).

2 open trials (total $n=228$ ), 1 controlled study ( $n=31$ intervention; $n=31$ waitlist control), 1 case series $(n=38), 1$ case report $(n=1)$ all with those with $\mathrm{BN}$ and/ or EDNOS. Both open trials had significant improvements in ED symptoms at follow-up $[68,69]$. In the controlled study, binge eating and vomiting abstinence rates differed significantly between the internet and control groups at posttreatment, favouring the internet group [70]. The case series saw significant decreases in vomiting and weight phobia, but when bingeing and vomiting decreased, exercise increased [71]. The case report did not see an improvement in ED symptoms during the intervention, although it involved ProYouth, which is used for ED prevention and early intervention [72].
Certainty Importance

$\oplus \oplus \oplus \oplus$

CRITICAL

$\mathrm{HIGH}$

$\bigoplus \oplus \oplus \oplus$

CRITICAL $\mathrm{HIGH}$

$\oplus \oplus \oplus \oplus$

CRITICAL

$\mathrm{HIGH}$

$\oplus \oplus \oplus \oplus \quad$ CRITICAL

$\mathrm{HIGH}$ 
Table 3 Internet CBT-based guided self-help for emerging adults (Continued)

\begin{tabular}{|c|c|c|c|c|c|c|c|c|c|}
\hline \multicolumn{7}{|c|}{ Certainty assessment } & \multirow[t]{2}{*}{ Impact } & \multirow[t]{2}{*}{ Certainty } & \multirow[t]{2}{*}{ Importance } \\
\hline $\begin{array}{l}\text { № of } \\
\text { studies }\end{array}$ & $\begin{array}{l}\text { Study } \\
\text { design }\end{array}$ & $\begin{array}{l}\text { Risk of } \\
\text { bias }\end{array}$ & Inconsistency & Indirectness & Imprecision & $\begin{array}{l}\text { Other } \\
\text { considerations }\end{array}$ & & & \\
\hline 1 & $\begin{array}{l}\text { randomized } \\
\text { trials }\end{array}$ & $\begin{array}{l}\text { not } \\
\text { serious }\end{array}$ & not serious & not serious & not serious & none & $\begin{array}{l}\text { 1 RCT with BN and EDNOS participants } \\
\text { ( } n=38 \text { Overcoming Bulimia Online } \\
\text { intervention; } n=38 \text { waitlist/delayed } \\
\text { treatment control) [62]. The intervention } \\
\text { group had higher rates of cessation from } \\
\text { binge eating and purging vs. delayed } \\
\text { treatment condition, who experienced } \\
\text { little change in cessation rates at } \\
\text { follow-up. Intervention group gains were } \\
\text { maintained or continued to improve } \\
\text { at follow-up. }\end{array}$ & $\begin{array}{l}\oplus \oplus \oplus \oplus \\
\mathrm{HIGH}\end{array}$ & CRITICAL \\
\hline
\end{tabular}

aNo control condition

${ }^{\mathrm{b}}$ No randomization

'Some discrepancies between study findings

dLarge effect sizes for changes in ED symptoms scale [70] and weight phobia [71] and from baseline to post-treatment. Bibliography:

RCTs - Aardoom 2016 [61], Aardoom 2017 [65], Aardoom 2016 [64], Fichter 2012 [63], Fichter 2013 [67], Fichter 2011 [66], Sanchez-Ortiz 2011 [62] Observational studies: Open trials - Pretorius 2009 [68], Carrard 2011 [69]; Controlled study - Fernandez-Aranda 2009 [70]; Case series - Nevonen 2006 [71]; Case report - Kindermann 2016 [72]

Non-randomized studies saw mixed results for individuals with $\mathrm{BN}$ and/or EDNOS and internet CBT-based guided self-help programs. Two open trials (total $n=$ 228) observed significant improvements in ED symptoms (e.g. decreased objective binge eating and vomiting) and general psychopathology following online CBTbased intervention programs $[68,69]$. One controlled study revealed significant decreases at follow-up in psychopathological levels, binge eating, and vomiting, favouring the intervention group $(n=31)$ over waitlist controls $(n=31)$ [70]. In contrast, one case series found that for participants $(n=38)$ who followed an internet CBT-based guided self-help program, there was a notable change in their methods of compensation rather than an actual improvement in behaviours (e.g. participants decreased vomiting frequency but increased excessive exercise episodes) [71]. Similarly, one case report with one individual observed no improvements in BN symptoms following a different internet CBT-based intervention ('ProYouth') [72] (Table 3).

In terms of qualitative findings, two qualitative studies reported that an internet CBT-based guided self-help intervention ('Overcoming Bulimia Online') was wellreceived among BN and EDNOS participants (total $n=$ 20 ); these favourable perceptions of the program were attributed to the programs' accessibility, flexibility, support, and content $[73,74]$. Notably, some participants used the program as a 'stepping-stone' to further treatment [73].

\section{CBT-based Bibliotherapy}

Emerging adults One RCT [75] and its subsequent studies [76, 77] compared internet-guided self-help (INT-GSH) and bibliotherapy-guided self-help (BIBGSH) among emerging adults with BN and/or EDNOS $(n=70$ INT-GSH, $n=56 \mathrm{BIB}-\mathrm{GSH})$ and reported significant improvements in ED symptoms in both groups. There was no significant difference regarding outcome between delivery modes of the treatment, and authors suggested that both may be equally effective treatment options for this population (Table 4).

\section{Manual CBT-based guided self-help}

Emerging adults One observational controlled study with individuals with AN studied a manualized CBTbased guided self-help intervention $(n=51)$ with exercises to practice coping skills and improve body image in addition to weekly telephone contact with a clinical psychologist, versus a waitlist control $(n=51)$ [78]. Both groups thereafter received inpatient treatment. Duration of inpatient treatment was significantly shorter (by an average of 5.2 days) among intervention participants compared to controls. Body image, slimness ideal, general psychopathology and atypical binges improved significantly during the guided self-help intervention; however, while the intervention group showed more weight gain, changes in BMI did not differ significantly between the groups.

\section{Internet-based relapse prevention MANTRA guided self-help}

Emerging adults One RCT of individuals with AN studied internet-based MANTRA (iMANTRA) guided selfhelp (MANTRA workbook and email support from a therapist) in addition to treatment as usual $(n=24)$ versus a treatment as usual only control group (treatment from a local community mental health team or child/ adolescent mental health team; $n=17$ ) [79]. This feasibility study examined the use of email guided self-care 
Table 4 CBT-based bibliotherapy for emerging adults

\begin{tabular}{|c|c|c|c|c|c|c|c|c|c|}
\hline \multicolumn{7}{|c|}{ Certainty assessment } & \multirow[t]{2}{*}{ Impact } & \multirow[t]{2}{*}{ Certainty } & \multirow[t]{2}{*}{ Importance } \\
\hline $\begin{array}{l}\text { № of } \\
\text { studies }\end{array}$ & $\begin{array}{l}\text { Study } \\
\text { design }\end{array}$ & $\begin{array}{l}\text { Risk of } \\
\text { bias }\end{array}$ & Inconsistency & Indirectness & Imprecision & $\begin{array}{l}\text { Other } \\
\text { considerations }\end{array}$ & & & \\
\hline \multicolumn{10}{|c|}{ Outcomes: ED symptoms (frequency of binge eating, compensatory measures, etc.); ED psychopathology (EDI-2 scores) } \\
\hline \multirow[t]{2}{*}{3} & $\begin{array}{l}\text { randomised } \\
\text { trials }\end{array}$ & $\begin{array}{l}\text { not } \\
\text { serious }\end{array}$ & not serious & not serious & not serious & none & $\begin{array}{l}1 \text { RCT [75] and its subsequent studies [76, 77] } \\
\text { with emerging adults with BN and EDNOS } \\
\text { (total } n=70 \text { INT-GSH; total } n=56 \text { BIB-GSH). } \\
\text { ED symptoms (objective binge eating and } \\
\text { compensatory behaviour) improved } \\
\text { significantly in both groups. Greatest } \\
\text { improvements in ED symptoms were after } \\
4 \text { months; by month 18, } 14.6 \%(7 / 48) \text { of } \\
\text { INT-GSH participants and } 25 \%(7 / 28) \text { of } \\
\text { BIB-GSH participants were abstinent from } \\
\text { binge eating and compensatory measures. } \\
\text { There were no significant differences in } \\
\text { outcomes found between the } 2 \text { groups. } \\
\text { In both groups, lower frequency of binge } \\
\text { eating at baseline predicted good outcomes } \\
\text { at long-term follow-up (18 months). }\end{array}$ & $\begin{array}{l}\oplus \oplus \oplus \oplus \\
\mathrm{HIGH}\end{array}$ & CRITICAL \\
\hline & & & & & & & $\begin{array}{l}\text { There were no group differences (between } \\
\text { INT-GSH and BIB-GSH) in EDI-2 subscales [75]. }\end{array}$ & & \\
\hline
\end{tabular}

Bibliography:

RCTs - Wagner 2013 [75], Wagner 2013 [76], Wagner 2015 [77]

treatment added to treatment as usual. This was a relapse prevention study post hospital or day treatment, and a key aim of iMANTRA was to facilitate patient engagement in ongoing outpatient treatment, so the generalizability of this study to other populations is limited. At 6 months, there was little difference between the groups in terms of outcomes, but at 12 months, the iMANTRA intervention group had a higher BMI and lower Depression, Anxiety, and Stress Scale (DASS-21) scores than treatment as usual controls; the iMANTRA group also had fewer readmission rates than the treatment as usual control group. Despite the differences between groups at 12 months, confidence intervals were wide and overlapped with zero, which decreases the certainty of the findings (Table 5).

\section{Unguided self-help \\ Internet-delivered self-compassionate letter writing unguided self-help}

Emerging adults One RCT with individuals with AN and atypical $\mathrm{AN}$ in an internet-delivered selfcompassionate letter-writing intervention (adapted from compassion-focused therapy) for non-treatment seeking individuals $(n=20)$ resulted in greater increases in selfcompassion and greater decreases in shame and fears of self-compassion, compared to waitlist controls $(n=20)$ [80]. This was a feasibility study examining the acceptability of a brief, internet-delivered self-compassion intervention. The intervention appeared to be acceptable and feasible, but changes in eating pathology (EDE-Q

Table 5 Internet-based MANTRA guided self-help for emerging adults

\begin{tabular}{|c|c|c|c|c|c|c|c|c|c|}
\hline \multicolumn{7}{|c|}{ Certainty assessment } & \multirow[t]{2}{*}{ Impact } & \multirow[t]{2}{*}{ Certainty } & \multirow[t]{2}{*}{ Importance } \\
\hline $\begin{array}{l}\text { № of } \\
\text { studies }\end{array}$ & $\begin{array}{l}\text { Study } \\
\text { design }\end{array}$ & $\begin{array}{l}\text { Risk } \\
\text { of } \\
\text { bias }\end{array}$ & Inconsistency & Indirectness & Imprecision & $\begin{array}{l}\text { Other } \\
\text { considerations }\end{array}$ & & & \\
\hline \multicolumn{10}{|c|}{ Outcomes: BMI; Depression Anxiety and Stress Scale (DASS-21) } \\
\hline \multirow[t]{2}{*}{1} & $\begin{array}{l}\text { randomised } \\
\text { trial }\end{array}$ & $\begin{array}{l}\text { not } \\
\text { serious }\end{array}$ & not serious & not serious & not serious & none & $\begin{array}{l}1 \text { feasibility RCT with AN participants ( } n=24 \\
\text { internet-MANTRA +treatment as usual; } n=17 \\
\text { treatment as usual) [79]. At } 6 \text { months: little } \\
\text { difference between iMANTRA group } \\
\text { (internet-based self-help workbook + email } \\
\text { support by therapist for AN relapse } \\
\text { prevention) and treatment as usual group. At } \\
12 \text { months: iMANTRA group had a higher BMI } \\
\text { than treatment as usual group, but confidence } \\
\text { intervals were wide and overlapped with } 0 \text {. }\end{array}$ & $\begin{array}{l}\oplus \oplus \oplus \oplus \\
\mathrm{HIGH}\end{array}$ & CRITICAL \\
\hline & & & & & & & $\begin{array}{l}\text { At } 12 \text { months, iMANTRA group had lower } \\
\text { DASS-21 scores compared to treatment as } \\
\text { usual group [79]. }\end{array}$ & & \\
\hline
\end{tabular}


scores) and readiness to get help for one's weight did not differ between conditions.

\section{Manual-based cognitive remediation therapy (CRT)}

Emerging adults One qualitative study found that a CRT self-help manual and diary entries for individuals with AN and EDNOS $(n=6)$ were well-received according to high levels of satisfaction and acceptability reported by participants [81]. Both individuals with AN and EDNOS and parent participants commented that they would recommend the treatment to others; however, participants suggested that CRT be adapted for delivery via a computer rather than a manual.

\section{Motivational enhancement treatment (MET) and self-help book}

Emerging adults One RCT with individuals with $\mathrm{BN}$ and BED compared a self-help only intervention $(n=$ 45), consisting of a CBT-based book ('Overcoming Binge Eating') completed at the participants' own pace, to inperson MET sessions supplemented with the same CBTbased book $(n=45)$ [82]. The MET intervention resulted in increased readiness to change for binge eating and significantly more participants in the MET condition were abstinent from bingeing at follow-up, compared with the self-help only intervention, but otherwise there were few differences between conditions for eating attitudes and frequency of binge eating and compensatory behaviours. With regard to eating behaviours, participants in both conditions had reduced frequencies of binge eating and compensatory behaviours, but withingroup effects indicated that individuals in the MET condition experienced significant reductions in binge eating, compensatory behaviours, and maladaptive attitudes, whereas changes in the self-help only condition were not significant [82].

\section{E-technology as adjunctive interventions CBT-based group internet interventions}

Emerging adults Two RCTs studying a CBT-based group internet intervention ('Set your body free' with eight weekly sessions led by a therapist) for emerging adults with probable $\mathrm{BN}$ and/or high body dissatisfaction were found [83, 84]. The pilot RCT compared face-toface delivery $(n=19)$ versus internet-delivery $(n=21)$ modes of the program, reporting on feasibility [83], whereas the full RCT compared effectiveness of face-toface delivery $(n=42)$, internet-delivery $(n=37)$, and delayed treatment control $(n=37)$ [84]. Both studies revealed large improvements in body dissatisfaction (Body Satisfaction Questionnaire [BSQ], Body Image
Avoidance Questionnaire [BIAQ] scores) and dietary restraint (Dutch Eating Behaviour Questionnaire Restraint Scale [DEBQ-R] scores) in face-to-face and internetdelivery groups. In the pilot RCT, no significant differences between delivery modes were observed at posttreatment and at 2-month follow-up [83]. However, in the full RCT, post-treatment improvements were greater in the face-to-face than the internet intervention, but, generally gains made in both groups were no longer clearly different from each other at 6-month follow-up [84] (Table 6).

\section{Moderated online forums}

Children/adolescents One qualitative study examining a moderated online discussion forum ( $n=119$ users), which aimed to facilitate support between adolescents regarding their ED and the recovery process, determined several themes illustrating how young people use the forum [85]. Themes included taking on the role of the mentor, establishing a safe space online, forming friendships, acquiring help when needed, and seeking peer support for recovery and relapse prevention. The study concluded that moderated online discussions may foster a supportive environment in recovery for children and adolescents with an ED.

Emerging adults One cross-sectional study found that a moderated online forum enabled empowerment for emerging adults experiencing ED symptoms through exchange of information and sharing experiences with others [86]. The most pronounced empowering outcome of using the forum was feeling better informed, and to a lesser degree, it increased help-seeking behaviour, optimism, control over the future, confidence in treatment; perceived improvements in the relationships with their therapists. The study determined that forum users had potential to become an active partner in the management of their ED.

\section{Smartphone applications}

Children/adolescents One qualitative study compared the impact of TCApp between individuals with AN, BN, and $\operatorname{EDNOS}(n=9)$, mobile health experts $(n=11)$, health care professionals $(n=10)$, and ED specialists $(n=8)$ [87]. TCApp is a mobile health app that connects children and adolescents with EDs with their therapists in the periods between medical consultation. The study found that most health care professionals considered the app difficult to use, with barriers related to external factors (e.g. lack of time because of workload), while individuals with EDs and ED specialists perceived the app as easy to use. Some individuals with EDs reported barriers 
Table 6 CBT-based group internet interventions for emerging adults

\begin{tabular}{|c|c|c|c|c|c|c|c|c|c|}
\hline \multicolumn{7}{|c|}{ Certainty assessment } & \multirow[t]{2}{*}{ Impact } & \multirow[t]{2}{*}{ Certainty } & \multirow[t]{2}{*}{ Importance } \\
\hline $\begin{array}{l}\text { № of } \\
\text { studies }\end{array}$ & $\begin{array}{l}\text { Study } \\
\text { design }\end{array}$ & $\begin{array}{l}\text { Risk } \\
\text { of } \\
\text { bias }\end{array}$ & Inconsistency & Indirectness & Imprecision & $\begin{array}{l}\text { Other } \\
\text { considerations }\end{array}$ & & & \\
\hline \multicolumn{10}{|c|}{ Outcomes: Body satisfaction, body attitudes, shape concerns, dietary restraint (BSQ, BIAQ, DEBQ-R) } \\
\hline 2 & $\begin{array}{l}\text { randomized } \\
\text { trials }\end{array}$ & $\begin{array}{l}\text { not } \\
\text { serious }\end{array}$ & not serious & not serious & not serious & none & $\begin{array}{l}2 \text { RCTs for CBT-based group therapy with } \\
\text { probable BN and high body dissatisfaction } \\
\text { participants (in } 1 \text { pilot RCT: } n=19 \text { face-to-face } \\
\text { delivery and } n=21 \text { internet-delivery [83]; in } \\
\text { other RCT: } n=42 \text { face-to-face delivery, } n=37 \\
\text { internet delivery, and } n=37 \text { delayed } \\
\text { treatment control [84]). Both face-to-face and } \\
\text { internet delivery intervention groups showed } \\
\text { large improvements in body dissatisfaction } \\
\text { (BSQ, BIAQ scores) and dietary restraint } \\
\text { (DEBQ-R). In the pilot study [83], no significant } \\
\text { differences were found between face-to-face } \\
\text { and internet-delivery modes at post-treatment } \\
\text { and follow-up. In the full study [84], gains at } \\
\text { post-treatment in face-to-face condition were } \\
\text { greater than those in the internet group, but } \\
\text { at 6-month follow-up generally gains made in } \\
\text { both groups were no longer clearly different } \\
\text { from each other. }\end{array}$ & $\begin{array}{l}\oplus \oplus \oplus \oplus \\
\mathrm{HIGH}\end{array}$ & CRITICAL \\
\hline
\end{tabular}

related to use of the app including lack of personalization and motivational components, where they also expressed a lack of enthusiasm about the web-based chat option with ED specialists, although this was a facilitator for use from the perspective of ED specialists.

One mixed methods study asked children and adolescents meeting clinical or subclinical criteria for $\mathrm{AN}, \mathrm{BN}$, or BED $(n=366)$ about their interest in trying a hypothetical evidence-based mobile mental health app for EDs that included e-coaching [88]. Respondents with more severe manifestations of illness were more interested in trying the app, compared to those with less severe signs of an ED. Unwillingness to try the app was related to privacy concerns, worries of parents' reaction, and feelings that their parents might not want them to participate.

Emerging adults A variety of evidence was found related to smartphone apps for emerging adults with EDs. One RCT consisted of individuals with AN in a 'Recovery Record' plus treatment as usual intervention group $(n=20)$ versus a treatment as usual control group $(n=$ 20) [89]. This was a feasibility study, examining the acceptability and preliminary effects of an innovative therapist-guided smartphone-based aftercare intervention following inpatient treatment. Recovery Record is a CBT-based mobile app which involves self-monitoring, encouraging feedback, and coping strategies, with a linking feature with the treating clinician enabling individuals with EDs to share self-entered data with their clinician. At post-intervention, this RCT found nonsignificant small to moderate between-group effect sizes favouring the smartphone app intervention group over the treatment as usual group regarding ED psychopathology (EDE-Q scores) and BMI. However, at the 6month follow-up, there were no significant differences between intervention and control groups for these measures (Table 7).

In terms of non-randomized evidence, one case report saw 108,996 downloads of the Recovery Record app over a two-year period, and of 2503 ratings of acceptability, $84 \%$ rated the app as $5 / 5$ [91]. From the case report, approximately $50 \%$ of Recovery Record app users stated that they do not currently receive ED treatment, suggesting that the app could be effective in reaching an underserved population. One mixed methods study consisting of nine individuals with severe body image and disordered eating concerns determined that a different CBTbased mobile app ('Students Bodies - ED mobile app') offering one-on-one in-app and phone-based coaching in addition to the app's core sessions was rated as highly usable by participants [92]. This was a feasibility study, examining usability and engagement aspects of the app and virtual program. The average usability score was originally $78 / 100$, but once modifications were made to the app based on user recommendations this score increased to $83 / 100$. Furthermore, an open trial with 13 universities found encouraging results for the Student Bodies ED mobile app. Specifically, participant restrictive eating and binge eating significantly decreased over the course of users' time in the intervention. Vomiting and diet pill/ laxative use were not found to significantly decrease over the course of the intervention, but reports of these behaviours were very low [90]. 
Table 7 Smartphone apps for emerging adults

\begin{tabular}{|c|c|c|c|c|c|c|c|c|c|}
\hline \multicolumn{7}{|c|}{ Certainty assessment } & \multirow[t]{2}{*}{ Impact } & \multirow[t]{2}{*}{ Certainty } & \multirow[t]{2}{*}{ Importanc } \\
\hline $\begin{array}{l}\text { № of } \\
\text { studies }\end{array}$ & $\begin{array}{l}\text { Study } \\
\text { design }\end{array}$ & $\begin{array}{l}\text { Risk of } \\
\text { bias }\end{array}$ & Inconsistency & Indirectness & Imprecision & $\begin{array}{l}\text { Other } \\
\text { considerations }\end{array}$ & & & \\
\hline \multicolumn{10}{|c|}{ Outcomes: ED psychopathology (EDE-Q); BMI } \\
\hline \multirow[t]{2}{*}{1} & $\begin{array}{l}\text { randomized } \\
\text { trials }\end{array}$ & $\begin{array}{l}\text { not } \\
\text { serious }\end{array}$ & not serious & not serious & not serious & none & $\begin{array}{l}1 \text { pilot RCT with individuals with AN ( } n=20 \\
\text { in Recovery Record intervention= guided } \\
\text { CBT-based smartphone app+ treatment as } \\
\text { usual; } n=\text { treatment as usual) [89]. At } \\
\text { post-intervention, non-significant small to } \\
\text { moderate between-group effect sizes } \\
\text { favoured the intervention group regarding } \\
\text { ED psychopathology (restraint and shape } \\
\text { concerns, assessed from EDE-Q). At 6-month } \\
\text { follow-up, effects wore off and no } \\
\text { significant differences between the } \\
\text { intervention and control groups were found. }\end{array}$ & $\begin{array}{l}\oplus \oplus \oplus \oplus \\
\mathrm{HIGH}\end{array}$ & CRITICAL \\
\hline & & & & & & & $\begin{array}{l}\text { At post-intervention, non-significant small } \\
\text { to moderate between-group effect sizes } \\
\text { favoured the intervention group regarding } \\
\text { BMI. At 6-month follow-up, effects wore off } \\
\text { and no significant differences between the } \\
\text { intervention and control groups were } \\
\text { found [89]. }\end{array}$ & & \\
\hline
\end{tabular}

Outcomes: ED behaviours (restrictive eating, binge eating, compensatory measures)

1 open trial very not serious not serious not serious none

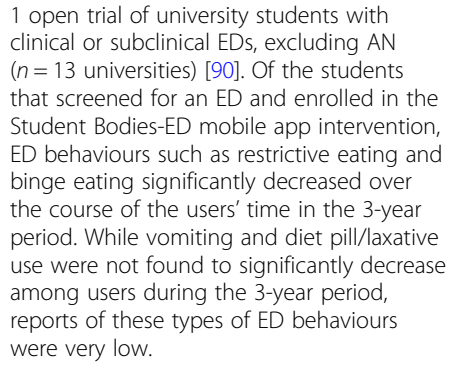

\section{Text messaging}

Emerging adults There was conflicting evidence for text messaging interventions for emerging adults with EDs. In one open trial, 12 individuals with $\mathrm{AN}$, subclinical $\mathrm{AN}$, or $\mathrm{BN}$ received personalized, motivational text messages following in-person psychoeducation sessions, which were sent prior to participants' mealtime [93]. This was a feasibility study, examining whether motivational text messages were acceptable as a CBT adjunct, and whether the text messages had an effect on behavioural outcomes. While the text messaging adjunctive therapy was deemed acceptable and feasible by participants in the open trial, there was no impact on behavioural outcomes including dietary restraint and kilocalorie intake, and underweight participants reported an increased desire to restrict in response to the text messages. In contrast, a case report with two individuals with $\mathrm{BN}$ found that a weekly textmessaging based intervention following discharge from inpatient treatment resulted in positive outcomes, including no binge eating or purging reported over the course of 14 weeks of use [94]. The results suggested that the use of text messaging aftercare offers the possibility of supplementing traditional psychotherapeutic treatments.

\section{Email and/or online counselling}

Children/adolescents Two case reports described individuals with $\mathrm{AN}$ (total $n=3$ ) used email as an adjunct to treatment to relay their mood, calorie intake, and ED behaviours to their treating physician $[95,96]$. In both case reports, individuals generally described email as a positive treatment adjunct, allowing for increased contact with the physician and individuals becoming more aware of their ED behaviours by documenting them online. Weight gain was achieved by one of the two individuals in one case report (16-year-old female) [95]. One qualitative study with individuals with any type of ED $(n=4)$ using an online email counselling service reported that the service provided a valuable place for 
young people to gain additional support and reduce feelings of isolation [97].

Emerging adults Two case reports with individuals with AN or BN (total $n=4$ ) found that treatment supplemented with email between the individual and clinician benefitted individuals in terms of improving coping behaviours and creating a greater sense of trust with their therapist $[98,99]$. Another case report described the effects of a clinician matching two groups of two individuals with AN (total $n=4$ ) with similar ED struggles and arranged for them to communicate via email as a means of supporting each other (without involving the clinician) [100]. These participants reported positive feelings towards the email matching program, and according to their treating clinician, all progressed well in their treatment. Two qualitative studies with individuals with AN, BN and EDNOS (total $n=309$ ) found email online counselling was rated positively amongst users, with the supportive comments, fast and easy contact, counsellors' competence related to EDs, and the service being free of charge as some of the main facilitators for using the online service [101, 102]. Two cross-sectional studies [103, 104] and one mixed methods study [105] were related to the same online consulting service, which involved anonymous emails with a health care professional for free via a website. All three studies found that the service was often the initial point of contact between users with $\mathrm{AN}, \mathrm{BN}$, and BED and a professional to get help for their ED; relatives of those with EDs were also accessing the online consulting service to learn more about EDs [103-105]. Finally, one open trial with individuals with $\mathrm{BN}, \mathrm{BED}$, and EDNOS $(n=23)$ further described the impact of using email to communicate food intake and symptoms with a therapist and in return, receiving CBTbased or eclectic support from the therapist [106]. This pilot study examined the feasibility of recruiting patients using the internet (email), and whether therapy for $\mathrm{BN}$ can be delivered via email. Results indicated significant improvements in depressive and bulimic symptoms at 3month follow-up [106].

\section{Caregiver interventions focused on child outcomes Online guided parental self-help - FBT}

Children/adolescents One case series with 19 families found that the individuals with AN in the online guided parental self-help FBT intervention experienced weight gain similar to clinician-delivered FBT programs, with improvements in ED-related psychopathology (EDE-Q scores) also reported by the end of the treatment [107]. In this study, parents watched a series of pre-recorded videos and met with a therapist by phone or videoconference for 20-30 min once weekly. Using similar methodology, individuals in one open trial $(n=12$ diagnosed with AN, $n=12$ at risk for AN, and $n=22$ at high-risk for AN) remained stable or increased in ideal body weight by post-intervention [108] (Table 8). This pilot study examined the feasibility, acceptability, and shortterm efficacy of the program.

Table 8 Online guided parental self-help - FBT for caregivers of children/adolescents

\begin{tabular}{|c|c|c|c|c|c|c|c|c|c|}
\hline \multicolumn{7}{|c|}{ Certainty assessment } & \multirow[t]{2}{*}{ Impact } & \multirow[t]{2}{*}{ Certainty } & \multirow[t]{2}{*}{ Importance } \\
\hline $\begin{array}{l}\text { № of } \\
\text { studies }\end{array}$ & $\begin{array}{l}\text { Study } \\
\text { design }\end{array}$ & $\begin{array}{l}\text { Risk of } \\
\text { bias }\end{array}$ & Inconsistency & Indirectness & Imprecision & $\begin{array}{l}\text { Other } \\
\text { considerations }\end{array}$ & & & \\
\hline \multicolumn{10}{|c|}{ Outcomes: Weight gain; EDE-Q } \\
\hline \multirow[t]{2}{*}{1} & $\begin{array}{l}\text { case } \\
\text { series }\end{array}$ & $\begin{array}{l}\text { very } \\
\text { serious }{ }^{a, b}\end{array}$ & not serious & not serious & not serious & $\begin{array}{l}\text { strong } \\
\text { association }\end{array}$ & $\begin{array}{l}1 \text { case series with } 19 \text { families caring for } \\
\text { adolescents with AN. At the end of the } \\
\text { treatment (guided caregiver FBT training) and } \\
\text { at follow-up, the adolescents experienced } \\
\text { weight gain similar to clinician delivered FBT } \\
\text { programs (large effect size) [107]. }\end{array}$ & $\begin{array}{l}\oplus \oplus \oplus \\
\text { MODERATE }\end{array}$ & CRITICAL \\
\hline & & & & & & & $\begin{array}{l}\text { ED-related psychopathology (EDE-Q scores) } \\
\text { for those with AN improved by the end of the } \\
\text { treatment [107]. }\end{array}$ & & \\
\hline 1 & $\begin{array}{l}\text { open } \\
\text { trial }\end{array}$ & $\begin{array}{l}\text { very } \\
\text { serious }\end{array}$ & not serious & not serious & not serious & none & $\begin{array}{l}1 \text { pilot open trial with adolescents with, at risk, } \\
\text { or at high-risk for AN ( } n=12 \text { diagnosed with } \\
\text { AN, } n=12 \text { at risk for AN, } n=22 \text { at high risk for } \\
\text { AN) [108]. At the end of the } 6 \text { family-based early } \\
\text { intervention online sessions, adolescents } \\
\text { remained stable or increased in ideal body } \\
\text { weight (weight gain). }\end{array}$ & $\begin{array}{l}\oplus \oplus \\
\mathrm{LOW}\end{array}$ & CRITICAL \\
\hline
\end{tabular}

\footnotetext{
${ }^{\mathrm{a} N o}$ control condition

${ }^{\mathrm{b}}$ No randomization

'Large effect size from baseline to end of treatment and baseline to follow-up [107]

Bibliography:

Case series - Lock 2017 [107]

Open trial - Jones 2012 [108]
} 
Caregiver interventions focused on caregiver outcomes Unguided caregiver self-help using web-based and /or prerecorded videos focused on psychoeducation and communication skills

Children/adolescents One mixed methods study that involved a Meal Support Training program (pre-recorded videos and an accompanying manual) was wellreceived by families with a child with $\mathrm{AN}, \mathrm{BN}$ or EDNOS $(n=40)$ [109]. Caregivers reported that the program was informative, convenient, and useful in fostering caregiver understanding and patience with their child and the ED recovery process (Table 9).

Emerging adults Two RCTs had mixed evidence for effectiveness measured by caregiver outcomes $[110,111]$. One RCT that compared a web-based group $(n=23)$ and an in-person workshop group $(n=27)$ for caregivers of emerging adults with $\mathrm{AN}$ and $\mathrm{BN}$ revealed improvements in the Caregiver Accommodation and Enabling Scale for EDs favouring the web-based intervention, while changes in caregiver burden favoured the workshop [110]. This was a feasibility study, examining the efficacy and feasibility of a web- and workshop-based psychoeducational intervention for caregivers of people with EDs. Another RCT with caregivers of emerging adults with $\mathrm{AN}, \mathrm{BN}$, atypical $\mathrm{AN}$, atypical $\mathrm{BN}$, and EDNOS that compared a DVD intervention $(n=147)$ to a control condition $(n=$ 138) found Caregiver Accommodation and Enabling Scales for EDs were not reduced by the DVD intervention, but caregiver burden was reduced by the intervention compared to controls [111] (Table 10).

\section{Guided caregiver self-help - skills}

Children/adolescents One mixed methods study, consisting of 16 caregivers for individuals with $\mathrm{AN}$ or $\mathrm{BN}$ watching DVDs on ED care with supplemental telephone coaching, found caregiver general distress (measured by General
Health Questionnaires scores) decreased significantly from baseline to post-intervention [112]. This was a pilot study, examining the feasibility and acceptability of this skills-based training for caregivers of people with EDs, and whether the anxiety, depression, and expressed emotion in caregivers were reduced. Caregivers also expressed high levels of satisfaction with most aspects of the intervention and reported improvements in psychological distress and depression following the intervention, although these measures did not reach statistical significance (Table 11).

\section{Guided parental self-help CBT (skills training approach + workbook or CBT-based online modules)}

Emerging adults Three RCTs studying variations in guided caregiver self-help based in CBT reported somewhat similar findings in terms of expressed emotion and ED symptom impact scale for caregivers of emerging adults with AN [79, 113, 114]. One RCT found its skills training intervention group ('Experienced Carers Helping Others' [ECHO]; $n=134$ ) had reduced caregiver expressed emotion levels and ED symptom impact scale scores, compared to the control group $(n=134)$ [79]. Another RCT found a CBT-based online module intervention ('Overcoming Anorexia Online'; $n=33$ ) significantly reduced caregivers' anxiety and depression at post-treatment compared to a telephone and email hotline support control group $(n=30)$ [113]. This was a pilot study, examining the efficacy of a novel, web-based systemic CBT intervention for caregivers of people with AN. Other outcomes, including caregivers' expressed emotion and ED symptom impact scores, also had greater reductions in the intervention group than the control group, however these were not statistically significant [113]. The third RCT compared a CBT-based online module intervention ('Overcoming Anorexia Online') plus professional guidance via telephone $(n=19)$ to a group that received the 'Overcoming Anorexia Online' intervention alone $(n=18)$, and reported similar reductions in caregiver expression of emotion and ED symptom impact scale scores

Table 9 Virtual parent meal support training for caregivers of children/adolescents

\begin{tabular}{|c|c|c|c|c|c|c|c|c|c|}
\hline \multicolumn{7}{|c|}{ Certainty assessment } & \multirow[t]{2}{*}{ Impact } & \multirow[t]{2}{*}{ Certainty } & \multirow[t]{2}{*}{ Importance } \\
\hline $\begin{array}{l}\text { № of } \\
\text { studies }\end{array}$ & $\begin{array}{l}\text { Study } \\
\text { design }\end{array}$ & $\begin{array}{l}\text { Risk of } \\
\text { bias }\end{array}$ & Inconsistency & Indirectness & Imprecision & $\begin{array}{l}\text { Other } \\
\text { considerations }\end{array}$ & & & \\
\hline \multicolumn{10}{|c|}{ Outcomes: Helpfulness of the contents of the video and manual for meal support training } \\
\hline 1 & $\begin{array}{l}\text { mixed } \\
\text { methods }\end{array}$ & $\begin{array}{l}\text { very } \\
\text { serious }{ }^{a, b}\end{array}$ & not serious & not serious & not serious & none & $\begin{array}{l}1 \text { mixed methods study with } 40 \text { families caring } \\
\text { for a person with AN, BN, or EDNOS [109]. The } \\
\text { Meal Support Training program was reported as } \\
\text { informative, convenient, and was well-received } \\
\text { by families. Many caregivers reported that the } \\
\text { manual and video resources helped them be } \\
\text { more understanding and patient with their } \\
\text { child and the recovery process. }\end{array}$ & $\begin{array}{l}\oplus \oplus \\
\mathrm{LOW}\end{array}$ & CRITICAL \\
\hline
\end{tabular}

a No control condition

${ }^{\mathrm{b}}$ No randomization

Bibliography:

Mixed methods - Cairns 2007 [109] 
Table 10 Unguided caregiver self-help using web-based and/or pre-recorded videos focused on psychoeducation and communication skills for caregivers of emerging adults

\begin{tabular}{|c|c|c|c|c|c|c|c|c|c|}
\hline \multicolumn{7}{|c|}{ Certainty assessment } & \multirow[t]{2}{*}{ Impact } & \multirow[t]{2}{*}{ Certainty } & \multirow[t]{2}{*}{ Importance } \\
\hline $\begin{array}{l}\text { № of } \\
\text { studies }\end{array}$ & $\begin{array}{l}\text { Study } \\
\text { design }\end{array}$ & $\begin{array}{l}\text { Risk } \\
\text { of } \\
\text { bias }\end{array}$ & Inconsistency & Indirectness & Imprecision & $\begin{array}{l}\text { Other } \\
\text { considerations }\end{array}$ & & & \\
\hline \multicolumn{10}{|c|}{ Outcomes: accommodation and enabling scale for EDs; caregiver burden } \\
\hline \multirow[t]{2}{*}{1} & $\begin{array}{l}\text { randomized } \\
\text { trial }\end{array}$ & $\begin{array}{l}\text { not } \\
\text { serious }\end{array}$ & not serious & not serious & not serious & none & $\begin{array}{l}1 \text { feasibility RCT with caregivers for AN and } \\
\text { BN emerging adults ( } n=23 \text { caregivers in } \\
\text { web-based intervention; } n=27 \text { caregivers } \\
\text { in workshop intervention) [110]. Positive } \\
\text { experiences were reported in both } \\
\text { interventions. From baseline to end of } \\
\text { intervention, small between-group effect } \\
\text { sizes were observed for changes in Caregiver } \\
\text { Accommodation and Enabling Scale for EDs, } \\
\text { favouring the web-based intervention. }\end{array}$ & $\begin{array}{l}\oplus \oplus \oplus \oplus \\
\mathrm{HIGH}\end{array}$ & CRITICAL \\
\hline & & & & & & & $\begin{array}{l}\text { Changes in caregiver burden favoured the } \\
\text { workshop intervention rather than the } \\
\text { web-based intervention [110]. }\end{array}$ & & \\
\hline \multirow[t]{2}{*}{1} & $\begin{array}{l}\text { randomized } \\
\text { trial }\end{array}$ & $\begin{array}{l}\text { not } \\
\text { serious }\end{array}$ & not serious & not serious & not serious & none & $\begin{array}{l}1 \text { RCT with caregivers for AN, atypical AN, } \\
\text { BN, atypical BN, and EDNOS emerging adults } \\
\text { ( } n=147 \text { DVD video training intervention; } n=138 \\
\text { control) [111]. Caregivers' accommodating } \\
\text { behaviours (accommodation and enabling } \\
\text { scale for EDs) were not reduced by the DVD } \\
\text { intervention. }\end{array}$ & $\begin{array}{l}\oplus \oplus \oplus \oplus \\
\mathrm{HIGH}\end{array}$ & CRITICAL \\
\hline & & & & & & & $\begin{array}{l}\text { Caregivers' burden and psychological distress } \\
\text { were more reduced by the DVD intervention } \\
\text { than control [111]. }\end{array}$ & & \\
\hline
\end{tabular}

between both groups, but no significant difference between groups [114] (Table 12). This was a feasibility study, examining the usefulness of an online information and skills development intervention for caregivers of individuals with AN.

\section{Moderated online caregiver forums}

Children/adolescents Two non-randomized studies evaluated the use and impact of moderated online forums for caregivers of children with EDs, both describing online tools positively $[115,116]$. In a qualitative study, five mothers explained that they use moderated blogs (available on the FEAST-Families Empowered and Supporting
Treatment of Eating Disorders website) as a tool to foster social support alongside FBT sessions [115]. One open trial that consisted of 13 caregivers with a child with AN engaging in weekly therapist-guided virtual chat sessions had high satisfaction ratings (91.7\%) in addition to reports that the sessions were accessible, convenient, and easy to use [116]. This was a pilot study, examining the technical feasibility and acceptability of a therapist-guided, internetbased chat support group for caregivers involved in FBT for adolescent EDs. Caregivers also reported looking forward to the chat sessions as they assisted in coping with their child's ED, and that they would recommend the chat to others [116] (Table 13).

Table 11 Guided caregiver self-help - Skills for caregivers of children and adolescents

\begin{tabular}{|c|c|c|c|c|c|c|c|c|c|}
\hline \multicolumn{7}{|c|}{ Certainty assessment } & \multirow[t]{2}{*}{ Impact } & \multirow[t]{2}{*}{ Certainty } & \multirow[t]{2}{*}{ Importance } \\
\hline $\begin{array}{l}\text { № of } \\
\text { studies }\end{array}$ & $\begin{array}{l}\text { Study } \\
\text { design }\end{array}$ & $\begin{array}{l}\text { Risk of } \\
\text { bias }\end{array}$ & Inconsistency & Indirectness & Imprecision & $\begin{array}{l}\text { Other } \\
\text { considerations }\end{array}$ & & & \\
\hline \multicolumn{10}{|c|}{ Outcomes: Caregiver general distress (General Health Questionnaire) } \\
\hline 1 & $\begin{array}{l}\text { mixed } \\
\text { methods }\end{array}$ & $\begin{array}{l}\text { very } \\
\text { serious }\end{array}$ & not serious & not serious & not serious & none & $\begin{array}{l}1 \text { pilot mixed methods study with caregivers } \\
\text { ( } n=16) \text { for children with AN and BN [112]. } \\
\text { Caregivers expressed high levels of satisfaction } \\
\text { with most aspects of the DVD and coaching } \\
\text { skills training. From baseline to } \\
\text { post-intervention, caregiver general distress } \\
\text { (General Health Questionnaire scores) decreased } \\
\text { significantly. }\end{array}$ & $\begin{array}{l}\oplus \oplus \\
\mathrm{LOW}\end{array}$ & CRITICAL \\
\hline
\end{tabular}


Table 12 Guided parental self-help CBT (skills training approach + workbook or CBT-based online modules) for caregivers of emerging adults

\begin{tabular}{|c|c|c|c|c|c|c|c|c|c|}
\hline \multicolumn{7}{|c|}{ Certainty assessment } & \multirow[t]{2}{*}{ Impact } & \multirow[t]{2}{*}{ Certainty } & \multirow[t]{2}{*}{ Importance } \\
\hline $\begin{array}{l}\text { № of } \\
\text { studies }\end{array}$ & $\begin{array}{l}\text { Study } \\
\text { design }\end{array}$ & $\begin{array}{l}\text { Risk } \\
\text { of } \\
\text { bias }\end{array}$ & Inconsistency & Indirectness & Imprecision & $\begin{array}{l}\text { Other } \\
\text { considerations }\end{array}$ & & & \\
\hline \multicolumn{10}{|c|}{ Outcomes: Expressed emotion scale; ED symptom impact scale } \\
\hline \multirow[t]{2}{*}{1} & $\begin{array}{l}\text { randomised } \\
\text { trials }\end{array}$ & $\begin{array}{l}\text { not } \\
\text { serious }\end{array}$ & not serious & not serious & not serious & none & $\begin{array}{l}1 \text { RCT with caregivers ( } n=134 \text { in telephone } \\
\text { coaching ECHO intervention; } n=134 \text { control) } \\
\text { for individuals with AN [79]. Caregivers in the } \\
\text { intervention group had reduced expressed } \\
\text { emotion levels at patient discharge and 6- } \\
\text { month follow-up. }\end{array}$ & $\begin{array}{l}\oplus \oplus \oplus \oplus \\
\mathrm{HIGH}\end{array}$ & CRITICAL \\
\hline & & & & & & & $\begin{array}{l}\text { Caregivers in the telephone coaching } \\
\text { intervention group experienced greater } \\
\text { reductions in ED symptom impact scale scores } \\
\text { than in the control group [79]. }\end{array}$ & & \\
\hline \multirow[t]{2}{*}{1} & $\begin{array}{l}\text { randomised } \\
\text { trials }\end{array}$ & $\begin{array}{l}\text { not } \\
\text { serious }\end{array}$ & not serious & not serious & not serious & none & $\begin{array}{l}1 \text { pilot RCT with caregivers for individuals with } \\
\text { AN ( } n=33 \text { in OAO web-based intervention; } \\
n=30 \text { in telephone and email hotline control) } \\
\text { [113]. Compared with control, the OAO inter- } \\
\text { vention significantly reduced anxiety and de- } \\
\text { pression in caregivers at post-treatment; } \\
\text { caregivers in the OAO intervention had } \\
\text { greater reductions in expressed emotion than } \\
\text { controls, but these were not significant. }\end{array}$ & $\begin{array}{l}\oplus \oplus \oplus \oplus \\
\mathrm{HIGH}\end{array}$ & CRITICAL \\
\hline & & & & & & & $\begin{array}{l}\text { Similar to expressed emotion, caregivers' ED } \\
\text { symptom impact scale scores were also } \\
\text { reduced across both groups, but there was no } \\
\text { significant difference between groups [113]. }\end{array}$ & & \\
\hline \multirow[t]{2}{*}{1} & $\begin{array}{l}\text { randomised } \\
\text { trials }\end{array}$ & $\begin{array}{l}\text { not } \\
\text { serious }\end{array}$ & not serious & not serious & not serious & none & $\begin{array}{l}1 \text { feasibility RCT with caregivers for individuals } \\
\text { with AN ( } n=19 \text { OAO + guidance intervention; } \\
n=18 \text { OAO only) [114]. Levels of expressed } \\
\text { emotion reported by caregivers at post- } \\
\text { intervention were reduced but did not differ sig- } \\
\text { nificantly between the groups. Those with AN did } \\
\text { not perceive that their caregivers' levels of } \\
\text { expressed emotion had significantly changed. }\end{array}$ & $\begin{array}{l}\oplus \oplus \oplus \oplus \\
H I G H\end{array}$ & CRITICAL \\
\hline & & & & & & & $\begin{array}{l}\text { Caregivers' ED symptom impact scale scores were } \\
\text { also reduced across both groups, but there was } \\
\text { no significant difference between groups [114]. }\end{array}$ & & \\
\hline
\end{tabular}

Bibliography:

RCTs - Schmidt 2017 [79], Grover 2011 [113], Hoyle 2013 [114]

Children/adolescents and emerging adults A case report using teleconferencing for caregiver ( $n=6$ parents) support for any ED in youth between the ages of 12 and 22 found this approach may be promising for developing healthy caregiver coping mechanisms during their child's recovery [117]. However, these authors concluded that in-person meetings may be more ideal (Table 13).

\section{In-person care versus home monitoring In-person medical evaluation}

Emerging adults Some evidence was found describing factors to consider when deciding if individuals with EDs should be seen in-person for evaluation following their remote care in accordance with COVID-19 social distancing regulations. A descriptive study indicated that a person with an ED should be asked to come in to a clinic for limited in-person sessions if they were clearly engaging in concerning behaviours (e.g. increased restricting, purging, over exercising) according to self or caregiver reports or if the provider or caregiver had a high index of suspicion for medical deterioration [47]. Furthermore, a commentary described that in the COVID-19 context, ED programs utilized weight and heart rate criteria to define urgency and need for in-person medical assessments, either from temporary 'vital signs clinics' where individuals with EDs would come in to a clinic for daily heart rate, blood pressure, and weight assessment (that was either followed by or preceded by a telehealth visit), or some programs enlisted parents to monitor and report vital signs including teaching parents to take pulses and assessing weights on home scales [48].

\section{Home monitoring}

Children/adolescents There was some limited evidence from a pilot open trial assessing the feasibility of wearable sensors combined with wireless technologies for children and adolescents with $\mathrm{AN}(n=27)$ to monitor heart rate and heart rate variability by a clinician (not by caregivers) 
Table 13 Moderated online caregiver forums and teleconferenced caregiver support groups for caregivers of children/adolescents and emerging adults

\begin{tabular}{|c|c|c|c|c|c|c|c|c|c|}
\hline \multicolumn{7}{|c|}{ Certainty assessment } & \multirow[t]{2}{*}{ Impact } & \multirow[t]{2}{*}{ Certainty } & \multirow[t]{2}{*}{ Importance } \\
\hline $\begin{array}{l}\text { № of } \\
\text { studies }\end{array}$ & $\begin{array}{l}\text { Study } \\
\text { design }\end{array}$ & $\begin{array}{l}\text { Risk of } \\
\text { bias }\end{array}$ & Inconsistency & Indirectness & Imprecision & $\begin{array}{l}\text { Other } \\
\text { considerations }\end{array}$ & & & \\
\hline \multicolumn{10}{|c|}{ Outcomes: Feasibility and acceptability } \\
\hline 1 & $\begin{array}{l}\text { open } \\
\text { trial }\end{array}$ & $\begin{array}{l}\text { very } \\
\text { serious }\end{array}$ & not serious & not serious & not serious & none & $\begin{array}{l}1 \text { pilot open trial with } 13 \text { caregivers with a child } \\
\text { with AN [116]. The virtual chat room sessions led } \\
\text { by an FBT-trained therapist had high satisfaction } \\
\text { ratings }(91.7 \% \text {; feasibility and acceptability) } \\
\text { among caregivers. Caregivers reported looking } \\
\text { forward to the chat sessions and that they were } \\
\text { accessible, convenient, and easy to use. }\end{array}$ & $\begin{array}{l}\oplus \oplus \\
\mathrm{LOW}\end{array}$ & CRITICAL \\
\hline 1 & $\begin{array}{l}\text { case } \\
\text { report }\end{array}$ & $\begin{array}{l}\text { very } \\
\text { serious }{ }^{a, b}\end{array}$ & & not serious & not serious & none & $\begin{array}{l}1 \text { case report with } 6 \text { caregivers with a child with } \\
\text { an ED, participating in teleconferencing group } \\
\text { sessions to foster caregiver support [117]. } \\
\text { Monthly in-person meetings were added as more } \\
\text { participants became interested. Overall, caregivers } \\
\text { in the teleconferencing support groups felt they } \\
\text { were helpful for those who feel emotionally iso- } \\
\text { lated (feasibility and acceptability), but in-person } \\
\text { meetings for support may be more ideal. }\end{array}$ & $\begin{array}{l}\oplus \oplus \\
\mathrm{LOW}\end{array}$ & CRITICAL \\
\hline
\end{tabular}

${ }^{\mathrm{a}}$ No control condition

${ }^{\mathrm{b}}$ No randomization

Bibliography:

Open trial - Binford Hopf 2013 [116]

Case report - Marx 2006 [117]

in a remote setting [118] (Table 14). However, other recent evidence described interventions for home monitoring to be performed by caregivers of children with EDs during the COVID-19 pandemic. For example, two descriptive studies discussed home monitoring for children and adolescents with $\mathrm{AN}$ in which caregivers were enlisted to measure their child's weight, heart rate, and blood pressure (Table 14), as well as record food intake and estimate energy expenditure, and report all findings to the clinician during telehealth sessions; clinicians were to visually assess individuals with EDs during telehealth visits $[44,46]$. Overall, these new responsibilities for caregivers may contribute to a higher caregiver burden. Other research suggests that only weight be monitored by caregivers at home [26].

\section{Sex, gender, and diversity considerations}

There was no evidence found related to the impact of sex, gender, and other considerations on virtual care for children, adolescents or emerging adults.

\section{Recommendations}

Section 1. Telehealth using synchronous videoconferencing and/or teleconferencing Telehealth FBT may be a reasonable treatment option for children and adolescents with AN

\section{Weak recommendation}

Qualifying Statements: Family-Based Treatment (FBT) focuses on empowering parents to renourish their children. Although the evidence is rather scant, the panel member clinicians indicated that due to COVID-19 many of them are now using FBT by telehealth in their routine clinical practice and they suggest that there is good clinical reason to support these methods. Although these are treatment adaptations to a virtual mode of delivery, this treatment is known to be effective in-person, which adds confidence that it is likely beneficial when delivered virtually as well. There is urgency to adopt these treatments and likely minimal harm involved in delivering them by telehealth, as long as individuals are properly monitored medically. Some clinicians have been reluctant to have parents weigh their own children which would be a necessary component of FBT by telehealth.

\section{Key Evidence:}

- Significant weight gain from baseline to end of treatment and/or at follow-up was seen among individuals with $\mathrm{AN}$ and atypical $\mathrm{AN}$ in one feasibility open trial (with moderate to large effect sizes; $n=$ 10) [56] and in one case report $(n=1)$ [57]. In the open trial videoconferencing was using to deliver FBT and in the case report, the telephone was used.

Telehealth relapse prevention using MANTRA may be a reasonable treatment option for emerging adults with $A N$

\section{Weak recommendation}

Qualifying Statements: Maudsley Model of AN Treatment for Adults (MANTRA) aims to address the cognitive, emotional, relational and biological factors which tend to maintain AN. This study followed inpatient admission/ 
Table $\mathbf{1 4}$ In person care versus home monitoring for children and adolescents

\begin{tabular}{|c|c|c|c|c|c|c|c|c|c|}
\hline \multicolumn{7}{|c|}{ Certainty assessment } & \multirow[t]{2}{*}{ Impact } & \multirow[t]{2}{*}{ Certainty } & \multirow[t]{2}{*}{ Importance } \\
\hline $\begin{array}{l}\text { № of } \\
\text { studies }\end{array}$ & $\begin{array}{l}\text { Study } \\
\text { design }\end{array}$ & $\begin{array}{l}\text { Risk of } \\
\text { bias }\end{array}$ & Inconsistency & Indirectness & Imprecision & $\begin{array}{l}\text { Other } \\
\text { considerations }\end{array}$ & & & \\
\hline \multicolumn{10}{|c|}{ Outcomes: Vital signs (heart rate and heart rate variability) } \\
\hline 1 & open trial & $\begin{array}{l}\text { very } \\
\text { serious }^{a, b}\end{array}$ & not serious & not serious & not serious & none & $\begin{array}{l}1 \text { pilot open trial comparing adolescent girls } \\
\text { with AN using wearable sensors plus wireless } \\
\text { technologies to monitor heart rate and heart } \\
\text { rate variability ( } n=27) \text { versus healthy controls } \\
(n=15) \text { [118]. Results showed that the } \\
\text { wearable sensors were feasible to monitor } \\
\text { vital signs in adolescents with AN, but by a } \\
\text { clinician rather than a caregiver. }\end{array}$ & $\begin{array}{l}\oplus \oplus \\
\mathrm{LOW}\end{array}$ & CRITICAL \\
\hline \multicolumn{10}{|c|}{ Outcomes: Monitoring weight at home } \\
\hline 1 & $\begin{array}{l}\text { case report } \\
\text { in a } \\
\text { descriptive } \\
\text { study }\end{array}$ & $\begin{array}{l}\text { very } \\
\text { serious }^{a, b}\end{array}$ & not serious & not serious & not serious & none & $\begin{array}{l}1 \text { case report in a descriptive study with } 1 \\
\text { child with AN [44]. The family utilized } \\
\text { telehealth for FBT during COVID-19 where } \\
\text { the child's caregivers successfully measured } \\
\text { the child's weight at home using a home } \\
\text { scale, as well as blood pressure and heart } \\
\text { rate and reported these measures to the } \\
\text { clinician. }\end{array}$ & $\begin{array}{l}\oplus \oplus \\
\mathrm{LOW}\end{array}$ & CRITICAL \\
\hline
\end{tabular}

a No control condition
${ }^{\mathrm{b}}$ No randomization
Bibliography:
Open trial - Billeci 2015 [118]
Case report - Wood 2020 [44]

day patient treatment for AN. Eight sessions were delivered by videoconference; the first and last sessions were in person. Although this was an open trial, this intervention could be quite useful for those leaving intensive treatment and could provide a bridge to outpatient care.

Key Evidence:

- At the end of treatment (4 months, 10 sessions), a pilot open trial with individuals with $\mathrm{AN}(n=16)$ resulted in increased BMI and reduced eating, shape, and weight concerns (EDE-Q scores) among participants [58].

\section{Additional promising interventions}

- Telehealth cognitive and behavioural treatments for ARFID and OSFED require more study [59, 60]. Although there is currently no evidence for family interventions for OSFED and ARFID delivered by telehealth, this should also be a focus of research.

Section 2. Self-help and guided self-help Internet CBT-based guided self-help is strongly recommended for emerging adults with $A N, B N, B E D$, and EDNOS, as well as relapse prevention in $A N$

\section{Strong recommendation}

Qualifying Statements: There is strong evidence that internet CBT-based guided self-help is effective for emerging adults with $\mathrm{AN}, \mathrm{BN}, \mathrm{BED}$, and EDNOS, and possibly for relapse prevention in AN. These young adults likely need to be motivated for recovery in order to benefit. Although CBT-based bibliotherapy had slightly less evidence (compared to CBT-based internet therapy), there was still some evidence that it was beneficial. The panel emphasized that many parents request psychoeducation on EDs, so there was endorsement of bibliotherapy not only for individuals but for parents as well. The panel recognized that books and workbooks on EDs may be especially useful if no internet or computer is available. One pitfall to all of these treatments is that speaking and reading in English is required, since all of the treatments included in this current review required speaking and reading in English, but it should be noted that translations are becoming available for some books on EDs.

\section{Key Evidence:}

CBT - Internet Guided Self-Help

- One RCT with those self-reporting AN, BN, BED, or EDNOS symptoms, assessed by the Short Evaluation of Eating Disorders (SEED): total $n=87$ Featback, $n=88$ Featback + low-intensity therapist support, $n=89$ Featback + high-intensity therapist support; $n=90$ waitlist control. Interventions were superior to control in reducing ED psychopathology (SEED and EDE-Q scores). No added value of therapist support in symptom reduction but contributed to greater satisfaction. No significant differences between therapist support conditions. Lowest costs in condition with low-intensity therapist support [61].

- One RCT with those diagnosed with BN or EDNOS: $n=38$ 'Overcoming Bulimia Online' intervention; $n=$ 38 waitlist control. Intervention group had higher rates of cessation from binge eating and purging than delayed treatment condition; gains maintained or continued to improve at follow-up [62]. 
- Relapse prevention in AN - one RCT: VIA intervention (relapse prevention based in CBT after AN inpatient treatment) $n=128$, control $n=130$. Moderate dropout rate (15.5\%); intervention completers gained significantly more weight (individuals with AN) than controls; favourable course for BMI-adherence to intervention, more spontaneity, better self-esteem [63].

\section{CBT-based Bibliotherapy}

- One RCT with those diagnosed with BN or EDNOS (with bulimic symptoms): total $n=70$ internet guided self-help (INT-GSH); $n=56$ bibliotherapy guided self-help (BIB-GSH). ED symptoms (binge eating and compensatory behaviour) improved significantly in both groups (no significant differences regarding outcomes between groups). No group differences in Eating Disorder Inventory (EDI) subscales (adolescents $n=29$, adults $=97$ ) [75].

Internet-based relapse prevention MANTRA guided self-help may be a reasonable treatment option for emerging adults with $A N$

\section{Weak recommendation}

Qualifying Statements: Internet-based Maudsley Model of AN Treatment for Adults (iMANTRA) involved a workbook and email support by a therapist 1-3 times a week for the first 6 months, then 1 time per week for months 7-12. Workbook content included nutrition planning, coping strategies, and strategies to reduce anxiety. This relapse prevention feasibility study examined the use of email guided self-care treatment added to treatment as usual post hospital or day treatment. A key aim of iMANTRA was to facilitate patient engagement in ongoing outpatient treatment, so the generalizability of this study to other populations is limited.

Key Evidence:

- One feasibility RCT with individuals with AN $n=24$ iMANTRA intervention + treatment as usual; $n=17$ treatment as usual. At 6 months, there was little difference between groups; at 12 months, the intervention group had a higher BMI and lower scores on Depression, Anxiety, and Stress Scale (DASS-21) than controls. Despite the differences between groups at 12 months, confidence intervals were wide and overlapped with zero, which decreases the certainty of the findings [79].

\section{Additional promising interventions}

- Internet-delivered self-compassionate letter writing unguided self-help for emerging adults with AN and atypical AN requires more study [80].
Section 3. E-technology as adjunctive interventions CBT-based group internet interventions may be a reasonable adjunctive treatment option for emerging adults with high body dissatisfaction

\section{Weak recommendation}

Qualifying Statements: Studies used a cognitive behavioural program called 'Set your body free'. This program included eight weekly 90 min group sessions led by a therapist by synchronous internet delivery via a chat room and using a manual (6-8 participants per group). Participants had high degrees of body dissatisfaction and the authors indicate that they had probable $\mathrm{BN}$, but it is difficult to make firm conclusions as a diagnosis of $\mathrm{BN}$ was not required to participate in the sessions. As a result, some participants in these studies may not have met criteria for $\mathrm{BN}$, however, our recommendation suggests that those with $\mathrm{BN}$ would likely benefit. One issue with virtually delivered treatments is that the generation of a diagnosis is more challenging and sometimes a diagnostic interview is not completed. Although evidence suggests that the 'Set your body free' program may be useful for addressing body dissatisfaction and may be helpful for those with $\mathrm{BN}$, this is not a standalone treatment for body dissatisfaction or BN.

\section{Key Evidence:}

- Two RCTs with those exhibiting BSQ scores above the community mean (> 81.5) and/or those who possibly had BN (according to BULIT-R scores): $n=19$ face-toface delivery and $n=21$ internet-delivery [83]; $n=42$ face-to-face delivery, $n=37$ internet-delivery, and $n=$ 37 delayed treatment control [84]. Both face-to-face and internet groups showed large improvements in body dissatisfaction (BSQ, BIAQ scores) and dietary restraint (DEBQ-R) (compared to control in the RCT with a delayed treatment control group); in the pilot $\mathrm{RCT}$, no significant differences between delivery modes were observed at post-treatment and at 2month follow-up [83]. However, in the full RCT, post-treatment improvements were greater in the face-to-face than the internet intervention, but generally gains made in both groups were no longer clearly different from each other at 6-month follow-up [84]; both were effective.

\section{Guided CBT-based smartphone apps may be reasonable adjunctive treatment options for emerging adults with $A N$}

\section{Weak recommendation}

Qualifying Statements: There was much discussion on the panel regarding the CBT app (Recovery Record) for emerging adults. The context in which the study was done was post inpatient admission for AN in emerging adults 
for a period of 8 weeks with feedback from a therapist on a weekly basis at minimum. Some panel members felt we should ensure the app was recommended only as an adjunct to standard treatment, offered concurrently. Some wondered if there could be unintended harms by individuals with EDs believing that they were in treatment by use of the app, when in fact they were not really making progress toward recovery, or that the app did not provide the level of treatment needed for those with more severe EDs. Some felt that these apps could serve a purpose in meeting young people where they are at in terms of level of motivation and that such an app might set them on a pathway to connect with more standard care. The app might also be able to reach more people who could not access standard care. We agreed to leave this as a weak recommendation, with the caveat that in more severe presentations of EDs, the app may be insufficient, and that the app should be used as it was in the study with guidance from a therapist. In fact, the panel felt it should only be endorsed as an adjunctive treatment, accompanying standard treatment.

Key Evidence:

- One pilot RCT with emerging adults diagnosed with AN: at post-intervention, non-significant small to moderate between-group effect sizes favoured the smartphone app intervention group with therapist feedback (received support from therapist through the app two times per week for $25 \mathrm{~min}$ each for the first 4 weeks, which decreased to once per week during the last 4 weeks; $n=20$ ) regarding ED psychopathology (EDE-Q scores) and BMI vs. control $(n=20)$; at 6-month follow-up: no significant differences between intervention and control groups for these measures [89].

\section{Additional promising treatments}

- Email therapy (as a treatment adjunct) for children and adolescents with AN requires more study [96].

- Email therapy and/or online counselling (as a treatment adjunct) for emerging adults with $\mathrm{AN}, \mathrm{BN}, \mathrm{BED}$, and EDNOS requires more study [98, 99, 105, 106].

- Text messaging therapy (as a treatment adjunct) for emerging adults with AN, subclinical AN, and BN requires more study $[93,94]$.

Section 4. Caregiver interventions focused on child outcomes Online guided parental self-help FBT may be a reasonable treatment option for children and adolescents with $A N$, and at risk for $A N$

\section{Weak recommendation}

Qualifying Statements: Research evidence evaluates the use of pre-recorded videos that parents can access via a web-based platform, along with coaching by a therapist via phone or videoconferencing. The videos focus on the principles of FBT including urgency to act, caregiver empowerment, externalization of the ED, agnosticism, and psychoeducation around medical complications. One study involved children and adolescents diagnosed with AN (according to DSM-5 criteria for AN), and the other included those with $\mathrm{AN}$, at risk for $\mathrm{AN}$, and at high risk for $\mathrm{AN}$, as determined by a diagnosis of AN within the past 6 months and/or screening results using established risk factors for EDs, retrospective correlates, and/or early symptoms of AN.

\section{Key Evidence:}

Online guided parental self-help - FBT

- One case series: $n=19$ families. At the end of the treatment and at follow-up, individuals with AN experienced weight gain similar to standard cliniciandelivered FBT programs. ED-related psychopathology (EDE-Q scores) of the children improved by end of treatment [107].

- After the family-based early intervention sessions (six online sessions) using pre-recorded videos, individuals in one pilot open trial $(n=12$ diagnosed with AN, $n=$ 12 at risk for $\mathrm{AN}$, and $n=22$ at high risk for $\mathrm{AN}$ ) remained stable or increased in ideal body weight [108].

\section{Section 5. Caregiver interventions focused on caregiver outcomes} Virtual parent meal support training may be beneficial for caregivers of children and adolescents with $A N, B N$, and OSFED

\section{Weak recommendation}

Qualifying Statements: Caregivers watched prerecorded video content and receive a manual on meal support strategies.

\section{Key Evidence:}

- One mixed methods study: the virtual Meal Support Training program was well-received by families $(n=40$; indicated by the lowest rating of the program being 3.79 $[\mathrm{SD}=0.843]$ on a 5 -point scale $[1=$ not informative, $3=$ somewhat informative, $5=$ very informative]), and families deemed the intervention as informative and convenient; caregivers reported that the program helped them to be more understanding and patient with their child and the ED recovery process [109].

\section{Unguided caregiver self-help using web-based and/or pre- recorded videos focused on psychoeducation and communication skills, may be beneficial for caregivers of emerging adults with $A N$, atypical $A N, B N$, atypical $B N$, and EDNOS}

\section{Weak recommendation}

Qualifying Statements: One study focused on a webbased intervention with 8 modules and a workbook. Core 
elements of the intervention were ED psychoeducation, communication skills, meal support strategies, caregiver needs. The other study provided 5 pre-recorded information sessions to caregivers on the impact of EDs, meal support strategies, communication skills, motivational stages of change. There was no contact with a therapist.

\section{Key Evidence:}

- One feasibility RCT with caregivers for individuals with AN and BN: $n=23$ web-based group; $n=27$ workshop group. Improvements in Caregiver Accommodation and Enabling Scale for EDs favored web-based intervention; changes in caregiver burden favored workshop intervention [110].

- One RCT with caregivers for individuals with AN, BN, atypical AN, atypical BN, and EDNOS: $n=147$ DVD intervention; $n=138$ control. Caregivers'

Accommodation and Enabling Scale for EDs scores were not reduced by DVD intervention, but caregiver burden was reduced by intervention compared to control [111].

\section{Guided parental self-help CBT (skills training approach + workbook or CBT-based online modules) is strongly recommended for caregivers of emerging adults with $A N$, and may be effective for caregivers of children and adolescents with $A N$ or $B N$}

\section{Strong recommendation}

Qualifying Statements: One study used Experienced Carers Helping Others (ECHO)- guided self-help skills training for caregivers using a book, pre-recorded videos and telephone coaching sessions. Another two studies used a web intervention using interactive multimedia CBT for caregivers to help them understand and meet their own needs; the latter intervention was called Overcoming Anorexia Online (OAO). The study involving caregivers of children and adolescents used a series of pre-recorded videos on communication skills, cycle of change, and strategies for supporting eating. Telephone or email support was also provided by a clinician. The panel agreed that these interventions for caregivers should be used in addition to treatment for the individual with an ED and should not be confused with actual treatment.

\section{Key Evidence:}

Guided self-help for caregivers of emerging adults

- One RCT with caregivers for individuals with AN: skills training intervention (ECHO) $(n=134)$ had reduced caregivers' expressed emotion levels and ED symptom impact scale scores, compared to controls $(n=134)$ [79].

- One feasibility RCT with caregivers for individuals with AN: Compared with telephone and email hotline support control $(n=30)$, the CBT-based online modules intervention group (OAO; $n=33)$ significantly reduced anxiety and depression in caregivers at posttreatment; caregivers in the $\mathrm{OAO}$ intervention group also had greater reductions in expressed emotion and ED symptom impact scale scores compared to controls, but these were not significant [113].

- One feasibility RCT with caregivers for individuals with AN: Caregiver expressed emotion and ED symptom impact scale scores were similarly reduced in both groups $(n=19 \mathrm{OAO}+$ guidance; $n=18 \mathrm{OAO}$ only); no significant difference between groups [114].

Guided caregiver self-help - Skills for caregivers of children and adolescents

- One pilot mixed methods study with caregiver for individuals with $\mathrm{AN}$ and $\mathrm{BN}(n=16)$. From baseline to post-intervention, caregiver general distress (General Health Questionnaire scores) decreased significantly [112].

\section{Moderated online caregiver forums and support groups may be beneficial for caregivers of children and adolescents with $A N$}

\section{Weak recommendation}

Qualifying Statements: Although the evidence was minimal, the online forum for caregivers was given a weak recommendation due to the enormous benefit to parents, as well as popularity of the Maudsley Parents forum. A note to readers here is that we did not include the search term 'social media' in our database searches; the panel agreed a priori that the research related to social media would be too large to review and would not meet our goals of answering our research questions related to the best treatments that can be delivered virtually or in the COVID-19 context. Thus, we focused on moderated forums (as opposed to unmoderated forums). The panel mentioned the importance of parent support as helpful in reducing caregiver burden. From their own experience running virtual parent-led support groups, many parents would prefer in-person support, but are glad there is a virtual option currently being offered in some locations. Virtual options might have benefits in terms of time and being able to access from home (no need for caregivers to arrange childcare). It is important to note here that no evidence exists to date for parental forums having an impact on child and adolescent outcomes. Further study is needed.

\section{Key Evidence:}

- One pilot open trial with caregivers for individuals with AN: virtual chat room sessions were highly feasible and acceptable (91.7\% satisfaction rating) among caregivers $(n=13)$, who reported sessions as accessible, convenient, and easy to use [116]. 
- One case series of teleconferencing for caregiver support for caregivers of those with any ED (not specified) aged 12-22 years found benefit for caregivers [117].

Section 6. In person care versus home monitoring It is strongly recommended that individuals (of all ages) with EDs are seen in-person for medical evaluation by specialists in conjunction with local care providers when necessary and that international guidelines and criteria for admission are followed

\section{Strong recommendation}

Qualifying Statements: This recommendation is based on expert consensus. The panel was unanimous in their agreement that it is not possible to offer all care virtually to this patient population. Guidelines by the Society for Adolescent Health and Medicine provide criteria for hospital admission and medical monitoring [119] in children, adolescents, and emerging adults and should be followed by all practitioners. Individuals with EDs must be able to access emergency rooms and hospital beds despite competing demands for resources in the COVID-19 era. The threshold for admission to hospital should not be changed due to the COVID-19 context. In fact, a direct relationship may exist between the pandemic and an increase in the number of young people needing admission to hospital for EDs. This was mentioned by panel members and there is preliminary evidence to support this (personal communication with several pediatricians across the country, and a study from Perth, Australia [120]).

In terms of monitoring at home, weight can be taken at home on a home scale, however FBT therapists should educate caregivers around possible falsification of weight. Monitoring of vital signs at home is not recommended due to difficulties in proper measurement interpretation and issues with methods of monitoring (may not be reliable or accurate) that could cause harm. Vital signs should be monitored by a health professional. Lack of progression in virtual therapy, concerns around accuracy of home weights, or new symptoms should signal the need for in-person evaluation.

Suicidality is another reason individuals may need to be assessed in-person. Should a young person not wish to come to hospital, but there is grave concern over physical or mental health, legal processes should be followed in order to ensure that the individual receives the assessment and treatment that they require.

\section{Key Evidence:}

- Some limited evidence of the feasibility of wearable sensors for adolescents with AN to monitor vital signs by a clinician, not by caregivers $(n=27)$ [118].

- Some studies indicate that with rapid scale up of virtual FBT, caregivers for those with AN were given the role of monitoring weight at home $[44,46]$.
Section 7. Sex, gender, and diversity considerations

We strongly recommend that equity-seeking groups and

marginalized youth should be provided equal access to treatment

\section{Strong recommendation}

Qualifying Statements: This recommendation was not based on research evidence, but rather on expert consensus. Equity-seeking groups as defined by the Public Service Alliance of Canada include racialized people, people with disabilities, Aboriginal (First Nations, Inuit and Métis), women, lesbian, gay, bi-sexual, and trans individuals [121]. Trans-youth and boys are at high risk of not being recognized by providers as having EDs. Providers need to be more vigilant with these groups, and also be aware of the barriers to care that they face. In addition, non-English speaking youth and their families struggle with extra barriers to care, especially in a virtual world. It is difficult for an interpreter to be involved virtually, although this should be attempted. Those in rural areas or of lower socioeconomic status may not have access to the internet, or they may face limitations related to internet speed and high cost. Providers should also be vigilant to violence occurring in homes as individuals experience heightened isolation. Health care workers should be aware of how racism affects the quality of and access to health care for racialized groups and should seek to reduce barriers. Indigenous peoples, especially in the far north, face additional barriers to care related to geographical isolation, lack of access to the internet or reliable internet, lack of access to videoconferencing centres, as well as lack of confidentiality due to small population sizes and therefore, increased likelihood of kinship, peer, or social connections to health care providers. Inclusion of equity-seeking groups in research is essential.

\section{Key Evidence:}

No evidence could be found in our search on these topics.

\section{Discussion}

These are the first Canadian Practice Guidelines to evaluate the evidence on virtual care focused specifically on children and adolescents ( $<18$ years) and emerging adults (18-25 years) with EDs, in the COVID-19 context. A strong recommendation was supported in favour of in-person medical evaluation, when necessary, for children, adolescents, and emerging adults with EDs; as was a strong recommendation that equity-seeking groups and marginalized youth should be provided equal access to treatment. In addition, for emerging adults, internet CBT-based guided self-help for AN, BN, BED, and EDNOS was strongly recommended. Weak recommendations were generated for CBT-based group internet interventions as treatment adjuncts for high body dissatisfaction, internet-based relapse prevention MANT RA guided self-help for $\mathrm{AN}$, telehealth relapse 
prevention using MANTRA for AN, and guided CBTbased smartphone apps as treatment adjuncts for AN in this age group. For children/adolescents with AN, weak recommendations were supported for telehealth FBT, and online guided parental self-help FBT. In terms of caregiver outcomes, guided parental self-help CBT for caregivers of emerging adults with $\mathrm{AN}$ or $\mathrm{BN}$ was strongly recommended, while unguided caregiver psychoeducation self-help was weakly recommended for most ED diagnoses. For caregivers of children and adolescents with EDs, weak recommendations were supported for virtual parent meal support training, as well as moderated online caregiver forums and support groups.

Recommendations were developed by taking into account research evidence, knowledge that treatments delivered in person generally translate well to virtual care, and the values, preferences, and opinions of panel members. In the absence of more robust research on the efficacy of virtually delivered ED treatments - particularly in the COVID-19 context - clinicians should use these guidelines and recommendations to inform their clinical decisions regarding what are likely the most effective and implementable treatments. Systematic review and metaanalysis evidence from non-ED research suggest that psychological treatments transfer well to virtual delivery, without the loss of efficacy or patient acceptability [1214]. Although the research evidence reviewed in this guideline may be perceived as weak on its own, the fact that the effects of virtually-delivered ED care also seem to be comparable to in-person delivery reinforces these conclusions. Readers must consider the fact that the evidence presented in studies conducted prior to the pandemic is within a context in which individuals with EDs, caregivers, and clinicians opted into virtual care or were randomized to virtual care having consented to participation. In the COVID-19 context, the vast majority of individuals now delivering or receiving virtual treatment have been left without a choice but to do so. Once restrictions are lifted and there is a gradual return to face-to-face treatment, it is possible that virtual care may become less acceptable.

Best practices for virtual therapy have been previously published pertaining to non-ED-related care [122-125]. Generally, these considerations can be applied to virtual ED therapy and clinicians would benefit by their review. See Table 15 for good practice points related to virtual care, summarizing issues that clinicians from all fields should be mindful of when delivering treatments virtually.

Panel members generally commented on the pros and cons of virtual care. While virtually delivered care may be easily accessible for those with a reliable internet connection at home, this poses a potential barrier to care for families without home internet access. Clinicians mentioned fatigue from virtual care and challenges navigating the legal and procedural aspects of technology-based care. Others mentioned that their patients and families often do not like to see their own image, which poses challenges when trying to conduct video call appointments. Suggestions for this problem were proposed by the panel including having the family block their own image by covering this portion of their own screen (e.g. hiding their image on the videoconferencing platform or using a sticky note on their monitor). Some panel members also indicated it is hard to evaluate weight status in patients by virtual means. This resonates with the literature already published on this topic. Three studies identified ED professionals' opinions on the impact of digital technologies on their patients, indicating potential

Table 15 Good Practice Points to Consider for Virtual Care

Practical/Technical Issues: Practitioner and patient preference, experience level, and organizational capacity should be considered when choosing a virtual platform, but reliable, secure video-call platforms should be favoured over the use of audio calls (e.g. to conduct a visual assessment of a patient). Prior to commencing online sessions, clinicians should prepare and share with patients a written plan detailing what to do in the event of technological failure (e.g. who should first attempt to re-establish a lost connection, when to attempt alternate technologies, how long to wait before presuming that a connection cannot be re-established).

Inclusivity: Virtual delivery poses a potential barrier to care for those without home internet access, or an electronic device, so alternatives such as books and workbooks for patients and caregivers should be encouraged where necessary. Language, sight/hearing impairment, and technological experience should also be considered (e.g. involving an interpreter in the care of non-English speaking individuals).

Confidentiality: Lack of privacy in homes may impact patient engagement in virtual therapy; headphones or establishing a 'time-out signal' can help to increase the level of privacy during sessions. End-to-end encryption should be prioritized, and passwords should be used regularly. Clinicians should inform patients of the measures being taken to protect their privacy and security.

Managing Medical and Psychological Safeguarding Risks: Clinicians providing virtual care must continue to practice within the jurisdiction in which they are licensed and according to their insurance coverage for malpractice. Crisis management plans should be available for every patient involved in virtual treatment. These plans can include patient-specific local resources (e.g. crisis lines, hospitals, emergency services). Clinicians must be able to coordinate care with local crisis resources if they are required (e.g. in case of high suicidality risk) and should be familiar with local mental health laws in responding to crises obligations (e.g. duty to call child protective services, when to call police). Creating a network with local providers may also be beneficial in the case of an emergency. Clinicians should also determine if the family context and home environment are considered safe and non-triggering for virtual contacts.

Managing Intensity, Difficult Family Dynamics, or Overwhelming Emotions: Clinicians should be vigilant to any violence or maltreatment that may be occurring in the family home. Follow-up with participants of virtual sessions that become highly intense, and when necessary, referral to additional health resources, is encouraged.

Length of Sessions: Duration of sessions may need to be changed, depending on the patient (e.g. briefer sessions may be more effective for younger patients/siblings with shorter attention spans).

Cultural and Socio-Economic Factors: The needs of equity-seeking groups should be acknowledged before and during treatment and reducing barriers to care should be of high priority. Clinicians and patients engaging in virtual therapy from their respective homes may result in feelings of blurred boundaries. To counteract this, participants should be encouraged to create a particular space in the home for virtual care. Involvement of parents should be explicitly discussed, as it is important to devise a plan outlining how family members will be involved (e.g. reserving time, being present when needed, and clarifying roles in treatment). 
benefits and drawbacks. Specifically, in two qualitative studies (total $n=65$ ) professionals described advantages in virtual care including better patient-clinician communication and access to patient reported data (via apps) ahead of scheduled sessions. However, disadvantages included added workload for the clinician and the risk that it may be easier for patients to continue with and hide their ED symptoms and behaviours in an online environment [126, 127]. Survey results from one cross-sectional study found that professionals $(n=282)$ believe e-health may be a more useful treatment for adolescents and adults than children and seniors, and may be more beneficial for anxiety and depressive disorders than for addiction and EDs [128].

An additional aspect to consider is how to appropriately train clinicians in virtual modalities. Although thought to be equally efficacious, virtual adaptations of treatments may have differences that could affect efficacy. Three studies observed the effectiveness of various web-centered ED training programs for health care professionals. In one RCT that compared a CBT-E web-centered supported training group (receiving phone call support in addition to the course components; $n=81$ ) to a CBT-E web-centered independent training group (only received access to the CBT-E course; $n=75$ ), it was confirmed that webcentered training can successfully train therapists to deliver CBT-E [129]. The supported and independent training programs were also equally effective as both training groups had increased scores in therapist competence from pre-intervention to post-intervention [129]. This CBT-E web-centered training program was also studied in an open trial $(n=765)$, similarly confirming that competence in delivering CBT-E was improved following web-based training. Factors associated with a beneficial effect from this training included compliance with training recommendations, higher number of training modules completed, and treating at least one patient while in training [130]. In a separate open trial that involved a telementoring project between ED specialists (mentors) and community-based practitioners (mentees) (Project ECHO; $n=99)$ which aimed to disseminate specialized ED knowledge to clinicians in need and located in underserved areas via Zoom, tele-mentoring was found to be promising to bridge the speciality-based knowledge gap between EDtrained and front-line clinicians [131].

Panel members also discussed the various platforms available for virtual care delivery. There is limited evidence describing what online platform is the most ideal to deliver ED care virtually, and as such, clinicians tend to only use what is available through their institution. However, one descriptive study that summarized the opinions of clinicians delivering CBT for EDs via telehealth during COVID-19 revealed positive experiences about working with cloud-based videoconferencing and live-chat services, including Zoom, Facetalk, Google
Meets, Vsee, and Microsoft Teams [50]. Other software choices, such as Skype and FaceTime were seen as less reliable and less secure in comparison, and therefore were not often recommended [50]. According to this descriptive study, platforms that allow for confidential sharing of documents during sessions, high security, white board feature, and ease of use may be the most favourable to support virtual care. However, other platforms endorsed by Canadian health care agencies as meeting privacy and security requirements were not evaluated in this particular study. Our panel also did not endorse one single platform; panel members identified benefits to several different platforms and acknowledge that practitioner context and organizational mandates may be a key factor in the selection of virtual technology.

Two studies described general recommendations for clinicians delivering virtual mental health interventions during COVID-19. One commentary focused on recommendations for improving the delivery of virtual mental health care, such as: programs offering training and supervision in virtual therapy tools, national licenses being implemented to practice virtual therapy (telehealth), providers being taught to ensure patient confidentially during virtual sessions, broadening reimbursement coverage to include evidence-based virtual therapies, continuous evaluation of the efficacy of virtual therapies on broader mental health disorders, and introducing innovative and timely virtual mental health practices into health care systems [132]. One descriptive review noted that guidelines for telepsychiatry in EDs are lacking, but in general, clinicians involved in telepsychiatry during COVID-19 should: a) familiarize themselves with the telehealth system to ensure sessions run smoothly; b) focus on effective communication during sessions; and c) document any issues with telehealth immediately, so that improvements can be made for future sessions [133].

\section{Strengths}

The strengths of this guideline are numerous. We used a rigorous and evidence-based methodology for our scoping review and our guideline development. Our scoping review methods included a thorough review of all literature (including a variety of databases, grey literature, and papers in any language), and we had few exclusion criteria. We translated several papers into English for fulltext review and we also examined the references of included reviews and book chapters to ensure we did not miss any relevant studies. In terms of guideline development, conflict of interest statements were reviewed by an impartial chair (MB) in order to address any biases. We had an initial virtual meeting to ensure that the research questions were unanimously agreed upon by the panel, as well as a second virtual meeting to discuss our recommendations, which was followed by an anonymous 
voting procedure. Furthermore, our panel included the voices of various stakeholder groups including researchers, clinicians, policymakers, parents, and those with lived experience of receiving treatment for an ED.

\section{Limitations}

Although thorough, our search strategy had limitations. We were unable to retrieve seven citations as full text articles as they could not be located. We also attempted to examine sex differences, but the numbers of male subjects were so small that no conclusions could be drawn, and studies did not comment on the impact of sex on virtual care. While we searched the literature thoroughly for virtual day hospital and virtual meal support, we were unsuccessful in finding any articles on these topics. We found one mixed methods study related to virtual meal support training (pre-recorded videos) for caregivers. Furthermore, virtual care presents some difficulties related to diagnostic certainty. Many studies enrolled participants based on symptom evaluation using instruments rather than diagnostic interview, with study inclusion criteria also bridging DSM-IV and DSM-5 criteria. Therefore, recommendations for specific ED diagnoses may be seen as suggestive rather than definitive.

While research about moderated online caregiver forums and support groups indicated that they are important sources of caregiver support, especially with resources being scarce during the COVID-19 pandemic, there is insufficient evidence of their impact on patient outcomes, and therefore are not being recommended as alternatives to treatment. Similarly, although self-help was not the main focus of our recommendations, the panel agreed a priori to our literature search that self-help resources such as books and manuals (including unguided self-help) should be examined as possible sources of support. After review and discussion of the findings, the panel concluded that book and manual self-help resources should be considered as adjuncts to virtual care, rather than treatment. Despite these limitations, these guidelines represent a significant step forward in adopting virtual care in the field of EDs for treatment among treatment-seeking children, adolescents, emerging adults and their families.

\section{Future directions}

Several gaps were noted by the guideline panel, which should be a focus for future study. These gaps include the impact of sex, gender, and underserved populations on virtual care among children, adolescents and emerging adults with EDs, as well as the efficacy of more intensive treatments such as virtual day hospital, or virtual meal support therapy. Mixed methods studies may be a useful study design for these understudied areas, to understand both quantitative and qualitative impacts. There were several other gaps identified by the panel as needing further study. The panel was unable to make any recommendations for adjunctive email therapy and/or online counselling, and text messaging therapy. While some encouraging evidence was found in these areas for children, adolescents and emerging adults with $\mathrm{AN}, \mathrm{BN}, \mathrm{BED}$, and EDNOS, the panel concluded that these therapies are promising in terms of possible adjuncts to treatment, however, should not be recommended without further study. The panel suggested that creative interventions be developed for those on a waiting list or transitioning in levels of care. Such a possibility might be self-compassionate letter writing unguided selfhelp (adapted from compassion-focused therapy) for emerging adults, [80] but again more research is required to support this recommendation. Furthermore, there was some positive evidence for telehealth cognitive and behavioural treatment for children and adolescents with ARFID and OSFED, but additional research is also required to draw conclusions, as sample sizes in these studies were small. Finally, research on telehealth family interventions for ARFID and OSFED is lacking but should be a focus of further study.

\section{Conclusions}

Our Canadian Practice Guidelines for virtual care during COVID-19 and beyond recommend several options for treatment (or adjuncts to treatment), as well as some general principles, and areas for future research. A strong recommendation was supported in favour of in-person medical evaluation, when necessary, for children, adolescents, and emerging adults with EDs; and that equityseeking groups and marginalized youth should be provided equal access to treatment. In addition, for emerging adults, internet CBT-based guided self-help for AN, BN, BED, and EDNOS was strongly recommended. Additionally, for this age group, weak recommendations were generated for CBT-based group internet interventions as treatment adjuncts for high body dissatisfaction, internet-based relapse prevention MANTRA guided self-help for AN, telehealth relapse prevention using MANTRA for AN, and guided CBT-based smartphone apps as treatment adjuncts for AN. For children and adolescents with AN, weak recommendations were supported for telehealth FBT, and online guided parental self-help FBT. In terms of caregiver outcomes for caregivers of emerging adults, guided parental self-help CBT was strongly recommended, while unguided caregiver psychoeducation selfhelp was weakly recommended. For caregivers of children and adolescents with EDs, weak recommendations were supported for virtual parent meal support training, as well as moderated online caregiver forums and support groups. Future research is required to understand the impact of sex, gender, race, socioeconomic status, and other factors on virtual care among children, adolescents and emerging adults with EDs; as well as research on more intensive services such as virtual day hospitals. 


\section{Appendix A}

Summary of included studies regarding the impact of COVID-19 on eating disorders

\begin{tabular}{|c|c|c|c|c|c|}
\hline Reference & Type of Study & $\begin{array}{l}\text { Age } \\
\text { group }\end{array}$ & $\begin{array}{l}\text { ED } \\
\text { diagnosis }\end{array}$ & Sample size & Main findings \\
\hline $\begin{array}{l}\text { Barney et al. } \\
2020 \text { [47] }\end{array}$ & Descriptive & $\begin{array}{l}18-25 \\
\text { years }\end{array}$ & All EDs & Not specified & $\begin{array}{l}\text { Telemedicine visits increased from } 0 \text { to } 97 \% \text { in } 1 \text { month. Providers noted ED patients } \\
\text { particularly benefitted from telemedicine as they are already often referred to clinics } \\
\text { from a much wider geographic range than typical primary care patients; also created } \\
\text { flexibility for families. Challenges: privacy (so providers encouraged headphones), } \\
\text { inability to assess anthropometric data (so providers trained families to take weights at } \\
\text { home or partnered with local primary care providers to collect data). }\end{array}$ \\
\hline $\begin{array}{l}\text { Bryant-Waugh, } \\
2020 \text { [53] }\end{array}$ & Editorial & $\begin{array}{l}\text { Any } \\
\text { age }\end{array}$ & ARFID & Not applicable & $\begin{array}{l}\text { When treating individuals with ARFID, especially during COVID-19, collaborative work } \\
\text { is encouraged between clinicians, researchers, and those with lived experience, to bet- } \\
\text { ter understand epidemiology, etiology, impact, and co-occurring conditions. It is im- } \\
\text { portant to foster communities of kindness towards ARFID (during and beyond COVID), } \\
\text { which involves carefully listening to individuals, family members, and partners of those } \\
\text { affected by ARFID. }\end{array}$ \\
\hline $\begin{array}{l}\text { Clark-Bryan et al. } \\
2020 \text { [49] }\end{array}$ & Qualitative & $\begin{array}{l}18-25 \\
\text { years }\end{array}$ & AN & $\begin{array}{l}n=21 \text { individuals with } \\
\mathrm{AN} ; n=28 \text { caregivers }\end{array}$ & $\begin{array}{l}\text { People with AN: reduced access to ED services (reliance on remote support which was } \\
\text { received with varying levels of acceptability); disruption to routine; reduced motivation } \\
\text { for recovery; heightened psychological distress and ED symptoms; increased attempts } \\
\text { at self-management in recovery. Caregivers: fears of premature discharge of patient; in- } \\
\text { creased demands to manage patient needs; new challenges around managing patient } \\
\text { well-being (spotting signs of relapse); new opportunities (gratitude for increased time } \\
\text { at home). }\end{array}$ \\
\hline
\end{tabular}

Davis et al. Descriptive $\quad<18$ All EDs Not specified

\begin{tabular}{|c|c|c|c|c|}
\hline $\begin{array}{l}\text { Emans et al. } \\
2020 \text { [48] }\end{array}$ & Commentary & $\begin{array}{l}18-25 \\
\text { years }\end{array}$ & All EDs & Not applicable \\
\hline $\begin{array}{l}\text { Janse van } \\
\text { Rensburg, } 2020 \\
{[52]}\end{array}$ & $\begin{array}{l}\text { Letter to the } \\
\text { editor }\end{array}$ & $\begin{array}{l}\text { Any } \\
\text { age }\end{array}$ & All EDs & Not applicable \\
\hline $\begin{array}{l}\text { Matheson et al. } \\
2020 \text { [26] }\end{array}$ & Descriptive & $\begin{array}{l}<18 \\
\text { years }\end{array}$ & $\begin{array}{l}\text { AN, BN, } \\
\text { ARFID }\end{array}$ & Not applicable \\
\hline $\begin{array}{l}\text { Murphy et al. } \\
2020 \text { [51] }\end{array}$ & Descriptive & $\begin{array}{l}\text { Any } \\
\text { age }\end{array}$ & All EDs & Not applicable \\
\hline $\begin{array}{l}\text { Waller et al. } \\
2020 \text { [50] }\end{array}$ & Descriptive & $\begin{array}{l}\text { Any } \\
\text { age }\end{array}$ & All EDs & $n=22$ clinicians \\
\hline $\begin{array}{l}\text { Walsh and } \\
\text { McNicholas, } \\
2020[46]\end{array}$ & Descriptive & $\begin{array}{l}<18 \\
\text { years }\end{array}$ & AN & Not applicable \\
\hline $\begin{array}{l}\text { Wood et al. } \\
2020[44]\end{array}$ & $\begin{array}{l}\text { Case report in a } \\
\text { descriptive study }\end{array}$ & $\begin{array}{l}<18 \\
\text { years }\end{array}$ & AN & $n=1$ \\
\hline $\begin{array}{l}\text { Weissman et al. } \\
2020[18]\end{array}$ & Editorial & $\begin{array}{l}\text { Any } \\
\text { age }\end{array}$ & All EDs & Not applicable \\
\hline $\begin{array}{l}\text { Weissman et al. } \\
2020[55]\end{array}$ & Cross-sectional & Any & & $n=187$ rese \\
\hline
\end{tabular}

age
Scaling up of outpatient treatment delivered via telehealth. Patients and families had heightened health-related fear. In the community, school counsellors and community social workers partnered with psychologists to support ED patients. Caregivers working greater hours due to the pandemic had difficulties with child meal supervision and being involved in care.

Some ED programs enlisted parents to monitor weight and vital signs. Some ED visits for patients were co-managed with local primary care providers until in-person visits could be arranged.

ED behaviours may be the only coping tool available for those with EDs during COVID-19, so a harm-reduction, person-centered approach is proposed. Goal: decrease likelihood of mortality by maintaining ED behaviours but increasing their safety; allowing the individual to set boundaries about what behaviours they are not willing to give up at that time.

Challenges: difficulties in ensuring accurate communication when monitoring remotely, patients not physically present for weigh-ins, privacy, hard to build rapport virtually, lack of family involvement in FBT via video, difficult to conduct family meal session of FBT, families abruptly leaving virtual sessions.

CBT-E is well suited for remote delivery during COVID-19 if adapted appropriately: have an assessment phase with patient to discuss a crisis plan, use video-call platforms instead of audio calls, keep virtual sessions the same length as in-person sessions, explain to patients how online sessions will work

Patients may view telehealth as 'second best', so clinicians need to stress that it is 'business as usual'. Reliable programs (e.g. Zoom, Microsoft Teams) should be used over unreliable programs (e.g. FaceTime). COVID-19-specific ED psychoeducation should be included in CBT sessions.

Weekly FBT sessions were held by telephone or Zoom, caregivers were required to weigh their child at home using a home scale, record food intake, estimate energy expenditure, collect vital signs; caregiver burden increased.

Using telehealth FBT, the case achieved prescribed calorie goals, reduced/eliminated purging, reduced emotional outbursts, engaged in care, and avoided re-hospitalization and other higher levels of care.

Most ED patients have favourable attitudes towards e-therapy and willingness to engage in it, but few express a preference for it over in-person therapy. Clinicians are concerned that patients may expect them to handle their issues during off-work hours, contributing to a higher workload.

During COVID-19, many ED researchers moved studies online and/or had to shut down part of their research. Researchers reported a need to advocate for ED research related to COVID-19. Strategies for dealing with research disruptions: employing technology, reprioritizing goals/tasks (e.g. changing future research directions), encouraging collaboration.

All EDs $n=187$ researchers

Researchers associated with the International Journal of Eating Disorders requested: more flexible timeframes to submit or review revisions, fast-tracking of COVID-19related studies for EDs, research conducted on the COVID-19 impact on ED research, standards for publication to be maintained. 


\section{Appendix B}

Summary of included studies regarding virtual care and eating disorders

\begin{tabular}{|c|c|c|c|c|c|}
\hline Reference & $\begin{array}{l}\text { Type of } \\
\text { Study }\end{array}$ & $\begin{array}{l}\text { Age } \\
\text { group }\end{array}$ & ED diagnosis & Sample size & Intervention \\
\hline $\begin{array}{l}\text { Aardoom et al. } \\
2014 \text { [86] }\end{array}$ & $\begin{array}{l}\text { Cross- } \\
\text { sectional }\end{array}$ & $\begin{array}{l}18-25 \\
\text { years }\end{array}$ & $\begin{array}{l}\text { Not specified; those } \\
\text { experiencing ED } \\
\text { symptoms }\end{array}$ & $n=311$ & Moderated online forums \\
\hline
\end{tabular}

Main findings

Exchanging information, finding recognition, and sharing experiences were the empowering processes often reported; most pronounced empowering outcome was feeling better informed. To a smaller degree, increased help-seeking behavior, optimism and control, and confidence in treatment and relationship with the therapist.

\begin{tabular}{|c|c|c|c|c|c|}
\hline $\begin{array}{l}\text { Aardoom et al. } \\
2016 \text { [61] }\end{array}$ & $\mathrm{RCT}$ & $\begin{array}{l}18-25 \\
\text { years }\end{array}$ & $\mathrm{AN}, \mathrm{BN}, \mathrm{BED}$ & $\begin{array}{l}n=87 \text { Featback; } n=88 \\
\text { Featback +low-intensity } \\
\text { therapist support; } n=89 \\
\text { Featback+ high-intensity ther- } \\
\text { apist support; } n=90 \text { waitlist } \\
\text { control }\end{array}$ & $\begin{array}{l}\text { Internet CBT-based } \\
\text { self-help (Featback) }\end{array}$ \\
\hline $\begin{array}{l}\text { Aardoom et al. } \\
2016 \text { [64] }\end{array}$ & $\begin{array}{l}\text { RCT } \\
\text { (economic } \\
\text { evaluation) }\end{array}$ & $\begin{array}{l}18-25 \\
\text { years }\end{array}$ & $\mathrm{AN}, \mathrm{BN}, \mathrm{BED}$ & $\begin{array}{l}n=87 \text { Featback; } n=88 \\
\text { Featback +low-intensity } \\
\text { therapist support; } n=89 \\
\text { Featback+ high-intensity ther- } \\
\text { apist support; } n=90 \text { waitlist } \\
\text { control }\end{array}$ & $\begin{array}{l}\text { Internet CBT-based } \\
\text { self-help (Featback) }\end{array}$ \\
\hline $\begin{array}{l}\text { Aardoom et al. } \\
2017 \text { [65] }\end{array}$ & $\mathrm{RCT}$ & $\begin{array}{l}18-25 \\
\text { years }\end{array}$ & $\begin{array}{l}\text { AN, BN, purging } \\
\text { disorder, EDNOS }\end{array}$ & $\begin{array}{l}n=60 \text { Featback; } n=70 \\
\text { Featback +low-intensity } \\
\text { therapist support; } n=71 \\
\text { Featback }+ \text { high-intensity ther- } \\
\text { apist support; } n=72 \text { waitlist } \\
\text { control }\end{array}$ & $\begin{array}{l}\text { Internet CBT-based } \\
\text { self-help (Featback) }\end{array}$ \\
\hline $\begin{array}{l}\text { Anastasiadou } \\
\text { et al. } 2019 \text { [87] }\end{array}$ & Qualitative & $\begin{array}{l}<18 \\
\text { years }\end{array}$ & AN, BN, EDNOS & $\begin{array}{l}n=9 \text { patients; } n=11 \text { mHealth } \\
\text { experts; } n=10 \text { healthcare } \\
\text { professionals; } n=8 \mathrm{ED} \\
\text { specialists }\end{array}$ & $\begin{array}{l}\text { Smartphone applicat } \\
\text { (TCApp) }\end{array}$ \\
\hline $\begin{array}{l}\text { Anderson } \\
\text { et al. } 2017 \text { [56] }\end{array}$ & $\begin{array}{l}\text { Open trial } \\
\text { (feasibility) }\end{array}$ & $\begin{array}{l}<18 \\
\text { years }\end{array}$ & AN, atypical AN & $n=10$ & Telehealth FBT \\
\hline $\begin{array}{l}\text { Bailey et al. } \\
2002 \text { [96] }\end{array}$ & Case report & $\begin{array}{l}<18 \\
\text { years }\end{array}$ & AN & $n=1$ & $\begin{array}{l}\text { Email and/or online } \\
\text { counselling }\end{array}$ \\
\hline
\end{tabular}

3 Featback conditions were superior to control in reducing ED

psychopathology, and ED symptoms (e.g. cessation from binge eating and purging). No added value of therapist support.

No significant differences between the study conditions were found regarding quality-adjusted life-years and societal costs, but the mean costs per participant were lowest in the Featback condition with low-intensity therapist support. Featback seems to therapist support. Featback seems to
be cost-effective compared to waitlist.

Baseline levels of ED psychopathology were found to moderate intervention response. Featback with and without therapist support is particularly useful in improving bulimic psychopathology but may be less suitable in improving severe anorectic psychopathology.

Professionals consider mHealth as difficult to obtain and use (barriers = lack of time). According to patients and ED specialists, app was easy to use and useful. Patient barriers were lack of personalization and lack of motivational and interactive components. Patients disliked webbased chat option with ED specialist.

Significant weight gain was achieved from baseline to end of treatment and baseline to 6-month follow-up.

Patient emailed psychiatrist several times/week, describing food eaten, mood, psychological changes, etc. Patient generally described email as a positive treatment adjunct that was good for self-reflection, but had issues with privacy, having "one more thing to do".

Barney et al. Descriptive 18-25 All EDs Not specified

In-person medical evaluation

If a patient was clearly engaging in concerning behaviours (e.g increased restricting, purging, over exercising) or the provider or caregiver had a high index of suspicion for medical deterioration, the patient was asked to come in for limited in-person sessions, rather than continuing with virtual care visits.

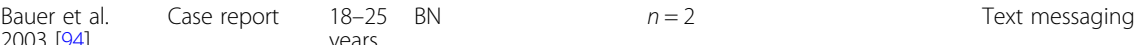

Generally positive outcomes of using the aftercare intervention (e.g. no bingeing/purging reported) over the course of 12 to 14 weeks of use. Some issues still present (e.g. low body satisfaction).

Billeci et al. Open trial $\quad<18$ AN $n=27$ with AN; $n=15$ healthy Home monitoring
controls

Wearable sensors combined with wireless technologies were feasible in young adolescents with AN, providing useful information on heart rate and heart rate variability. Instruments proved to be suitable in AN subjects; their applications could open new approaches of vital signs monitoring at home, but by a clinician rather than a caregiver. 
Summary of included studies regarding virtual care and eating disorders (Continued)

\begin{tabular}{|c|c|c|c|c|c|}
\hline Reference & $\begin{array}{l}\text { Type of } \\
\text { Study }\end{array}$ & $\begin{array}{l}\text { Age } \\
\text { group }\end{array}$ & ED diagnosis & Sample size & Intervention \\
\hline $\begin{array}{l}\text { Binford Hopf } \\
\text { et al. } 2013 \\
\text { [116] }\end{array}$ & $\begin{array}{l}\text { Open trial } \\
\text { (pilot) }\end{array}$ & $\begin{array}{l}<18 \\
\text { years }\end{array}$ & AN & $n=13$ & $\begin{array}{l}\text { Moderated online caregiver } \\
\text { forums }\end{array}$ \\
\hline
\end{tabular}

Main findings

High chat programme satisfaction

ratings $(91.7 \%)$. Parents reported

looking forward to chat sessions and

would recommend to others. Vast

majority reported that the chat helped

them cope with child's ED and to

implement FBT; overall rated as

accessible, convenient, and easy to

use

$\begin{array}{lll}\begin{array}{ll}\text { Bloomfield } \\ \text { et al. 2019 [59] }\end{array} & \text { Case report } & \begin{array}{l}<18 \\ \text { years }\end{array} \\ \text { Cairns et al. } & \text { Mixed } & <18 \\ \text { 2007 [109] } & \text { methods } & \text { years }\end{array}$

ARFID

$n=1$

Telehealth CBT

Increased frequency of bites of nonpreferred foods consumed.

Unguided caregiver self-help using web-based and/or pre recorded videos focused on psychoeducation and communication skills

Program was reported as informative, convenient and was well-received by families. Many parents reported that the resources helped them be more understanding and patient with their youth and the recovery process.

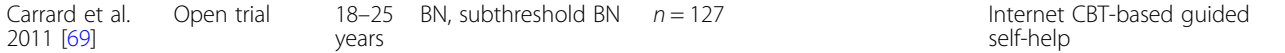

Cavazos-Rehg Mixed $\quad<18 \quad$ AN, BN, BED, $\quad n=366$

et al. 2020 [88] methods years subclinical BN or BED, purging disorder, unspecified feeding or eating disorder

Dimitropoulos RCT 18-25 AN, BN et al. $2019 \quad$ (feasibility) years
[110]

Severity of ED symptoms (e.g. bingeing) and general psychopathology improved significantly

Smartphone applications

Those with more severe

manifestations of illness were more interested in trying the app. Primary reasons for unwillingness: wanting to retain privacy, felt parents lack awareness of mental health issues, concerns of parents' reaction, poor parent-teen relationship, feeling of parent not wanting child to participate.

Unguided caregiver self-help From baseline to end of intervention, using web-based and/or pre- small between-group effect sizes were recorded videos focused on observed for changes in caregiver ac-

$\begin{array}{lllll}\begin{array}{l}\text { Duncan et al. } \\ 2014[60]\end{array} & \text { Case report } & \begin{array}{l}<18 \\ \text { years }\end{array} & \text { EDNOS } & n=1 \\ & & & \\ \begin{array}{l}\text { Dunn et al. } \\ 2006 \text { [82] }\end{array} & \text { RCT } & \begin{array}{l}18-25 \\ \text { years }\end{array} & \text { BN, BED } & \begin{array}{l}n=45 \text { self-help only; } n=45 \\ \text { MET adjunct + self-help }\end{array}\end{array}$

Emans et al. 2020 [48]
Commentary $18-25$ All EDs years $n=23$ caregivers in web-based intervention; $n=27$ caregivers in workshop intervention MET adjunct + self-help
Telehealth CBT

MET and self-help book (Overcoming Binge Eating) psychoeducation and com- commodation, problem-solving abilmunication skills

ities, the quality of psychological health, and quality of social relationships, favouring web intervention, and changes in expressed emotion in family context, caregiver burden, perceived stress, and the quality of the environment, supporting the workshop intervention.

Increase in food intake, improvements in growth, and reduced depression scores post-treatment.

MET intervention resulted in increased readiness to change for binge eating compared with the self-help only intervention. Few differences between conditions for eating attitudes and frequency of binge eating and compensatory behaviours (both groups had improvements). Within-group effects indicated that those in MET condition had significant reductions in binge had significant reductions in binge eating, compensatory behaviours, and
maladaptive attitudes; changes in selfhelp only were not significant.

n-person medical evaluation During COVID-19, ED programs utilized weight and heart rate criteria to define urgency and need for inperson medical assessments. Some programs established 'vital signs clinics', where patients come in for a Clinics, where patients come in for a
heart rate, blood pressure, and weight assessment, then either followed or preceded by a telehealth visit.

Internet CBT-based guided self-help

$n=31$ intervention; $n=31$ waitlist control
Significant decreases at follow-up in psychopathological levels, binge eating, and vomiting, favouring intervention group over controls. 
Summary of included studies regarding virtual care and eating disorders (Continued)

\begin{tabular}{|c|c|c|c|c|c|}
\hline Reference & $\begin{array}{l}\text { Type of } \\
\text { Study }\end{array}$ & $\begin{array}{l}\text { Age } \\
\text { group }\end{array}$ & ED diagnosis & Sample size & Intervention \\
\hline $\begin{array}{l}\text { Fichter et al. } \\
2008[78]\end{array}$ & $\begin{array}{l}\text { Observational } \\
\text { (controlled } \\
\text { study) }\end{array}$ & $\begin{array}{l}18-25 \\
\text { years }\end{array}$ & AN & $\begin{array}{l}n=51 \text { manual intervention; } n= \\
51 \text { waitlist control }\end{array}$ & $\begin{array}{l}\text { Manual CBT-based guided } \\
\text { self-help }\end{array}$ \\
\hline
\end{tabular}

Main findings

Duration of inpatient treatment was

significantly shorter (by 5.2 days)

among participants that received guided self-help. Body image, slimness ideal, general psychopathology and some bulimic symptoms improved significantly for intervention group. BMI did not differ significantly between groups, but intervention group showed more weight gain.

\begin{tabular}{|c|c|c|c|c|c|}
\hline $\begin{array}{l}\text { Fichter et al. } \\
2011 \text { [66] }\end{array}$ & $\begin{array}{l}\mathrm{RCT} \\
\text { (feasibility) }\end{array}$ & $\begin{array}{l}18-25 \\
\text { years }\end{array}$ & AN & $\begin{array}{l}n=128 \text { VIA intervention; } n= \\
130 \text { treatment as usual }\end{array}$ & $\begin{array}{l}\text { Internet CBT-based guided } \\
\text { self-help (VIA) }\end{array}$ \\
\hline $\begin{array}{l}\text { Fichter et al. } \\
2012 \text { [63] }\end{array}$ & $\mathrm{RCT}$ & $\begin{array}{l}18-25 \\
\text { years }\end{array}$ & AN & $\begin{array}{l}n=128 \text { VIA intervention; } n= \\
130 \text { treatment as usual control }\end{array}$ & $\begin{array}{l}\text { Internet CBT-based guided } \\
\text { self-help (VIA-Virtual Inter- } \\
\text { vention for AN) }\end{array}$ \\
\hline
\end{tabular}

$\begin{array}{llll}\text { Fichter et al. } & \text { RCT (follow- } & 18-25 & \text { AN } \\ 2013[67] & \text { up study) } & \text { years } & \end{array}$

$n=92$ VIA intervention; $n=120$ control

Internet CBT-based guided self-help (VIA)

Smartphone applications

Fitzsimmons

Open trial

$18-25$

Clinical or subclinical $n=13$ universities

Craft et al.

years

$E D$, excluding AN

(Student Bodies-ED)

VIA program was highly feasible with moderate overall dropout rate (15.5\%); program was well-received.

VIA intervention group gained significantly more weight than controls. Group by time comparisons for eating-related cognitions, behaviours, and general psychopathology showed a significantly more favourable course in the intervention for bulimic symptoms.

Most variables showed improvements in VIA intervention, but only some reached statistical significance (e.g bulimic behaviour). Very good results for BMl for full completers (9 months).

SB-ED results were encouraging as restrictive eating and binge eating significantly decreased over the course of users' time in the intervention but vomiting and diet pill/laxative use were not found to significantly decrease (but reports of these behaviours were very low).

\begin{tabular}{|c|c|c|c|c|c|}
\hline $\begin{array}{l}\text { Giel et al. } 2015 \\
{[58]}\end{array}$ & $\begin{array}{l}\text { Open trial } \\
\text { (pilot) }\end{array}$ & $\begin{array}{l}18-25 \\
\text { years }\end{array}$ & AN & $n=12$ & $\begin{array}{l}\text { Relapse prevention (MANT } \\
\text { RA) via telehealth }\end{array}$ \\
\hline $\begin{array}{l}\text { Goldfield and } \\
\text { Boachie, } 2003 \\
\text { [57] }\end{array}$ & Case report & $\begin{array}{l}<18 \\
\text { years }\end{array}$ & AN & $n=1$ & Telehealth FBT \\
\hline $\begin{array}{l}\text { Gollings et al. } \\
2006 \text { [83] }\end{array}$ & RCT (pilot) & $\begin{array}{l}18-25 \\
\text { years }\end{array}$ & $\begin{array}{l}\text { Probable } \mathrm{BN} \text { and/or } \\
\text { high body } \\
\text { dissatisfaction }\end{array}$ & $\begin{array}{l}n=19 \text { face-to-face delivery; } n= \\
21 \text { internet-delivery }\end{array}$ & $\begin{array}{l}\text { CBT-based group internet } \\
\text { intervention ('Set your body } \\
\text { free') }\end{array}$ \\
\hline
\end{tabular}

Grover et al. RCT (pilot) 18-25 AN years

$n=33$ carers in web-based intervention; $n=30$ carers in hotline control

Guided parental self-help CBT (skills training approach + workbook or CBT-based online modules

At post-treatment, participants' BMI increased, and eating, shape, and weight concerns (EDE-Q scores) decreased, compared to baseline.

Significant weight gain was achieved from baseline to end of treatment

Large improvements in body dissatisfaction (BSQ, BIAQ scores) and dietary restraint (DEBQ-R scores) in face-to-face and internet-delivery groups. No significant differences between delivery modes at posttreatment or 2-month follow-up.

Compared with hotline control, the web-based intervention had a significantly greater positive impact on caregivers' depression and anxiety (primary outcome), with similar trend in caregivers' expressed emotion. Other secondary outcome measures were also reduced across both groups, but there was no significant difference between groups (did not favour webbased intervention).

Email and/or online counselling

$n=240$ datasets of affected persons; $n=85$ datasets of relatives

$22.5 \%$ of affected persons and $49.4 \%$ of relatives stated that answers provided by online consultants led to a better understanding EDs. 55.4\% of affected persons and $81.2 \%$ of relatives had not turned to professional help before the use of the online service. $20 \%$ of affected persons went to see a therapist as a result of online consultation.

Consulting service was predominantly used by persons suffering from BN or their friends/families. Content of emails also included seeking info about EDs, asking for help to find specialized clinics/therapists. 
Summary of included studies regarding virtual care and eating disorders (Continued)

\begin{tabular}{|c|c|c|c|c|c|}
\hline Reference & $\begin{array}{l}\text { Type of } \\
\text { Study }\end{array}$ & $\begin{array}{l}\text { Age } \\
\text { group }\end{array}$ & ED diagnosis & Sample size & Intervention \\
\hline $\begin{array}{l}\text { Hoyle et al. } \\
2013 \text { [114] }\end{array}$ & $\begin{array}{l}\mathrm{RCT} \\
\text { (feasibility) }\end{array}$ & $\begin{array}{l}18-25 \\
\text { years }\end{array}$ & AN & $\begin{array}{l}n=19 \mathrm{OAO}+\text { guidance } \\
\text { intervention; } n=18 \mathrm{OAO} \text { only } \\
\text { intervention }\end{array}$ & $\begin{array}{l}\text { Guided parental self-help } \\
\text { CBT (skills training approach } \\
+ \text { workbook or CBT-based } \\
\text { online modules }\end{array}$ \\
\hline
\end{tabular}

Main findings

Significant reductions were found for

caregiver intrusiveness, negative

experiences of caregiving, and the

impact of starvation and guilt. Within

group effect sizes: mixed feelings with

respect to whether greater benefits

were conferred for caregivers

receiving clinician guidance.

Individuals with AN did not perceive

that their caregiver's levels of

expressed emotion had significantly

changed but decreases in perceived

intrusiveness of the caregiver by the

person with AN had a large effect size.

Caregivers' ED symptom impact scale

scores were also reduced but did not differ between conditions.

Jones et al. Open trial $\quad<18$ AN, or high-risk for $n=12$ diagnosed with $\mathrm{AN}, n=\quad$ Online guided parental self$2012[108]$ (pilot) years AN

12 at risk for $\mathrm{AN}, n=22$ at high- help - FBT risk for AN

Children remained stable or increased in ideal body weight and reported decreased ED attitudes and behaviours. Parents with at-risk children rated the programme more favourable than parents with children who had diagnosed AN.

\begin{tabular}{|c|c|c|c|c|c|}
\hline $\begin{array}{l}\text { Kelly and } \\
\text { Waring, } 2018 \\
\text { [80] }\end{array}$ & $\begin{array}{l}\mathrm{RCT} \\
\text { (feasibility) }\end{array}$ & $\begin{array}{l}18-25 \\
\text { years }\end{array}$ & AN, atypical AN & $\begin{array}{l}n=20 \text { intervention; } n=20 \\
\text { waitlist control }\end{array}$ & $\begin{array}{l}\text { Internet-delivered self- } \\
\text { compassionate letter writi } \\
\text { unguided self-help }\end{array}$ \\
\hline $\begin{array}{l}\text { Kendal et al. } \\
2017 \text { [85] }\end{array}$ & Qualitative & $\begin{array}{l}<18 \\
\text { years }\end{array}$ & All EDs & $n=119$ & Moderated online forums \\
\hline
\end{tabular}

\begin{tabular}{|c|c|c|c|c|c|}
\hline $\begin{array}{l}\text { Kindermann } \\
\text { et al. } 2016 \text { [72] }\end{array}$ & Case report & $\begin{array}{l}18-25 \\
\text { years }\end{array}$ & BN symptoms & $n=1$ & $\begin{array}{l}\text { Internet CBT-based } \\
\text { self-help (ProYouth) }\end{array}$ \\
\hline $\begin{array}{l}\text { Kundiger et al. } \\
2010 \text { [105] }\end{array}$ & $\begin{array}{l}\text { Mixed } \\
\text { methods }\end{array}$ & $\begin{array}{l}18-25 \\
\text { years }\end{array}$ & $A N, B N$ & $n=803$ & $\begin{array}{l}\text { Email and/or online } \\
\text { counselling }\end{array}$ \\
\hline
\end{tabular}

Moderated online caregiver forums

Intervention appeared to be acceptable, feasible, and efficacious: greater increases in self-compassion and greater decreases in shame and fears of self-compassion comparted to waitlist controls. Changes in EDE-Q scores and readiness to get help for one's weight did not differ between conditions.

How young people use the forum: taking on the role of a mentor, online discussion forum as a safe space, discussion forum as a safe space,
friendship within the online forum, flexible help, peer support for recovery and relapse prevention. Moderated forums may foster a supportive environment.

Symptoms did not improve following intervention, but case reported the program contributed to decision to pursue face-to-face treatment.

Main group of users were females, persons affected, relatives/friends of those affected. $24.5 \%$ of inquiries asked for contact info for local mental health professionals or institutions. For many, this was first point of contact with mental health professional.

Main themes: (1) the importance of support; (2) shifts in parenting. Blogs detailed how parents actively seek to meet needs during a difficult time using online interactions to bolster sources of support that exist offline. Blogs were used as adjunct support for families.

\begin{tabular}{|c|c|c|c|c|c|}
\hline $\begin{array}{l}\text { Lang et al. } \\
2015 \text { [81] }\end{array}$ & Qualitative & $\begin{array}{l}18-25 \\
\text { years }\end{array}$ & AN, EDNOS & $n=6$ & Manual-based CRT \\
\hline $\begin{array}{l}\text { Lock et al. } \\
2017 \text { [107] }\end{array}$ & Case series & $\begin{array}{l}<18 \\
\text { years }\end{array}$ & AN & $n=19$ & $\begin{array}{l}\text { Online guided parental self- } \\
\text { help - FBT }\end{array}$ \\
\hline $\begin{array}{l}\text { Marx and } \\
\text { Cohen, } 2006\end{array}$ & Case report & $\begin{array}{l}12-22 \\
\text { years }\end{array}$ & All EDs & $n=6$ & $\begin{array}{l}\text { Moderated online caregiver } \\
\text { forums }\end{array}$ \\
\hline
\end{tabular}

High level of satisfaction and acceptability for self-help format and working with parents: parents and individuals stated they would recommend it, but suggested computerized CRT for the future.

Patients experienced weight gain similar to clinician-delivered FBT programs and ED-related psychopathology improved by end of treatment.

Teleconferencing was seen as an effective modality to help parents who feel emotionally isolated. While in-person meetings may be more ideal, teleconferencing may be the only way for some parents to have a voice in helping their child, and themselves. 
Summary of included studies regarding virtual care and eating disorders (Continued)

\begin{tabular}{|c|c|c|c|c|c|}
\hline Reference & $\begin{array}{l}\text { Type of } \\
\text { Study }\end{array}$ & $\begin{array}{l}\text { Age } \\
\text { group }\end{array}$ & ED diagnosis & Sample size & Intervention \\
\hline $\begin{array}{l}\text { Matheson } \\
\text { et al. } 2020 \text { [26] }\end{array}$ & Descriptive & $\begin{array}{l}<18 \\
\text { years }\end{array}$ & $A N, B N, A R F I D$ & Not applicable & Home monitoring \\
\hline $\begin{array}{l}\text { Moessner and } \\
\text { Bauer, } 2012 \\
{[101]}\end{array}$ & Qualitative & $\begin{array}{l}18-25 \\
\text { years }\end{array}$ & $\mathrm{AN}, \mathrm{BN}$ & $n=238$ & $\begin{array}{l}\text { Email and/or online } \\
\text { counselling }\end{array}$ \\
\hline $\begin{array}{l}\text { Murdoch and } \\
\text { Connor- } \\
\text { Greene, } 2000 \\
\text { [99] }\end{array}$ & Case report & $\begin{array}{l}18-25 \\
\text { years }\end{array}$ & $\begin{array}{l}\text { Likely BN or AN- } \\
\text { purging type }\end{array}$ & $n=1$ & $\begin{array}{l}\text { Email and/or online } \\
\text { counselling }\end{array}$ \\
\hline $\begin{array}{l}\text { Neumayr et al. } \\
2019 \text { [89] }\end{array}$ & RCT (pilot) & $\begin{array}{l}18-25 \\
\text { years }\end{array}$ & AN & $\begin{array}{l}n=20 \text { Recovery Record }+ \\
\text { treatment as usual } n=20 \\
\text { treatment as usual }\end{array}$ & $\begin{array}{l}\text { Smartphone applications } \\
\text { (Recovery Record) }\end{array}$ \\
\hline $\begin{array}{l}\text { Nevonen et al. } \\
2006 \text { [71] }\end{array}$ & Case series & $\begin{array}{l}18-25 \\
\text { years }\end{array}$ & BN, EDNOS & $n=38$ & $\begin{array}{l}\text { Internet CBT-based guided } \\
\text { self-help }\end{array}$ \\
\hline
\end{tabular}

Main findings

Caregivers were taught how to weigh

child at home with the therapist virtually present for telehealth FBT.

Rated very positively; majority would use again and recommend to others. Main reasons for using online services: anonymity, fast and easy contact, competence related to ED, and free

Email as a therapy adjunct served as an important outlet and means of coping; created a greater sense of trust with therapist.

Non-significant small to moderate between-group effect sizes favouring Recovery Record group over treatment as usual only group (in BMI and EDE-Q scores). 6-month follow-up: effects wore off and no significant differences between the intervention and control groups were evident.

Significant decrease in core ED symptoms (vomiting, dietary restraint, weight phobia) except for binge eating and excessive exercise. When bingeing and vomiting decreased, exercise increased $\rightarrow$ participants were changing their ways of compensating.

\begin{tabular}{|c|c|c|c|c|}
\hline $\begin{array}{l}\text { Nitsch et al. } \\
2016 \text { [92] }\end{array}$ & $\begin{array}{l}\text { Mixed } \\
\text { methods } \\
\text { (feasibility) }\end{array}$ & $\begin{array}{l}18-25 \\
\text { years }\end{array}$ & $\begin{array}{l}\text { Those with body } \\
\text { image concerns, } \\
\text { disordered eating } \\
\text { symptoms, but } \\
\text { excludes full } \\
\text { syndrome AN }\end{array}$ & $n=9$ \\
\hline $\begin{array}{l}\text { Paxton et al. } \\
2007 \text { [84] }\end{array}$ & $\mathrm{RCT}$ & $\begin{array}{l}18-25 \\
\text { years }\end{array}$ & $\begin{array}{l}\text { Probable BN and/or } \\
\text { high body } \\
\text { dissatisfaction }\end{array}$ & $\begin{array}{l}n=42 \text { face-to-face delivery; } n= \\
37 \text { internet-delivery; } n=37 \text { de- } \\
\text { layed treatment control }\end{array}$ \\
\hline
\end{tabular}

Smartphone applications (Student Bodies-ED)

Participants were satisfied with the overall usability of the program (average usability score: 77.5/100 and improved to 83.1/100 after modifications)

CBT-based group internet intervention ('Set your body free')

Large improvements in body dissatisfaction (BSQ, BIAQ scores) and dietary restraint (DEBQ-R scores) in face-to-face and internet-delivery groups compared with control. Posttreatment improvements were greater in face-to-face group than internet group, but gains made in both groups were maintained at 6-month followup, and groups were not clearly different from each other at 6-month follow-up.

Users suggested the forums were supportive environments where they felt able to interact with others, share advice, ask questions- making them feel less alone and more connected to others.

Significant improvements in ED symptoms (decreased objective binge eating and vomiting) from baseline to 3 months and maintained at 6 months.

Participants liked the programme for its accessibility, flexibility, support, and its accessibility, flexibility, suppc information. Some used the
intervention as a stepping-stone to further treatment.

Internet CBT-based guided self-help (Overcoming Bulimia Online)

Acceptability of the intervention was

Unguided caregiver self-help using web-based and/or prerecorded videos focused on psychoeducation and communication skills high. Caregivers' burden and psychological distress were reduced by the intervention, but not caregivers' accommodating behaviours.

Email and/or online counselling
At 3-month follow-up, there were significant improvements in depressive and bulimic symptoms. Email therapy was seen as acceptable to patients who may be reluctant to seek treatment, and may provide a useful treatment for $\mathrm{BN}$. 
Summary of included studies regarding virtual care and eating disorders (Continued)

\begin{tabular}{|c|c|c|c|c|c|}
\hline Reference & $\begin{array}{l}\text { Type of } \\
\text { Study }\end{array}$ & $\begin{array}{l}\text { Age } \\
\text { group }\end{array}$ & ED diagnosis & Sample size & Intervention \\
\hline $\begin{array}{l}\text { Sanchez-Ortiz } \\
\text { et al. } 2011 \text { [62] }\end{array}$ & $\mathrm{RCT}$ & $\begin{array}{l}18-25 \\
\text { years }\end{array}$ & BN, EDNOS & $\begin{array}{l}n=38 \text { iCBT; } n=38 \text { waitlist/ } \\
\text { delayed treatment control }\end{array}$ & $\begin{array}{l}\text { Internet CBT-based guided } \\
\text { self-help (Overcoming Bu- } \\
\text { limia Online) }\end{array}$ \\
\hline
\end{tabular}

\section{Main findings}

Significantly greater reductions in EDE

scores, binge eating episodes, all

other $E D$ variables in intervention

group immediate iCBT access. Gains

maintained or continued to improve

at follow-up.

\begin{tabular}{|c|c|c|c|c|c|}
\hline $\begin{array}{l}\text { Sanchez-Ortiz } \\
\text { et al. } 2011 \text { [74] }\end{array}$ & Qualitative & $\begin{array}{l}18-25 \\
\text { years }\end{array}$ & BN, EDNOS & $n=9$ & $\begin{array}{l}\text { Internet CBT-based } g \\
\text { self-help (Overcomin } \\
\text { limia Online) }\end{array}$ \\
\hline $\begin{array}{l}\text { Sanchez-Ortiz } \\
\text { et al. } 2011 \\
\text { [102] }\end{array}$ & Qualitative & $\begin{array}{l}18-25 \\
\text { years }\end{array}$ & BN, EDNOS & $n=71$ & $\begin{array}{l}\text { Email and/or online } \\
\text { counselling }\end{array}$ \\
\hline
\end{tabular}

counselling

\begin{tabular}{|c|c|c|c|c|}
\hline $\begin{array}{l}\text { Sansone, } 2001 \\
{[100]}\end{array}$ & Case report & $\begin{array}{l}18-25 \\
\text { years }\end{array}$ & AN & $n=4$ \\
\hline $\begin{array}{l}\text { Sepulveda } \\
\text { et al. } 2008 \\
{[112]}\end{array}$ & $\begin{array}{l}\text { Mixed } \\
\text { methods } \\
\text { (pilot) }\end{array}$ & $\begin{array}{l}<18 \\
\text { years }\end{array}$ & $\mathrm{AN}, \mathrm{BN}$ & $n=16$ \\
\hline
\end{tabular}

Email/and or online counselling (without clinician)

\section{Guided caregiver self-help -} Skills

$n=86$ patients and $n=134$ caregivers in $\mathrm{ECHO}$ intervention +treatment as usual; $n=92$ patients and $n=134$ caregivers in treatment as usual

Schmidt et al. RCT $\begin{aligned} & 18-25 \text { AN } \\ & \text { years }\end{aligned}$
[79]

Schmidt et al. 2017 [79]

RCT (feasibility)

18-25 AN years

Shingleton Open trial et al. 2016 [93] (feasibility)

$18-25$ years BN

$\mathrm{N}$, subclinical AN,

$n=12$

$n=24$ iMANTRA +treatment as usual; $n=17$ treatment as usual

Internet-based MANTRA guided self-help

Guided parental self-help CBT (skills training approach + workbook or CBT-based online modules

ext messaging

Tregarthen Case report 18-25 All EDs et al. 2015 [91] years
Smartphone applications (Recovery Record)
Caregivers expressed high levels of crease in ED symptoms and an imunderweight participants had an 2013 [75]
18-25 BN, EDNOS years $n=70$ INT-GSH,$n=56$ BIB-GSH CBT-based bibliotherapy
Program received positively as a way of fitting treatment into busy lives. Email support was perceived as an essential part of treatment and a source of motivation

105 (14.7\%) of the emails that therapists sent contained at least 1 CBT comment, 679 (95.4\%) contained at least 1 supportive comment, and 97 (13.6\%) contained at least 1 technical/ study-related comment.

Participants described positive feelings about program and gained support. All participants progressed well in treatments. Risks may include email partners comparing weights amongst each other. satisfaction with most aspects of DVD and coaching training. Caregiver general distress (General Health Questionnaire) decreased significantly from baseline to post-intervention. Caregiver psychological distress and depression after intervention did improve but not statistically significant.

Caregivers in the $\mathrm{ECHO}$ group spent less time caregiving and had less burden and expressed emotion at discharge and/or 6-month follow-up; greater reduction in ED symptom impact scale scores in the intervention group compared to control. At 6 months, patients experienced a deproved quality of life.

6 months: little difference between iMANTRA group and treatment as usual group. 12 months: iMANTRA group had higher BMI and lower scores on depression, anxiety, and stress scales; confidence intervals were wide and overlapped with 0.

Well accepted and feasible. Text messages did not impact behavioural outcomes (dietary restraint and calorie intake); had mixed effects on motivation to change dietary restraint. In response to text messages, increased desire to restrict and increased action toward reducing restriction, whereas normal weight participants reported only increased action toward restricting.

In 2 years, 108,996 downloaded the app; 89\% monitored at least 3 meals per day; $67 \%$ continued using app 30 days later. Of 2503 ratings, $84 \%$ rated it $5 / 5$. Since $\sim 50 \%$ users reported that it $5 / 5$. Since $\sim 50 \%$ users reporte
they do not currently receive treatment, app may be effective in reaching an underserved population, but raises concern that for some, it may replace seeking treatment, which might be clinically warranted.

Significant improvements in ED symptoms in both groups. No
significant difference regarding outcome between delivery modes. Email guided self-help (delivered via internet or bibliotherapy) is equally effective for adolescents and adults. 
Summary of included studies regarding virtual care and eating disorders (Continued)

\begin{tabular}{|c|c|c|c|c|c|c|}
\hline Reference & $\begin{array}{l}\text { Type of } \\
\text { Study }\end{array}$ & $\begin{array}{l}\text { Age } \\
\text { group }\end{array}$ & ED diagnosis & Sample size & Intervention & Main findings \\
\hline $\begin{array}{l}\text { Wagner et al. } \\
2013 \text { [76] }\end{array}$ & $\begin{array}{l}\text { RCT (follow- } \\
\text { up study) }\end{array}$ & $\begin{array}{l}18-25 \\
\text { years }\end{array}$ & BN, EDNOS & $n=70$ INT-GSH,$n=56$ BIB-GSH & CBT-based bibliotherapy & $\begin{array}{l}\text { Greatest improvements after } 4 \\
\text { months. Continued reduction in ED } \\
\text { symptomatology at month } 7 \text { and } 18 . \\
\text { No differences regarding outcome } \\
\text { between the } 2 \text { groups were found. }\end{array}$ \\
\hline $\begin{array}{l}\text { Wagner et al. } \\
2015 \text { [77] }\end{array}$ & $\begin{array}{l}\mathrm{RCT} \text { (follow- } \\
\text { up study) }\end{array}$ & $\begin{array}{l}18-25 \\
\text { years }\end{array}$ & BN, EDNOS & $n=70 \mathrm{INT}-\mathrm{GSH}, n=56 \mathrm{BIB}-\mathrm{GSH}$ & CBT-based bibliotherapy & $\begin{array}{l}\text { Higher motivation, lower frequency of } \\
\text { binge eating, and lower body } \\
\text { dissatisfaction at baseline predicted } \\
\text { good outcomes after the end of both } \\
\text { treatments. }\end{array}$ \\
\hline $\begin{array}{l}\text { Walsh and } \\
\text { McNicholas, } \\
2020 \text { [46] }\end{array}$ & Descriptive & $\begin{array}{l}<18 \\
\text { years }\end{array}$ & AN & Not applicable & Home monitoring & $\begin{array}{l}\text { For telehealth FBT, caregivers are } \\
\text { required to collect weekly weights, } \\
\text { record food intake, estimate energy } \\
\text { expenditure, and collect vital signs of } \\
\text { the child. }\end{array}$ \\
\hline $\begin{array}{l}\text { Wood et al. } \\
2020[44]\end{array}$ & $\begin{array}{l}\text { Descriptive } \\
\text { study }\end{array}$ & $\begin{array}{l}<18 \\
\text { years }\end{array}$ & AN & Not applicable & Home monitoring & $\begin{array}{l}\text { For telehealth FBT: the patient's heart } \\
\text { rate, blood pressure, and weight were } \\
\text { monitored by a parent at home. The } \\
\text { clinician visually inspected the patient } \\
\text { via videoconferencing and had } \\
\text { frequent follow-up visits to allow for } \\
\text { regular assessment of progress. }\end{array}$ \\
\hline $\begin{array}{l}\text { Yager, } 2001 \\
\text { [98] }\end{array}$ & Case report & $\begin{array}{l}18-25 \\
\text { years }\end{array}$ & AN & $n=3$ & $\begin{array}{l}\text { Email and/or online } \\
\text { counselling }\end{array}$ & $\begin{array}{l}\text { Email seemed to have helped patients } \\
\text { - no negative effects experienced by } \\
\text { patients or clinician. Email had } \\
\text { excellent patient acceptability and } \\
\text { adherence. }\end{array}$ \\
\hline $\begin{array}{l}\text { Yager, } 2003 \\
{[95]}\end{array}$ & Case report & $\begin{array}{l}<18 \\
\text { years }\end{array}$ & AN & $n=2$ & $\begin{array}{l}\text { Email and/or online } \\
\text { counselling }\end{array}$ & $\begin{array}{l}\text { Weight gain achieved in } 1 / 2 \text { patients. } \\
\text { Potential benefits of email adjunct: } \\
\text { flexibility, increased contact with } \\
\text { physician, patients can become more } \\
\text { aware of their ED behaviours by } \\
\text { documenting them. }\end{array}$ \\
\hline
\end{tabular}

\section{Abbreviations}

AGREE II: Appraisal of guidelines for research and evaluation; AN: Anorexia Nervosa; ARFID: Avoidant/Restrictive Food Intake Disorder; BED: Binge Eating Disorder; BIAQ: Body Image Avoidance Questionnaire; BIB-GSH: Bibliotherapy guided self-help; BMI: Body mass index; BN: Bulimia Nervosa; BSQ: Body Shape Questionnaire; BULIT-R: Bulimia Test-Revised; CBT: Cognitive behavioural therapy; CBT-E: Enhanced cognitive behavioural therapy; CRT: Cognitive remediation therapy; DASS-21: Depression, Anxiety, and Stress Scales; DEBQ-R: Dutch Eating Behaviour Questionnaire Restraint Scale; ECHO: Experienced Carers Helping Others; ED: Eating disorder; EDE-Q: Eating Disorder Examination-Questionnaire; EDI: Eating Disorders Inventory; EDNOS: Eating Disorder Not Otherwise Specified; FBT: Family-based treatment; FEAST: Families Empowered and Supporting Treatment of Eating Disorders; GDP: Guideline development panel; GRADE: Grading of Recommendations, Assessment, Development, and Evaluation system; GUIDE-M: Guideline implementability for decision excellence model; INTGSH: Internet guided self-help; iMANTRA: internet-based Maudsley Model of Anorexia Nervosa Treatment for Adults; MANTRA: Maudsley Model of Anorexia Nervosa Treatment for Adults; MET: Motivational Enhancement Treatment; OAO: Overcoming Anorexia Online; OSFED: Other Specified Feeding and Eating Disorder; PRISMA: Preferred reporting items for systematic reviews and meta-analyses; RCT: Randomized controlled trial; SD: Standard deviation; SEED: Short Evaluation of Eating Disorders; VIA: Virtual Intervention for Anorexia Nervosa; WHO: World Health Organization

\section{Acknowledgements}

We would like to thank all of the patients and families with whom we work with on a daily basis.

\section{Authors' contributions}

$J C$ conceived the idea for this project with input from CM, GM, LI, MN, WP, $M B, M K, S F, N B$, and CW. JC was primarily responsible for the overall project design, oversight of the project, and drafting of the manuscript and recommendations. NB designed and executed comprehensive searches in the databases. Several authors participated in screening abstracts and full text articles including JC, DP, and CW. DP assisted JC in the drafting of the manuscript. MB led the consensus discussions of the GDP and oversaw conflict-of-interest disclosures and management. All panel members contributed to the drafting and finalization of the recommendations and included: $J C, D P, C M, S F, L I, M K, G M, M N, W S, C W, W P, R L, T L, E W, C F, A B, C S, J G, A L$, $S G, M J, G D, K B, D P, J C, A L, D K, N J$. All authors read and edited the manuscript and approved the final manuscript.

\section{Funding}

Funding for this study was provided by The Canadian Institutes of Health Research.

\section{Availability of data and materials}

Not applicable.

\section{Declarations}

Ethics approval and consent to participate

Not applicable.

\section{Consent for publication}

Not applicable.

\section{Competing interests}

The authors declare that they have no competing interests.

\section{Author details}

${ }^{1}$ McMaster University, Hamilton, ON, Canada. ${ }^{2}$ McMaster Children's Hospital, 1200 Main St W, Hamilton, Ontario L8N 3Z5, Canada. ${ }^{3}$ Canadian Mental Health Association - Waterloo Wellington, Waterloo, ON, Canada. ${ }^{4}$ University of Toronto, Toronto, ON, Canada. ${ }^{5}$ St. Joseph's Care Group - Thunder Bay, Thunder Bay, ON, Canada. ${ }^{6}$ University of Ottawa, Ottawa, ON, Canada. ${ }^{7}$ The University of British Columbia, Vancouver, BC, Canada. ${ }^{8}$ University of Calgary, Calgary, AB, Canada. ${ }^{9}$ Ontario Ministry of Health and Long-Term Care,

Toronto, ON, Canada. ${ }^{10}$ Dalhousie University, Halifax, NS, Canada.

${ }^{11}$ Laurentian University, Sudbury, ON, Canada. ${ }^{12}$ Patient advocate, Woodstock, ON, Canada. ${ }^{13}$ Parent advocate, Woodstock, ON, Canada. ${ }^{14}$ National Initiative 
for Eating Disorders, Toronto, ON, Canada. ${ }^{15}$ Parent advocate, Ottawa, ON, Canada.

\section{Received: 28 November 2020 Accepted: 11 March 2021 Published online: 16 April 2021}

\section{References}

1. Fiorillo A, Gorwood P. The consequences of the COVID-19 pandemic on mental health and implications for clinical practice. Eur Psychiatry. 2020; 63(1):e32. https://doi.org/10.1192/j.eurpsy.2020.35.

2. Huang $Y$, Zhao N. Chinese mental health burden during the COVID-19 pandemic. Asian J Psychiatr. 2020;51:102052. https://doi.org/10.1016/j.ajp.202 0.102052 .

3. Torales J, O'Higgins M, Castaldelli-Maia JM, Ventriglio A. The outbreak of COVID-19 coronavirus and its impact on global mental health. Int J Soc Psychiatry. 2020;66(4):317-20

4. Di Renzo L, Gualtieri P, Cinelli G, Bigioni G, Soldati L, Attina A, et al. Psychological Aspects and Eating Habits during COVID-19 Home Confinement: Results of EHLC-COVID-19 Italian Online Survey. Nutrients. 2020;12(7):2152.

5. Kochhar AS, Bhasin R, Kochhar GK, Dadlani H, Mehta W, Kaur R, et al. Lockdown of 1.3 billion people in India during Covid-19 pandemic: A survey of its impact on mental health. Asian J Psychiatr. 2020;54:102213.

6. Fernandez-Aranda F, Casas M, Claes L, Bryan DC, Favaro A, Granero R, et al. COVID-19 and implications for eating disorders. Eur Eat Disord Rev. 2020; 28(3):239-45. https://doi.org/10.1002/erv.2738.

7. Termorshuizen JD, Watson HJ, Thornton LM, Borg S, Flatt RE, MacDermod CM, et al. Early impact of COVID-19 on individuals with self-reported eating disorders: a survey of $\sim 1,000$ individuals in the United States and the Netherlands. Int J Eat Disord. 2020;53(11):1780-90. https://doi.org/10.1002/ea t 23353

8. Phillipou A, Meyer D, Neill E, Tan EJ, Toh WL, Van Rheenen TE, et al. Eating and exercise behaviors in eating disorders and the general population during the COVID-19 pandemic in Australia: initial results from the COLLATE project. Int J Eat Disord. 2020;53(7):1158-65. https://doi.org/10.1002/eat.2331 7.

9. Branley-Bell D, Talbot CV. Exploring the impact of the COVID-19 pandemic and UK lockdown on individuals with experience of eating disorders. J Eat Disord. 2020;8(1):44. https://doi.org/10.1186/s40337-020-00319-y.

10. Arcelus J, Mitchell AJ, Wales J, Nielsen S. Mortality rates in patients with anorexia nervosa and other eating disorders. A meta-analysis of 36 studies. Arch Gen Psychiatry. 2011;68(7):724-31. https://doi.org/10.1001/a rchgenpsychiatry.2011.74

11. Monaghesh $\mathrm{E}$, Hajizadeh $\mathrm{A}$. The role of telehealth during COVID-19 outbreak: a systematic review based on current evidence. BMC Public Health. 2020:20(1):1193. https://doi.org/10.1186/s12889-020-09301-4.

12. Luo C, Sanger N, Singhal N, Pattrick K, Shams I, Shahid H, Hoang P, Schmidt J, Lee J, Haber S, Puckering M, Buchanan N, Lee P, Ng K, Sun S, Kheyson S, Chung DCY, Sanger S, Thabane L, Samaan Z. A comparison of electronicallydelivered and face to face cognitive behavioural therapies in depressive disorders: a systematic review and meta-analysis. EClinicalMedicine. 2020;24: 100442. https://doi.org/10.1016/j.eclinm.2020.100442.

13. Carlbring P, Andersson G, Cuijpers P, Riper H, Hedman-Lagerlof E. Internetbased vs. face-to-face cognitive behavior therapy for psychiatric and somatic disorders: an updated systematic review and meta-analysis. Cogn Behav Ther. 2018;47(1):1-18. https://doi.org/10.1080/16506073.2017.1401115.

14. Wootton BM. Remote cognitive-behavior therapy for obsessive-compulsive symptoms: a meta-analysis. Clin Psychol Rev. 2016;43:103-13. https://doi org/10.1016/j.cpr.2015.10.001

15. Norwood C, Moghaddam NG, Malins S, Sabin-Farrell R. Working alliance and outcome effectiveness in videoconferencing psychotherapy: a systematic review and noninferiority meta-analysis. Clin Psychol Psychother. 2018;25(6): 797-808. https://doi.org/10.1002/cpp.2315.

16. McLean SA, Booth AT, Schnabel A, Wright BJ, Painter FL, Mclntosh JE. Exploring the efficacy of telehealth for family therapy through systematic, meta-analytic, and qualitative evidence. Clin Child Fam Psychol Rev. 2021. https://doi.org/10.1007/s10567-020-00340-2.

17. Helps S, Le Coyte Grinney M. Synchronous digital couple and family psychotherapy: a meta-narrative review. J Fam Ther. 2021; Early view: https://onlinelibrary.wiley.com/doi/full/10.1111/1467-6427.12333. Accessed 24 Feb 2021.
18. Weissman RS, Bauer S, Thomas JJ. Access to evidence-based care for eating disorders during the COVID-19 crisis. Int J Eat Disord. 2020;53(5):639-46. https://doi.org/10.1002/eat.23279.

19. Huff C. For people with anorexia, COVID-19 presents new challenges: American Psychological Association; 2020. Available from: https://www.apa. org/topics/covid-19/eating-disorders

20. Todisco P, Donini LM. Eating disorders and obesity (ED\&O) in the COVID-19 storm. Eat Weight Disord. 2020. https://doi.org/10.1007/s40519-020-00938-z.

21. Shah M, Sachdeva M, Johnston H. Eating disorders in the age of COVID-19. Psychiatry Res. 2020;290:113122. https://doi.org/10.1016/j.psychres.2020.113122.

22. Rodgers RF, Lombardo C, Cerolini S, Franko DL, Omori M, Fuller-Tyszkiewicz M, Linardon J, Courtet P, Guillaume S. The impact of the COVID-19 pandemic on eating disorder risk and symptoms. Int J Eat Disord. 2020; 53(7):1166-70. https://doi.org/10.1002/eat.23318.

23. Cooper M, Reilly EE, Siegel JA, Coniglio K, Sadeh-Sharvit S, Pisetsky EM, Anderson LM. Eating disorders during the COVID-19 pandemic and quarantine: an overview of risks and recommendations for treatment and early intervention. Eat Disord. 2020:1-23. https://doi.org/10.1080/10640266.2020.1790271.

24. Touyz S, Lacey H, Hay P. Eating disorders in the time of COVID-19. J Eat Disord. 2020;8(1):19. https://doi.org/10.1186/s40337-020-00295-3.

25. Couturier J, Isserlin L, Norris M, Spettigue W, Brouwers M, Kimber M, McVey G, Webb C, Findlay S, Bhatnagar N, Snelgrove N, Ritsma A, Preskow W, Miller C, Coelho J, Boachie A, Steinegger C, Loewen R, Loewen T, Waite E, Ford C, Bourret K, Gusella J, Geller J, LaFrance A, LeClerc A, Scarborough J, Grewal S, Jericho M, Dimitropoulos G, Pilon D. Canadian practice guidelines for the treatment of children and adolescents with eating disorders. J Eat Disord. 2020;8(1):4. https://doi.org/10.1186/s40337-020-0277-8.

26. Matheson BE, Bohon C, Lock J. Family-based treatment via videoconference: clinical recommendations for treatment providers during COVID-19 and beyond. Int J Eat Disord. 2020;53(7):1142-54. https://doi.org/10.1002/ea t.23326

27. Arksey H, O'Malley L. Scoping studies: towards a methodological framework Int J Soc Res Methodol. 2005;8(1):19-32. https://doi.org/10.1080/1364557032 000119616.

28. Levac D, Colquhoun H, O'Brien KK. Scoping studies: advancing the methodology. Implement Sci. 2010;5(1):69. https://doi.org/10.1186/17485908-5-69.

29. Pham MT, Rajic A, Greig JD, Sargeant JM, Papadopoulos A, McEwen SA. A scoping review of scoping reviews: advancing the approach and enhancing the consistency. Res Synth Methods. 2014;5(4):371-85. https://doi.org/10.1 002/jrsm.1123.

30. Tricco AC, Lillie E, Zarin W, O'Brien K, Colquhoun H, Kastner M, et al. A scoping review on the conduct and reporting of scoping reviews. BMC Med Res Methodol. 2016;16(1):15. https://doi.org/10.1186/s12874-016-0116-4.

31. Guyatt GH, Oxman AD, Schunemann HJ, Tugwell P, Knottnerus A. GRADE guidelines: a new series of articles in the journal of clinical epidemiology. J Clin Epidemiol. 2011;64(4):380-2. https://doi.org/10.1016/j.jclinepi.2010.09.011.

32. Guyatt GH, Oxman AD, Vist GE, Kunz R, Falck-Ytter Y, Alonso-Coello P, Schünemann HJ, GRADE Working Group. GRADE: an emerging consensus on rating quality of evidence and strength of recommendations. BMJ. 2008; 336(7650):924-6. https://doi.org/10.1136/bmj.39489.470347.AD.

33. Jaeschke R, Guyatt GH, Dellinger P, Schunemann H, Levy MM, Kunz R, Norris $\mathrm{S}$, Bion J, for the GRADE working group. Use of GRADE grid to reach decisions on clinical practice guidelines when consensus is elusive. BMJ. 2008:337(jul31 1):a744. https://doi.org/10.1136/bmj.a744.

34. Brouwers MC, Kho ME, Browman GP, Burgers JS, Cluzeau F, Feder G, Fervers B, Graham ID, Grimshaw J, Hanna SE, Littlejohns P, Makarski J, Zitzelsberger $L$, for the AGREE Next Steps Consortium. AGREE II: advancing guideline development, reporting and evaluation in health care. CMAJ. 2010;182(18): E839-42. https://doi.org/10.1503/cmaj.090449.

35. Telemedicine vs. Virtual Care: Definining the Difference [Internet]. In Touch Technologies Inc.; 2020. Available from: https://intouchhealth.com/findingthe-right-term-for-modern-digital-healthcare/. Accessed 20 Nov 2020.

36. Telemedicine: Opportunities and developments in member states. Report on the second global survey on eHealth. World Health Organization; 2010 [Global observatory for eHealth series - Volume 2]. Available from: https:// www.who.int/goe/publications/goe_telemedicine_2010.pdf. Accessed 20 Nov 2020.

37. Deshpande A, Khoja S, McKibbon A, Jadad AR. Overview of assessments of real-time (synchronous) and asynchronous telehealth. Ottawa: Canadian Agency for Drugs and Technologies in Health; 2008. Available from: https:// 
www.cadth.ca/sites/default/files/pdf/O0427_Real-Time-\%28Synchronous\%2 9-Asynchronous-Telehealth_to_e.pdf

38. Brouwers MC, Kerkvliet K, Spithoff K, Consortium ANS. The AGREE reporting checklist: a tool to improve reporting of clinical practice guidelines. BMJ. 2016;352:i1152.

39. Brouwers MC, Makarski J, Kastner M, Hayden L, Bhattacharyya O, Team GMR. The Guideline Implementability Decision Excellence Model (GUIDE-M): a mixed methods approach to create an international resource to advance the practice guideline field. Implement Sci. 2015;10:36.

40. Eccles MP, Grimshaw JM, Shekelle P, Schunemann HJ, Woolf S. Developing clinical practice guidelines: target audiences, identifying topics for guidelines, guideline group composition and functioning and conflicts of interest. Implement Sci. 2012;7(1):60. https://doi.org/10.1186/1748-5908-7-60.

41. Kunz R, Fretheim A, Cluzeau F, Wilt TJ, Qaseem A, Lelgemann M, Kelson M, Guyatt G, Schünemann HJ, ATS/ERS Ad Hoc Committee on Integrating and Coordinating Efforts in COPD Guideline Development. Guideline group composition and group processes: article 3 in integrating and coordinating efforts in COPD guideline development. An official ATS/ERS workshop report. Proc Am Thorac Soc. 2012;9(5):229-33. https://doi.org/10.1513/pats.2 01208-056ST.

42. Qaseem A, Forland F, Macbeth F, Ollenschlager G, Phillips S, van der Wees $P$, et al. Guidelines international network: toward international standards for clinical practice guidelines. Ann Intern Med. 2012;156(7):525-31. https://doi. org/10.7326/0003-4819-156-7-201204030-00009.

43. MI Y. Using experts' opinion through the Delphi technique. Pract Assess Res Eval. 2007;12(4):1-8

44. Wood SM, White K, Peebles R, Pickel J, Alausa M, Mehringer J, Dowshen N. Outcomes of a rapid adolescent Telehealth scale-up during the COVID-19 pandemic. J Adolesc Health. 2020;67(2):172-8. https://doi.org/10.1016/j.ja dohealth.2020.05.025.

45. Davis C, Ng KC, Oh JY, Baeg A, Rajasegaran K, Chew CSE. Caring for children and adolescents with eating disorders in the current coronavirus 19 pandemic: a Singapore perspective. J Adolesc Health. 2020;67(1):131-4. https://doi.org/10.1016/j.jadohealth.2020.03.037.

46. Walsh O, McNicholas F. Assessment and Management of Anorexia Nervosa during COVID-19. Ir J Psychol Med. 2020;37(3):1-8.

47. Barney A, Buckelew S, Mesheriakova V, Raymond-Flesch M. The COVID-19 pandemic and rapid implementation of adolescent and young adult telemedicine: challenges and opportunities for innovation. J Adolesc Health. 2020;67(2):164-71. https://doi.org/10.1016/j.jadohealth.2020.05.006.

48. Emans SJ, Ford CA, Irwin CE Jr, Richardson LP, Sherer S, Sieving RE, Simpson T. Early COVID-19 impact on adolescent health and medicine programs in the United States: LEAH program leadership reflections. J Adolesc Health. 2020;67(1):11-5. https://doi.org/10.1016/j.jadohealth.202 0.04.010.

49. Clark Bryan D, Macdonald P, Ambwani S, Cardi V, Rowlands K, Willmott D, Treasure J. Exploring the ways in which COVID-19 and lockdown has affected the lives of adult patients with anorexia nervosa and their carers. Eur Eat Disord Rev. 2020;28(6):826-35. https://doi.org/10.1002/erv.2762.

50. Waller G, Pugh M, Mulkens S, Moore E, Mountford VA, Carter J, Wicksteed A, Maharaj A, Wade TD, Wisniewski L, Farrell NR, Raykos B, Jorgensen S, Evans J, Thomas JJ, Osenk I, Paddock C, Bohrer B, Anderson K, Turner H, Hildebrandt T, Xanidis N, Smit V. Cognitive-behavioral therapy in the time of coronavirus: clinician tips for working with eating disorders via telehealth when face-to-face meetings are not possible. Int J Eat Disord. 2020;53(7): 1132-41. https://doi.org/10.1002/eat.23289.

51. Murphy R, Calugi S, Cooper Z, Dalle Grave R. Challenges and opportunities for enhanced cognitive behaviour therapy (CBT-E) in light of COVID-19. Cogn Behav Therap. 2020;13:1-18.

52. Janse van Rensburg M. COVID19, the pandemic which may exemplify a need for harm-reduction approaches to eating disorders: a reflection from a person living with an eating disorder. J Eat Disord. 2020;8:26.

53. Bryant-Waugh R. Avoidant restrictive food intake disorder: in need of a dose of kindness? Clin Child Psychol Psychiatry. 2020;25(3):712-5. https://doi.org/1 $0.1177 / 1359104520929054$.

54. Weissman RS, Klump KL, Wade T, Thomas JJ, Frank G, Waller G. IJED support for eating disorders research in the time of COVID-19. Int J Eat Disord. 2020; 53(7):1017-20. https://doi.org/10.1002/eat.23293.

55. Weissman RS, Klump KL, Rose J. Conducting eating disorders research in the time of COVID-19: a survey of researchers in the field. Int J Eat Disord. 2020; 53(7):1171-81. https://doi.org/10.1002/eat.23303.
56. Anderson KE, Byrne CE, Crosby RD, Le Grange D. Utilizing Telehealth to deliver family-based treatment for adolescent anorexia nervosa. Int J Eat Disord. 2017;50(10):1235-8. https://doi.org/10.1002/eat.22759.

57. Goldfield GS, Boachie A. Delivery of family therapy in the treatment of anorexia nervosa using telehealth. Telemed J E Health. 2003;9(1):111-4. https://doi.org/10.1089/153056203763317729.

58. Giel KE, Leehr EJ, Becker S, Herzog W, Junne F, Schmidt U, Zipfel S. Relapse prevention via videoconference for anorexia nervosa - findings from the RESTART pilot study. Psychother Psychosom. 2015;84(6):381-3. https://doi. org/10.1159/000431044.

59. Bloomfield BS, Fischer AJ, Clark RR, Dove MB. Treatment of food selectivity in a child with avoidant/restrictive food intake disorder through parent Teleconsultation. Behav Anal Pract. 2019;12(1):33-43. https://doi.org/10.1 007/s40617-018-0251-y.

60. Duncan $A B$, Velasquez SE, Nelson EL. Using videoconferencing to provide psychological services to rural children and adolescents: a review and case example. J Clin Child Adolesc Psychol. 2014;43(1):115-27. https://doi.org/1 0.1080/15374416.2013.836452.

61. Aardoom JJ, Dingemans AE, Spinhoven P, van Ginkel JR, de Rooij M, van Furth EF. Web-based fully automated self-help with different levels of therapist support for individuals with eating disorder symptoms: a randomized controlled trial. J Med Internet Res. 2016;18(6):e159. https://doi. org/10.2196/jmir.5709.

62. Sánchez-Ortiz VC, Munro C, Stahl D, House J, Startup H, Treasure J, et al. A randomized controlled trial of internet-based cognitive-behavioural therapy for bulimia nervosa or related disorders in a student population. Psychol Med. 2011;41(2):407-17. https://doi.org/10.1017/S0033291710000711.

63. Fichter MMQ N, NissImuller K, Lindner S, Osen B, Huber T, Wunsch-Leiteritz $W$. Does internet-based prevention reduce the risk of relapse for anorexia nervosa? Behav Res Ther. 2012;50(3):180-90. https://doi.org/10.1016/j.brat.2 011.12.003.

64. Aardoom JJ, Dingemans AE, van Ginkel JR, Spinhoven P, Van Furth EF, Van den Akker-van Marle ME. Cost-utility of an internet-based intervention with or without therapist support in comparison with a waiting list for individuals with eating disorder symptoms: a randomized controlled trial. Int J Eat Disord. 2016;49(12):1068-76. https://doi.org/10.1002/eat.22587.

65. Aardoom JJ, Dingemans AE, Fokkema M, Spinhoven P, Van Furth EF. Moderators of change in an internet-based intervention for eating disorders with different levels of therapist support: what works for whom? Behav Res Ther. 2017;89:66-74. https://doi.org/10.1016/j.brat.2016.11.012.

66. Fichter MM, Quadflieg N, Nisslmuller K, Lindner S, Voderholzer U, WunschLeiteritz W, et al. Internet-based approaches in the therapy of eating disorders. Nervenarzt. 2011;82(9):1107-17. https://doi.org/10.1007/s00115-010-3228-9.

67. Fichter MM, Quadflieg N, Lindner S. Internet-based relapse prevention for anorexia nervosa: nine- month follow-up. J Eat Disord. 2013;1(1):23. https:// doi.org/10.1186/2050-2974-1-23.

68. Pretorius N, Arcelus J, Beecham J, Dawson H, Doherty F, Eisler I, Gallagher C, Gowers S, Isaacs G, Johnson-Sabine E, Jones A, Newell C, Morris J, Richards L, Ringwood S, Rowlands L, Simic M, Treasure J, Waller G, Williams C, Yi I, Yoshioka M, Schmidt U. Cognitive-behavioural therapy for adolescents with bulimic symptomatology: the acceptability and effectiveness of internetbased delivery. Behav Res Ther. 2009;47(9):729-36. https://doi.org/10.1016/j. brat.2009.05.006.

69. Carrard I, Fernandez-Aranda F, Lam T, Nevonen L, Liwowsky I, Volkart AC, Rouget P, Golay A, van der Linden M, Norring C. Evaluation of a guided internet selftreatment programme for bulimia nervosa in several European countries. Eur Eat Disord Rev. 2011;19(2):138-49. https://doi.org/10.1002/erv.1043.

70. Fernandez-Aranda F, Nunez A, Martinez C, Krug I, Cappozzo M, Carrard I, et al. Internet-based cognitive-behavioral therapy for bulimia nervosa: a controlled study. CyberPsychol Behav. 2009;12(1):37-41. https://doi.org/10.1 089/cpb.2008.0123.

71. Nevonen L, Mark M, Levin B, Lindstrom M, Paulson-Karlsson G. Evaluation of a new internet-based self-help guide for patients with bulimic symptoms in Sweden. Nord J Psychiatry. 2006;60(6):463-8. https://doi.org/10.1080/080394 80601021993.

72. Kindermann SAK, Minarik C, Moessner M, Bauer S. Enhancing help-seeking behavior in individuals with eating disorder symptoms via internet: a case report. Mental Health Prev. 2016;4(2):69-74. https://doi.org/10.1016/j.mhp.2 016.04.002.

73. Pretorius N, Rowlands L, Ringwood S, Schmidt U. Young people's perceptions of and reasons for accessing a web-based cognitive 
behavioural intervention for bulimia nervosa. Eur Eat Disord Rev. 2010;18(3): 197-206. https://doi.org/10.1002/erv.985.

74. Sanchez-Ortiz VC, House J, Munro C, Treasure J, Startup H, Williams C, et al. "A computer isn't gonna judge you": a qualitative study of users' views of an internet-based cognitive behavioural guided self-care treatment package for bulimia nervosa and related disorders. Eat Weight Disord. 2011;16(2): e93-e101. https://doi.org/10.1007/BF03325314.

75. Wagner G, Penelo E, Nobis G, Mayerhofer A, Schau J, Spitzer M, et al. Is technology assisted guided self-help successful in treating female adolescents with bulimia nervosa? Neuropsychiatr. 2013;27(2):66-73. https:// doi.org/10.1007/s40211-013-0062-x.

76. Wagner $G$, Penelo $E$, Wanner $C$, Gwinner $P$, Trofaier ML, Imgart $H$, Waldherr K, Wöber-Bingöl Ç, Karwautz AFK. Internet-delivered cognitive-behavioural therapy $\mathrm{v}$. conventional guided self-help for bulimia nervosa: long-term evaluation of a randomised controlled trial. Br J Psychiatry. 2013;202(2):13541. https://doi.org/10.1192/bjp.bp.111.098582.

77. Wagner G, Penelo E, Nobis G, Mayrhofer A, Wanner C, Schau J, Spitzer M, Gwinner P, Trofaier ML, Imgart H, Fernandez-Aranda F, Karwautz A. Predictors for good therapeutic outcome and drop-out in technology assisted guided self-help in the treatment of bulimia nervosa and bulimia like phenotype. Eur Eat Disord Rev. 2015;23(2):163-9. https://doi.org/10.1002/erv.2336.

78. Fichter M, Cebulla M, Quadflieg N, Naab S. Guided self-help for binge eating/purging anorexia nervosa before inpatient treatment. Psychother Res. 2008;18(5):594-603. https://doi.org/10.1080/10503300802123252.

79. Schmidt USH, Bartholdy S, Bonin E-M, Davies H, Easter A, et al. Treatment of anorexia nervosa: a multimethod investigation translating experimental neuroscience into clinical practice. Programme Grants Appl Res. 2017;5(16): 53-69, 85-94.

80. Kelly AC, Waring SV. A feasibility study of a 2-week self-compassionate letter-writing intervention for nontreatment seeking individuals with typical and atypical anorexia nervosa. Int J Eat Disord. 2018;51(8):1005-9. https:// doi.org/10.1002/eat.22930.

81. Lang K, Treasure J, Tchanturia K. Acceptability and feasibility of self-help cognitive remediation therapy for anorexia nervosa delivered in collaboration with carers: a qualitative preliminary evaluation study. Psychiatry Res. 2015;225(3):387-94. https://doi.org/10.1016/.psychres.2 014.12.008.

82. Dunn EC, Neighbors C, Larimer ME. Motivational enhancement therapy and self-help treatment for binge eaters. Psychol Addict Behav. 2006;20(1):44-52. https://doi.org/10.1037/0893-164X.20.1.44.

83. Gollings EK, Paxton SJ. Comparison of internet and face-to-face delivery of a group body image and disordered eating intervention for women: a pilot study. Eat Disord. 2006;14(1):1-15. https://doi.org/10.1080/10640260500403790.

84. Paxton SJ, McLean SA, Gollings EK, Faulkner C, Wertheim EH. Comparison of face-to-face and internet interventions for body image and eating problems in adult women: an RCT. Int J Eat Disord. 2007;40(8):692-704. https://doi. org/10.1002/eat.20446

85. Kendal S, Kirk S, Elvey R, Catchpole R, Pryjmachuk S. How a moderated online discussion forum facilitates support for young people with eating disorders. Health Expect. 2017;20(1):98-111. https://doi.org/10.1111/hex.12439.

86. Aardoom JJ, Dingemans AE, Boogaard LH, Van Furth EF. Internet and patient empowerment in individuals with symptoms of an eating disorder: a cross-sectional investigation of a pro-recovery focused e-community. Eat Behav. 2014;15(3):350-6. https://doi.org/10.1016/j.eatbeh.2014.04.003.

87. Anastasiadou D, Folkvord F, Serrano-Troncoso E, Lupianez-Villanueva F. Mobile health adoption in mental health: user experience of a Mobile health app for patients with an eating disorder. JMIR Mhealth Uhealth. 2019; 7(6):e12920. https://doi.org/10.2196/12920.

88. Cavazos-Rehg P, Min C, Fitzsimmons-Craft EE, Savoy B, Kaiser N, Riordan R, Krauss M, Costello S, Wilfley D. Parental consent: a potential barrier for underage teens' participation in an mHealth mental health intervention. Internet Interv. 2020;21:100328. https://doi.org/10.1016/j.invent.2020.100328.

89. Neumayr C, Voderholzer U, Tregarthen J, Schlegl S. Improving aftercare with technology for anorexia nervosa after intensive inpatient treatment: a pilot randomized controlled trial with a therapist-guided smartphone app. Int J Eat Disord. 2019;52(10):1191-201. https://doi.org/10.1002/eat.23152.

90. Fitzsimmons-Craft EE, Firebaugh ML, Graham AK, Eichen DM, Monterubio GE, Balantekin KN, Karam AM, Seal A, Funk B, Taylor CB, Wilfley DE. Statewide university implementation of an online platform for eating disorders screening and intervention. Psychol Serv. 2019;16(2):239-49. https://doi. org/10.1037/ser0000264.
91. Tregarthen JP, Lock J, Darcy AM. Development of a smartphone application for eating disorder self-monitoring. Int J Eat Disord. 2015;48(7):972-82. https://doi.org/10.1002/eat.22386.

92. Nitsch M, Dimopoulos CN, Flaschberger E, Saffran K, Kruger JF, Garlock L, Wilfley $D E$, Taylor $C B$, Jones M. A guided online and Mobile self-help program for individuals with eating disorders: an iterative engagement and usability study. J Med Internet Res. 2016;18(1):e7. https://doi.org/10.2196/jmir.4972.

93. Shingleton RM, Pratt EM, Gorman B, Barlow DH, Palfai TP, ThompsonBrenner $\mathrm{H}$. Motivational text message intervention for eating disorders: a single-case alternating treatment design using ecological momentary assessment. Behav Ther. 2016;47(3):325-38. https://doi.org/10.1016/j.beth.2 016.01.005.

94. Bauer SP R, Okon E, Meermann R, Kordy H. Use of text messaging in the aftercare of patients with bulimia nervosa. Eur Eat Disord Rev. 2003;11(3): 279-90. https://doi.org/10.1002/erv.521.

95. Yager J. E-mail therapy for anorexia nervosa: prospects and limitations. Eur Eat Disord Rev. 2003;11(3):198-209. https://doi.org/10.1002/erv.526.

96. Bailey R, Yager J, Jenson J. The psychiatrist as clinical computerologist in the treatment of adolescents: old barks in new bytes. Am J Psychiatry. 2002; 159(8):1298-304. https://doi.org/10.1176/appi.ajp.159.8.1298.

97. Prescott J, Hanley T, Gomez KT. Why do young people use online forums for mental health and emotional support? Benefits and challenges. Br I Guid Couns. 2019;47(3):317-27. https://doi.org/10.1080/03069885.2019.1619169.

98. Yager J. E-mail as a therapeutic adjunct in the outpatient treatment of anorexia nervosa: illustrative case material and discussion of the issues. Int $J$ Eat Disord. 2001;29(2):125-38. https://doi.org/10.1002/1098-108X(200103 )29:2<125:AID-EAT1002>3.0.CO;2-S.

99. Murdoch JW, Connor-Greene PA. Enhancing therapeutic impact and therapeutic Alliance through electronic mail homework assignments. J Psychother Pract Res. 2000;9(4):232-7.

100. Sansone RA. Patient-to-patient E-mail: support for clinical practices. Eat Disord. 2001;9(4):373-5. https://doi.org/10.1080/106402601753454930.

101. Moessner M, Bauer S. Online counselling for eating disorders: reaching an underserved population? J Ment Health. 2012;21(4):336-45. https://doi.org/1 0.3109/09638237.2011.643512.

102. Sanchez-Ortiz VC, Munro C, Startup H, Treasure J, Schmidt U. The role of email guidance in internet-based cognitive-behavioural self-care treatment for bulimia nervosa. Eur Eat Disord Rev. 2011;19(4):342-8. https://doi.org/1 $0.1002 /$ erv. 1074

103. Grunwald M, Wesemann D. Individual use of online-consulting for persons affected with eating disorders and their relatives - Evaluation of an online consulting service. Eur Eat Disord Rev. 2006;14:218-25.

104. Grunwald M, Wesemann D. Special online consulting for patients with eating disorders and their relatives: analysis of user characteristics and Email content. CyberPsychol Behav. 2007;10(1):57-63. https://doi.org/10.1089/ cpb.2006.9992.

105. Kundiger C, Wesemann D, Verhey R, Grunwald M. Online Counselling for Eating Disorders - An Established Service Complementing Traditional Settings. J CyberTher Rehabil. 2010;3(4):383-94.

106. Robinson PH, Serafty MA. The use of e-mail in the identification of bulimia nervosa and its treatment. Eur Eat Disord Rev. 2001;9(3):182-93. https://doi. org/10.1002/erv.411.

107. Lock J, Darcy A, Fitzpatrick KK, Vierhile M, Sadeh-Sharvit S. Parental guided self-help family based treatment for adolescents with anorexia nervosa: a feasibility study. Int J Eat Disord. 2017;50(9):1104-8. https://doi.org/10.1002/ eat.22733.

108. Jones M, Volker U, Lock J, Taylor CB, Jacobi C. Family-based early intervention for anorexia nervosa. Eur Eat Disord Rev. 2012;20(3):e137-43. https://doi.org/10.1002/erv.2167.

109. Cairns JC, Styles LD, Leichner P. Evaluation of meal support training for parents and caregivers using a video and a manual. J Can Acad Child Adolesc Psychiatry. 2007;16(4):164-6.

110. Dimitropoulos G, Landers A, Freeman V, Novick J, Schmidt U, Olmsted M. A feasibility study comparing a web-based intervention to a workshop intervention for caregivers of adults with eating disorders. Eur Eat Disord Rev. 2019;27(6):641-54. https://doi.org/10.1002/erv.2678.

111. Quadflieg N, Schadler D, Naab S, Fichter MM. RCT of a video-based intervention program for caregivers of patients with an eating disorder. Eur Eat Disord Rev. 2017;25(4):283-92. https://doi.org/10.1002/erv.2521.

112. Sepulveda AR, Lopez C, Macdonald P, Treasure J. Feasibility and acceptability of DVD and telephone coaching-based skills training for carers 
of people with an eating disorder. Int J Eat Disord. 2008;41(4):318-25. https://doi.org/10.1002/eat.20502.

113. Grover M, Naumann U, Mohammad-Dar L, Glennon D, Ringwood S, Eisler I, Williams C, Treasure J, Schmidt U. A randomized controlled trial of an internet-based cognitive-behavioural skills package for carers of people with anorexia nervosa. Psychol Med. 2011;41(12):2581-91. https://doi.org/10.101 7/S0033291711000766

114. Hoyle D, Slater J, Williams C, Schmidt U, Wade TD. Evaluation of a webbased skills intervention for carers of people with anorexia nervosa: a randomized controlled trial. Int J Eat Disord. 2013;46(6):634-8. https://doi. org/10.1002/eat.22144.

115. LaMarre A, Robson J, Dawczyk A. Mothers' use of blogs while engaged in family-based treatment for a child's eating disorder. Fam Syst Health. 2015; 33(4):390-4. https://doi.org/10.1037/fsh0000153.

116. Binford Hopf RB, Le Grange D, Moessner M, Bauer S. Internet-based chat support groups for parents in family-based treatment for adolescent eating disorders: a pilot study. Eur Eat Disord Rev. 2013;21(3):215-23. https://doi. org/10.1002/erv.2196.

117. Marx RD, Cohen M. Questions \& answers: what is teleconferencing and how is it used as a therapeutic intervention? Eat Disord. 2006;14(5):417-22. https://doi.org/10.1080/10640260600952555.

118. Billeci L, Tartarisco G, Brunori E, Crifaci G, Scardigli S, Balocchi R, Pioggia G, Maestro S, Morales MA. The role of wearable sensors and wireless technologies for the assessment of heart rate variability in anorexia nervosa. Eat Weight Disord. 2015;20(1):23-31. https://doi.org/10.1007/s40519-014-0135-2.

119. Golden NH, Katzman DK, Sawyer SM, Ornstein RM, Rome ES, Garber AK, et al. Position paper of the Society for Adolescent Health and Medicine: medical management of restrictive eating disorders in adolescents and young adults. J Adolesc Health. 2015;56(1):121-5. https://doi.org/10.1016/j.ja dohealth.2014.10.259.

120. Haripersad YV, Kannegiesser-Bailey M, Morton K, Skeldon S, Shipton N, Edwards $\mathrm{K}$, et al. Outbreak of anorexia nervosa admissions during the COVID-19 pandemic. Arch Dis Child. 2020;106:e15.

121. Human Rights [Internet]. Public Service Alliance of Canada; 2015. Available from: http://ontario.psac.com/topics/human-rights. Accessed 2 Nov 2020.

122. Caldwell BE, Bischoff RJ, Derrig-Palumbo KA, Liebert JD. Best Practices in the Online Practice of Couple and Family Therapy: American Association for Marriage and Family Therapy; 2017. Available from: https://sextherapyonline.com/wp-content/uploads/2018/01/AAMFT_Best_Practices_for_ Online_MFT.pdf.

123. Pennington M, Patton R, Ray A, Katafiasz H. A brief report on the ethical and legal guides for technology use in marriage and family therapy. J Marital Fam Ther. 2017;43(4):733-42. https://doi.org/10.1111/jmft.12232.

124. Weinberg $\mathrm{H}$, Rolnick $\mathrm{A}$. Theory and practice of online therapy: internetdelivered interventions for individuals, groups, families, and organizations. New York: Routledge; 2020.

125. Wrape ER, McGinn MM. Clinical and ethical considerations for delivering couple and family therapy via Telehealth. J Marital Fam Ther. 2019;45(2): 296-308. https://doi.org/10.1111/jmft.12319.

126. Cevelicek M, Smahelova M, Smahel D. Professionals' reflections about the impact of digital technologies on eating disorders basic and applied social psychology; 2018.

127. Lindgreen P, Clausen L, Lomborg K. Clinicians' perspective on an app for patient self-monitoring in eating disorder treatment. Int J Eat Disord. 2018; 51(4):314-21. https://doi.org/10.1002/eat.22833.

128. Surmann M, Bock EM, Krey E, Burmeister K, Arolt V, Lencer R. Attitudes towards using eHealth in psychiatry and psychotherapy : a pilot survey at the DGPPN congress 2014. Nervenarzt. 2017;88(9):1036-43. https://doi.org/1 0.1007/s00115-016-0208-8.

129. Cooper Z, Bailey-Straebler S, Morgan KE, O'Connor ME, Caddy C, Hamadi L, Fairburn CG. Using the internet to train therapists: randomized comparison of two scalable methods. J Med Internet Res. 2017;19(10):e355. https://doi. org/10.2196/jmir.8336.

130. O'Connor M, Morgan KE, Bailey-Straebler S, Fairburn CG, Cooper Z. Increasing the availability of psychological treatments: a multinational study of a scalable method for training therapists. J Med Internet Res. 2018;20(6): e10386. https://doi.org/10.2196/10386.

131. Tantillo M, Starr T, Kreipe R. The recruitment and acceptability of a project $\mathrm{ECHO}(\mathrm{R})$ eating disorders clinic: a pilot study of telementoring for primary medical and behavioral health care practitioners. Eat Disord. 2020:28(3):23055. https://doi.org/10.1080/10640266.2019.1580125.
132. Taylor CB, Fitzsimmons-Craft EE, Graham AK. Digital technology can revolutionize mental health services delivery: the COVID-19 crisis as a catalyst for change. Int J Eat Disord. 2020;53(7):1155-7. https://doi.org/10.1 002/eat.23300.

133. Smith K, Ostinelli E, Macdonald O, Cipriani A. COVID-19 and Telepsychiatry: development of evidence-based guidance for clinicians. JMIR Ment Health. 2020;7(8):e21108. https://doi.org/10.2196/21108.

\section{Publisher's Note}

Springer Nature remains neutral with regard to jurisdictional claims in published maps and institutional affiliations.
Ready to submit your research? Choose BMC and benefit from:

- fast, convenient online submission

- thorough peer review by experienced researchers in your field

- rapid publication on acceptance

- support for research data, including large and complex data types

- gold Open Access which fosters wider collaboration and increased citations

- maximum visibility for your research: over $100 \mathrm{M}$ website views per year

At $\mathrm{BMC}$, research is always in progress.

Learn more biomedcentral.com/submissions 